\title{
WELD READ-THROUGH DEFECTS IN LASER TRANSMISSION WELDING
}

by

Xiaochao Cao

A thesis submitted to the Department of Chemical Engineering

In conformity with the requirements for

the degree of Master of Applied Science

Queen's University

Kingston, Ontario, Canada

(July, 2010)

Copyright CXiaochao Cao, 2010 


\begin{abstract}
In laser Transmission Welding (LTW), the laser beam passes through the transparent part and is dissipated as heat in the absorbent material through the use of laser-absorbing pigments such as carbon black (CB). This energy is then conducted further into both parts. Melting and subsequent solidification occur at the interface causing a weld to form between the two parts.

Gluing or welding structures to the back of automotive Class-A panels often results in the appearance of undesirable surface deformations on the Class-A side. Through control of the laser welding and material parameters, it may be possible to use contour LTW as a means of joining structures to the back of absorbent Class-A panels without creating these unwanted surface defects.
\end{abstract}

A series of lap welds was made using a range of $\mathrm{CB}$ levels, laser powers and polypropylene part thicknesses. A profilometer was used to measure the size and shape of the defects generated on the surface of the black part. Two types of defects were observed: ribs and sink marks. It was observed that lower powers combined with higher carbon black levels generally resulted in smaller defects. The type of defect depended on the boundary conditions between the two parts and the flow of polymer that had thermally expanded during welding (flash). If weld flash flowed into gaps between the two plates, rib defects were always observed. If flash flowed elsewhere and no gaps existed between the plates, sink marks occurred. Finite element modeling was used to qualitatively validate these observations. 


\section{Acknowledgements}

First of all I would like to thank my supervisors, Dr. Phil Bates and Dr. Gene Zak, for their support, encouragement, and enthusiasm. Their guidance and support, as well as their extensive knowledge in the polymer welding area have been instrumental in making this thesis a success.

I'd also like to thank Dr. Mingliang Chen in our research group. Thank you for the many useful discussions which have been a great help, particularly in the field of Modeling.

Special thanks also go to Ms. Kedzie Davis Fernholz of the Ford Company; Mr. John Perreault, Mr. Clarence McEwen, Mr. Kommy Farahani and Ms. Jennifer Snelgrove of the Royal Military College of Canada (RMC); and Ms. Leone Ploeg of the Queen's University Human Mobility Research Centre (HMRC). Without your great help, this study couldn't have been successfully finished. Thank you.

Finally I'd like to thank my parents Ms. Xiulian Wang and Mr. Zilin Cao, my husband Mike Guo and my daughter Ella Guo for their continued support. You've always been there to help me follow my dreams. 


\section{Table of Contents}

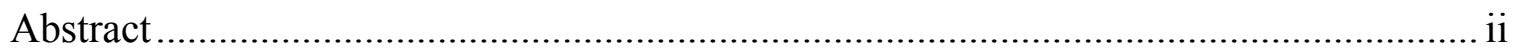

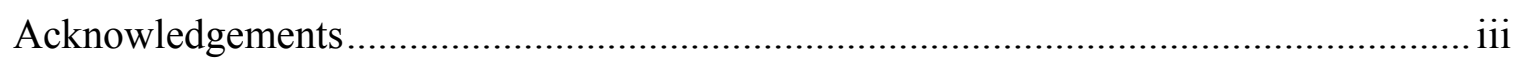

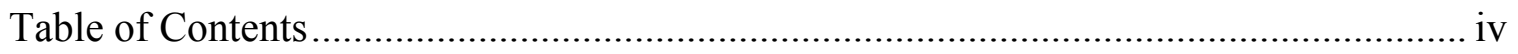

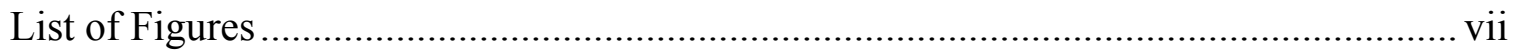

List of Abbreviations and Acronyms ................................................................. xiii

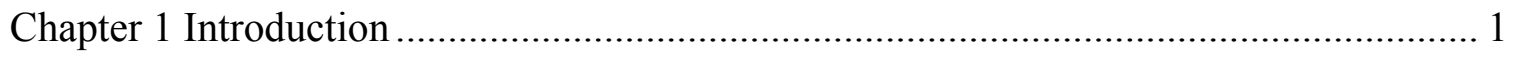

1.1 Laser transmission welding................................................................ 1

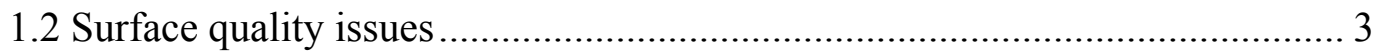

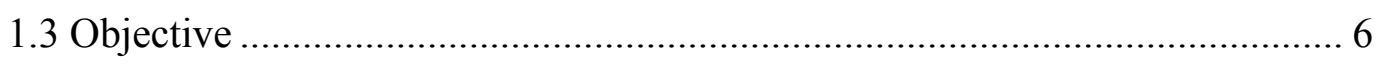

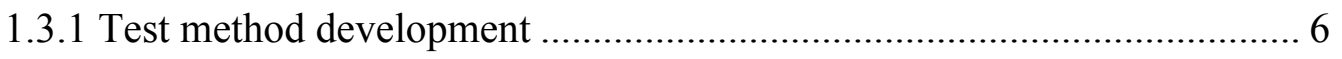

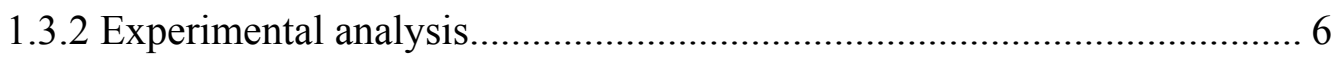

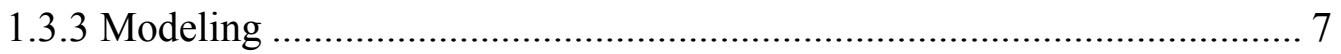

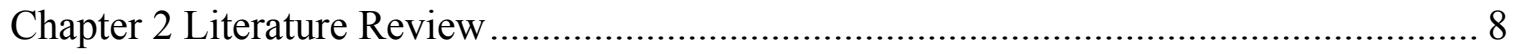

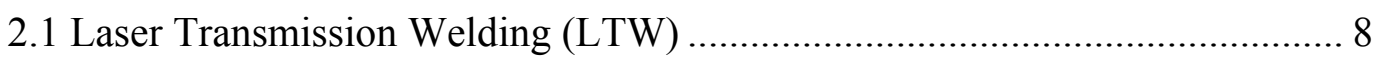

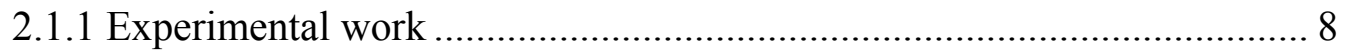

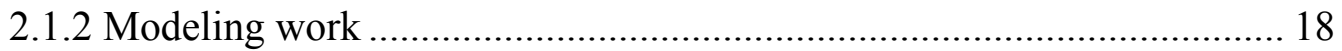

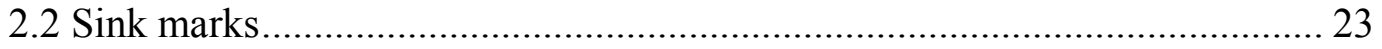

2.2.1 Sink marks in injection moulding ............................................... 25

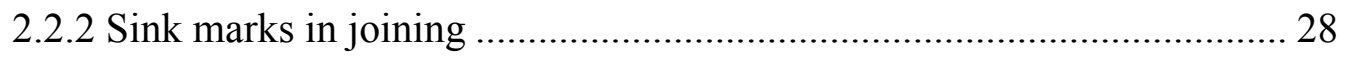

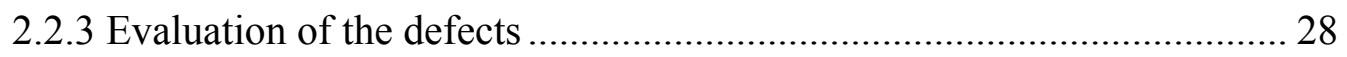

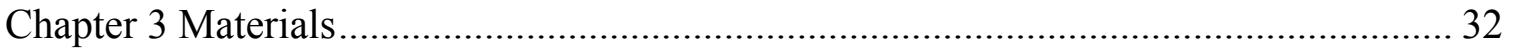

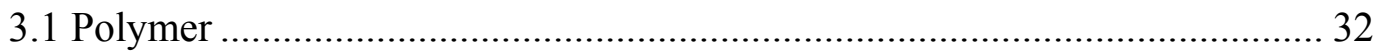




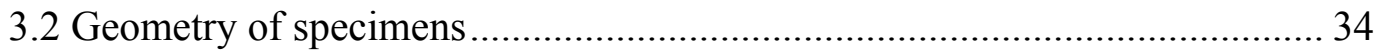

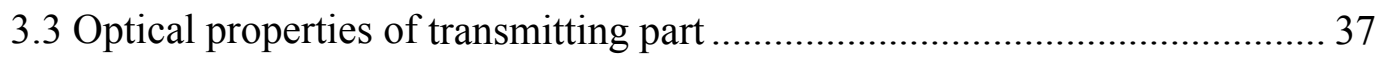

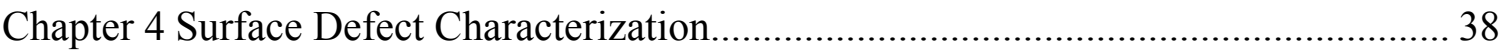

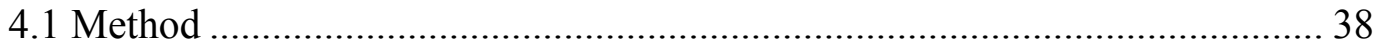

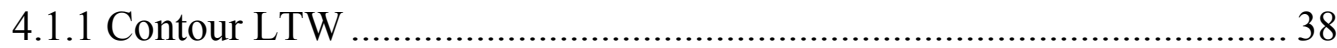

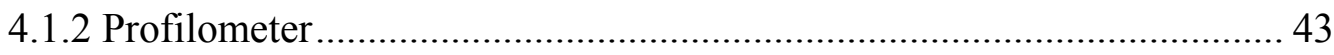

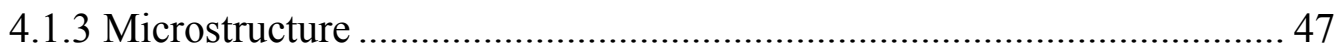

4.2 Assessment of weld read-through ...................................................... 47

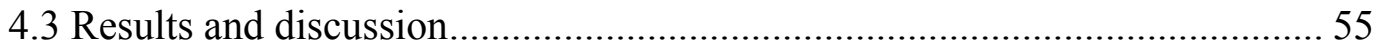

4.3.1 The welding experiments and profiler traces .................................. 55

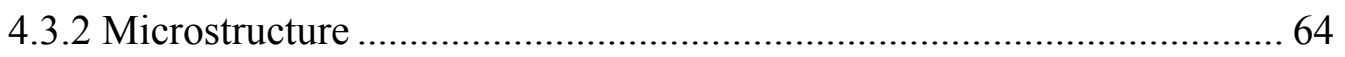

4.3.3 Possible mechanism ................................................................ 76

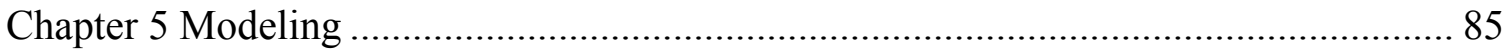

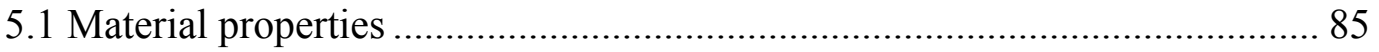

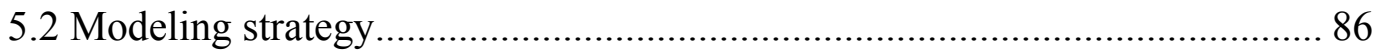

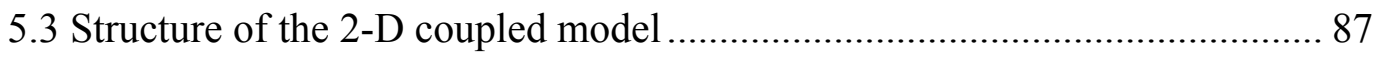

5.4 Modeling results and discussion ..................................................... 90

5.4.1 Mesh size and time step sensitivity .............................................. 90

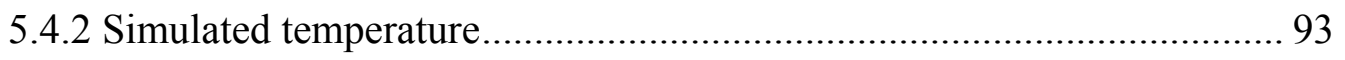

5.4.3 Simulated deformation of the surface ............................................... 95

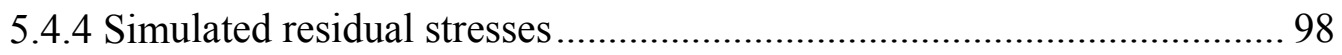

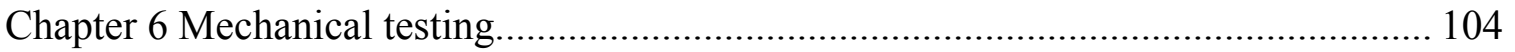

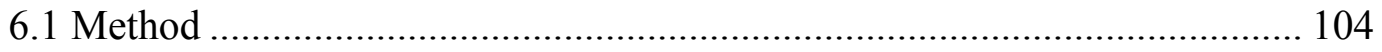

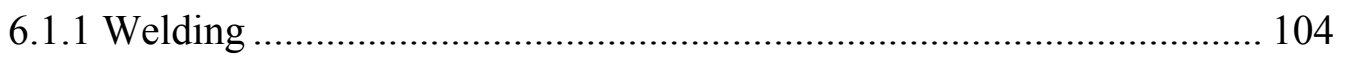

6.1.2 The tensile shear strength test .................................................. 105 


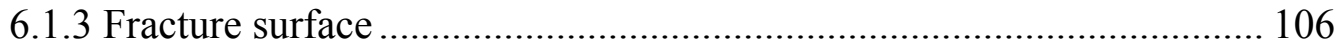

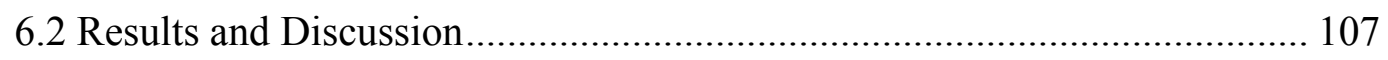

Chapter 7 Conclusions and Recommendations.......................................................... 111

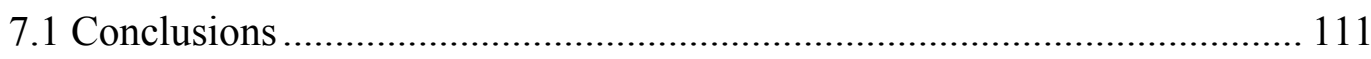

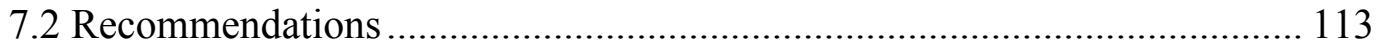

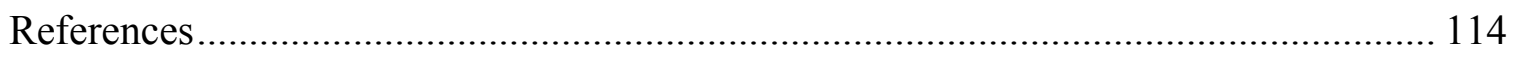

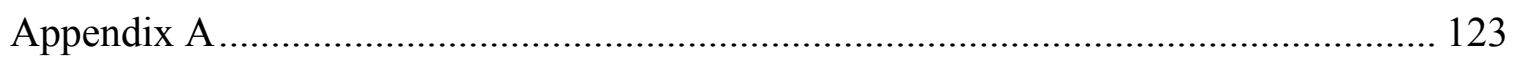

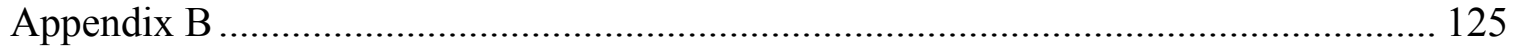




\section{List of Figures}

Figure 1-1 Schematic representation of a sink mark due to thick rib on the back of a

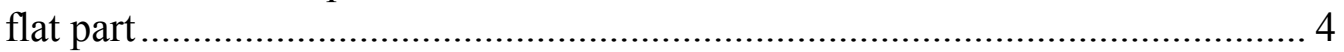

Figure 1-2 Schematic of joining rib-like feature to a simple part.............................. 5

Figure 2-1 Effect of light scattering by crystals (Left: amorphous, right: crystalline)

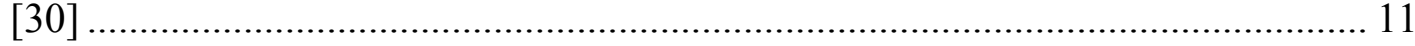

Figure 2-2 Typical PVT profile during Injection Moulding [71] ………................ 24

Figure 2-3 Appearance of sink marks with conventional injection moulding [72] .. 25

Figure 2-4 A schematic representation of sink mark due to thick rib on the back of a flat part. The image shows is a range of rib/wall ratios and fillet radii. Sink mark depth decreases as the rib/wall ratio decrease [8] ................................................ 26

Figure 2-5 An example of hiding the sink marks using the surface texture ............. 27

Figure 2-6. Schematic of dimensions of the part [82] ........................................... 29

Figure 2-7 Visual relationship between altitude, slope and curvature [84] .............. 31

Figure 3-1 Schematic of changing the rib-plate weld to lap weld ............................ 34

Figure 3-2 Polished mould insert made of brass..................................................... 35

Figure 3-3 Schematic of the moulded plaque ………………………………....... 36

Figure 3-4 Setup for transmittance measurement of polymers (drawn by M. Chen) 37

Figure 4-1 Rofin-Sinar diode laser cabinet (left) and close-up view of the DLx16

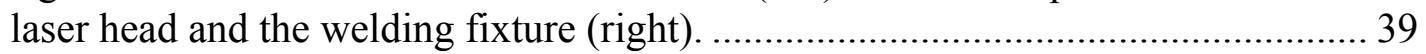

Figure 4-2 Typical 1-D laser beam profile at a work distance of $82.5 \mathrm{~mm}$ for DLx 16

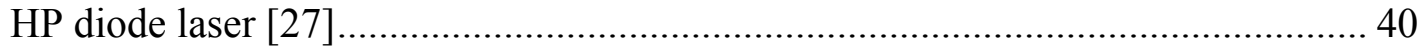

Figure 4-3 Schematic of the welding fixture ........................................................ 41

Figure 4-4 Schematic of an over-lap joint specimens................................................ 41

Figure 4-5 The KLA-Tencor P-15 Profiler........................................................... 44

Figure 4-6 Schematic of 3D profilometer trace using the P-15 profiler................... 45

Figure 4-7 Specimen holding fixture used in profiler trace, (a) the fixture without specimen, (b) the fixture with the specimen ............................................................ 46

Figure 4-8 An example of raw data taken from P-15 profiler (Thickness of parts: $2 \mathrm{~mm}$ CB level : $0.05 \mathrm{wt} . \%$, Laser power: $18 \mathrm{~W}$, Clamp pressure: 300 psi, Laser scan speed: $1500 \mathrm{~mm} / \mathrm{min}$, Profilometer trace speed: $1000 \mathrm{um} / \mathrm{s}$, Sampling rate: $10 \mathrm{~Hz}$ )48 


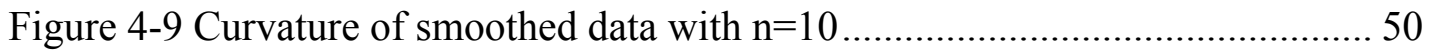

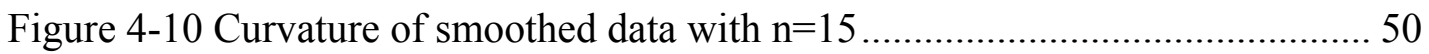

Figure 4-11 Schematic of the curvature of the sink mark and rib ......................... 51

Figure 4-12 The curvature for the parts with the same thickness (2mm), CB level

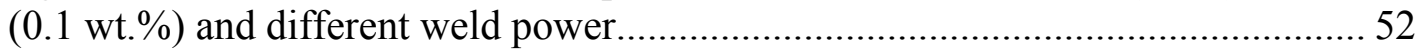

Figure 4-13 Raw data and its fitted curve .......................................................... 54

Figure 4-14 Fitted data in Figure 4-13 subtracted from the raw data ...................... 55

Figure 4-15 A typical shape of ribs obtained using the method in Section 4.2. This data is for a $2 \mathrm{~mm}$ thick part containing a CB level of $0.05 \mathrm{wt} \% \%$ and welded at a power of $18 \mathrm{~W}$ (this defect was created near the beginning of the "weld seam") ... 56

Figure 4-16 A typical shape of sink marks obtained using the method in Section 4.2. This data is for a $2 \mathrm{~mm}$ thick part, CB level $0.05 \mathrm{wt}$ \% and welded at a power of 18 W (this defect was created near the end of the "weld seam")................................ 57

Figure 4-17 A 2D schematic of the tracing position............................................ 58

Figure 4-18 Height or depth of the defects as a function of the position along the weld seam (the part thickness is $2 \mathrm{~mm}$, laser power is $18 \mathrm{~W}$, laser scan speed is 1500

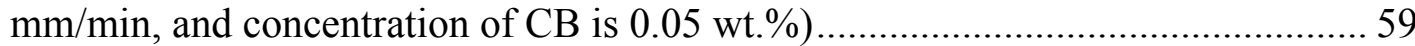

Figure 4-19 The height of the defects as a function of the position along the weld seam (the part thickness is $3 \mathrm{~mm}$, laser power is $23 \mathrm{~W}$, laser scan speed is 1500 $\mathrm{mm} / \mathrm{min}$, and concentration of $\mathrm{CB}$ is $0.05 \mathrm{wt} . \%$ ). 60

Figure 4-20 Depth of sink marks as a function of laser power (part thickness is 2 $\mathrm{mm})$. 61

Figure 4-21 Height of ribs as a function of laser power (part thickness is $2 \mathrm{~mm}$ )... 63 Figure 4-22 Height of ribs as a function of laser power (part thickness is $3 \mathrm{~mm}$ ).... 64 Figure 4-23 Micrograph of a weld interface showing heat affected zone (HAZ) and flash. Laser power is $10 \mathrm{~W}$ and scanning speed is $1500 \mathrm{~mm} / \mathrm{min}$. The thickness for both transparent and absorbent parts is $3 \mathrm{~mm}$. CB level is $0.1 \mathrm{wt} . \%$ 65

Figure 4-24 Magnified image taken near the edge of the HAZ in Figure 4-23 as shown in the square. 65

Figure 4-25 Heat Affected Zone geometry viewed under polarized-light microscope for a PP joint processed with $12 \mathrm{~W}$ laser power, $2 \mathrm{~mm}$ thickness for both transparent and absorbent parts. (a) CB level is $0.05 \mathrm{wt} \%$ (b) $\mathrm{CB}$ level is $0.1 \mathrm{wt} . \%$ (c) $\mathrm{CB}$ level is $0.2 \mathrm{wt} . \%$. The defect type associated with this microstructure is a sink mark. 67 
Figure 4-26 Micrograph of a weld interface showing heat affected zone (HAZ) (a) Laser power is $14 \mathrm{~W}$. The part thickness is $2 \mathrm{~mm}$. CB level is $0.1 \mathrm{wt} . \%$. (b) Laser power $18 \mathrm{~W}$, the part thickness $2 \mathrm{~mm}$ and the CB level $0.05 \mathrm{wt} . \%$. The defect type associated with this microstructure is a sink mark.

Figure 4-27 Magnified image taken near the edge of the HAZ in Figure 4-26 as shown in the square. 70

Figure 4-28 Micrograph of a weld interface showing heat affected zone (HAZ) and flash for a power of $18 \mathrm{~W}$ and a CB level of $0.05 \mathrm{wt} . \%$ at apart thickness of $2 \mathrm{~mm}$. The defect type associated with this microstructure is a rib. 71

Figure 4-29 Heat Affected Zone geometry viewed under polarized-light microscope for a PP joint processed with $10 \mathrm{~W}$ laser power. The thickness for both transparent and absorbent parts is $3 \mathrm{~mm}$. (a) CB level is 0.1 wt. \% (b) CB level is 0.2 wt. \%.. 72

Figure 4-30 Micrograph of a weld interface showing heat affected zone and flash. Laser power $23 \mathrm{~W}$, CB level $0.05 \mathrm{wt} \%$, part thickness $3 \mathrm{~mm}$. (a) the defect was created near the beginning of the weld seam; (b) the defect was created near the end of the weld seam. The direction of the laser scan is shown in Figure 4-19 ........... 73

Figure 4-31 Weld seam visible through the transparent part (laser power is $18 \mathrm{~W}$, CB level is 0.05 wt. $\%$, and the thickness of both transparent part and absorbent part is $2 \mathrm{~mm}$ ). 75

Figure 4-32 Weld seam visible through the transparent part: (laser power is $23 \mathrm{~W}$, CB level is 0.05 wt. \%, and the thickness of both transparent part and absorbent part is $3 \mathrm{~mm}$ ) 76

Figure 4-33 Schematic drawing of internal stresses on a simple laser transmission joint when there is no gap between transparent part and absorbent part (the top bulk is transparent part, the bottom bulk is the absorbent part, and the semi-circle in the middle is the HAZ). 77

Figure 4-34 Schematic drawing of internal stresses on a simple laser transmission joint when there is gap between transparent part and absorbent part (the top bulk is transparent part, the bottom bulk is the absorbent part, and the semi-circle in the

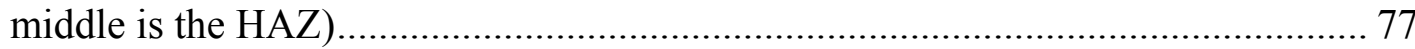

Figure 4-35 Profilometer traces for a $3 \mathrm{~mm}$ thick unwelded plate ........................ 80

Figure 4-36 Profilometer traces for a $2 \mathrm{~mm}$ unwelded plate ................................ 81

Figure 4-37 Schematic of a lap-joint specimen in Chen's thesis........................... 81

Figure 4-38 Weld fractures of laser-absorbent PA6 parts after pull test $(0.025 \mathrm{wt} . \%$ $\mathrm{CB}$, power $92 \mathrm{~W}$, speed $25 \mathrm{~mm} / \mathrm{s}$ ) [27] 82 
Figure 4-39 Cross-section views of the PA6 welds under microscope for different power and gap setting; Top material is laser-transparent and bottom material is laser-absorbent. (0.025 wt.\% CB, speed $25 \mathrm{~mm} / \mathrm{s}$ ) [27] 83

Figure 5-1 Model mesh of the 2-D thermal-mechanical coupled FE model without gap. 88

Figure 5-2 Model mesh of the 2-D thermal-mechanical coupled FE model with gap.

Figure 5-3 Sensitivity analysis for the mesh sizes influence on the simulated temperature and surface deformation of absorbent part. 92

Figure 5-4 Sensitivity analysis of the time step influence on the simulated

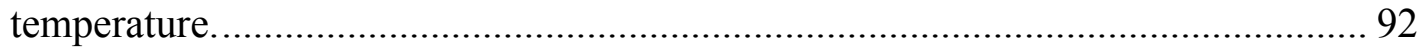

Figure 5-5 Example of heat transfer model output (no-gap model) ........................ 94

Figure 5-6 Example of heat transfer model output (gap model).............................95

Figure 5-7 Deformation on surface of absorbent part (no gap model) .................... 97

Figure 5-8 Deformation on surface of absorbent part (gap model) ......................... 98

Figure 5-9 Distribution of the residual normal stresses in the vertical y-direction generated in the 2-D coupled modeling (no gap model) ..................................... 99

Figure 5-10 Distribution of the residual normal stresses in the horizontal x-direction generated in the 2-D coupled modeling (no gap model) 100

Figure 5-11 Distribution of the residual normal stresses in the vertical y-direction generated in the 2-D coupled modeling (gap model). 102

Figure 5-12 Distribution of the residual normal stresses in the horizontal y-direction generated in the 2-D coupled modeling (gap model) ....................................... 103

Figure 6-1 Dimensions of the lap shear strength test specimens ......................... 105

Figure 6-2 Schematic representation of lap joint shear strength test ..................... 105

Figure 6-3 Weld width and length measurement on the fracture surface after the shear strength test. 106

Figure 6-4 Maximum force at break as a function of laser power (the error bars represent one standard deviation). 107

Figure 6-5 Weld width as a function of laser power.... 108

Figure 6-6 Weld shear strength as a function of laser power (the error bars represent standard deviation). 109 
Figure 6-7 Microstructures of the fracture surface taken by the SEM. Part thickness is $3 \mathrm{~mm}$, laser power is: (a) $6 \mathrm{~W}$, (b) $7 \mathrm{~W}$, (c) $10 \mathrm{~W}$, (d) $12 \mathrm{~W}$ 110

Figure A-1 Schematic representation of the non-contact scanning experimental setup [88] 123

Figure A-2 Surface appearance of the laser-absorbent part after a series of laser scans in non-contact method for PP (Thickness 2 mm, 0.2 wt.\% CB, Speed 1500 $\mathrm{mm} / \mathrm{min}$ ) 124 


\section{List of Tables}

Table 2-1 Mechanical Performance of Thermoplastics, PA6 [40] .......................... 13

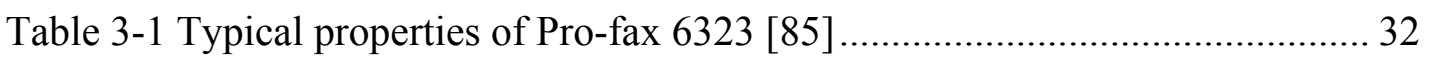

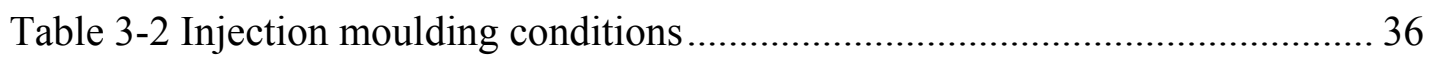

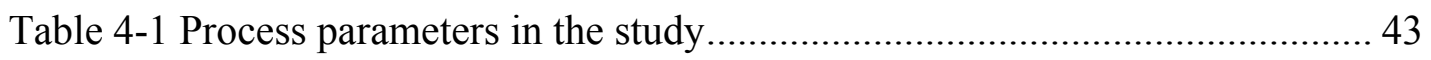

Table 5-1 PP homopolymer material properties used in the model........................ 86 


\section{List of Abbreviations and Acronyms}

$\begin{array}{ll}\text { CB } & \text { Carbon Black } \\ \text { CCD } & \text { Charge-coupled device } \\ \text { FEM } & \text { Finite Element Method } \\ \text { FDM } & \text { Finite Difference Method } \\ \text { GF } & \text { Glass Fiber } \\ \text { HAZ } & \text { Heat Affected Zone } \\ \text { HDPE } & \text { High Density Polyethylene } \\ \text { LE } & \text { Line Energy } \\ \text { LTW } & \text { Laser Transmission Welding } \\ \text { Nd-YAG } & \text { Neodymium-doped Yttrium Aluminum Garnet } \\ \text { PA } & \text { Polyamide (nylon) } \\ \text { PA6 } & \text { Polyamide 6 } \\ \text { PA66 } & \text { Polyamide 6,6 } \\ \text { PA mXD6 } & \text { Polyarylamide } \\ \text { PC } & \text { Polycarbonate } \\ \text { PEEK } & \text { Polyetheretherketone } \\ \text { PP } & \text { Polypropylene } \\ \text { PVC } & \text { Polyvinyl Chloride } \\ \text { TEM } & \text { Transmission Electron Microscopy } \\ \text { TPO } & \text { Shermoplastic Olefin } \\ \text { SEM } & \text { SMC }\end{array}$




\section{Chapter 1 \\ Introduction}

This chapter introduces the concept of Laser Transmission Welding (LTW) in the

first section (Section 1.1). It then addresses the issue of surface quality during welding (Section 1.2). Finally, in Section 1.3, the objectives of the thesis are stated.

\subsection{Laser transmission welding}

In laser transmission welding (LTW) of thermoplastics, the laser beam penetrates the transparent part and is absorbed by the absorbent part through the use of laser-absorbing dyes or pigments such as carbon black. The radiation is converted into heat and melting takes place. The heat required to melt the transparent part is received via thermal conduction from the absorbing part. Once the transparent part has melted at the weld interface, molecular diffusion occurs. As the interface cools down, solidification occurs, which causes a weld to form between the two parts.

There are several technologies used in LTW: simultaneous welding, quasisimultaneous welding, and contour welding. In simultaneous welding, one or more lasers heat the entire weld seam simultaneously causing all points along the interface to melt. This welding method is often suitable for welding small parts due to the high number or power of lasers required. With the appropriate selection of weld geometry, meltdown of 
the weld seam or gaps filling between the two parts is possible. In quasi-simultaneous welding, scanning mirrors deflect the laser spot and guide it along the welding path at a very high speed. The joining surface is traversed several times per second, whereby the laser beam effectively heats the entire welding seam at the same time [1]. Again, with the appropriate geometry, meltdown of the seam is possible. However, welding large three-dimensional weld seams is often difficult. Contour welding, the technique used in this project, involves a relatively slow moving beam that moves once around the weld seam. Generally speaking, meltdown is not possible as the weld seam is not entirely molten at any instant. However, contour welding is ideally suited for welding threedimensional weld seams. In this thesis, unless otherwise stated, LTW refers to contour welding.

The advantages of the laser transmission welding are listed below [2-4]:

- Fast, in many applications, weld times ranging from milliseconds to 1-2 seconds have been achieved [5].

- Precisely controlled energy delivery.

- Non-contact process.

- Small heat-affected zone depending on the dimension of the laser beam and the concentration of the laser absorbing pigment. The heat-affected zone (HAZ) is the area of base material, which has had its microstructure and properties altered by welding operations. The heat from the welding process and subsequent recooling causes microstructural changes in the area surrounding the weld.

- Low level of flash. Flash refers to polymer that flows from the weld area under pressure when it was in the molten state. 
- No relative movement or vibration of the parts being joined that might damage sensitive electronic components.

- Given its small heat-affected zone [2], LTW contour welding has less residual stresses compared to other welding methods such as hot plate, resistance, vibration, and ultrasonic welding.

\subsection{Surface quality issues}

In the increasingly competitive automotive industry, the aesthetic body panel of a car is important in order to impress the customer. A flawless Class A surface finish is therefore required on a car's painted body panels [6]. Class A surfaces are defined as the aesthetic/free-form surfaces that are visible to us (interior/exterior), that have an optimal aesthetic shape and high surface quality [7]. Mathematically, Class A surfaces are those surfaces that have a continuous curvature without any undesirable waviness [7].

Many automotive parts are injection moulded. A common source of dimensional irregularities in injection mouldings is the thermal residual stresses, which are normally compressive at the surface and tensile at the core. These stresses can cause sink marks to form on the surface of, for example, a plate-rib type geometry. Figure 1-1 shows a schematic representation of a sink mark due to the rib located on the underside of a flat part. These so-called sink marks are formed when the plastic in the thicker sections solidifies in the absence of packing pressure. 


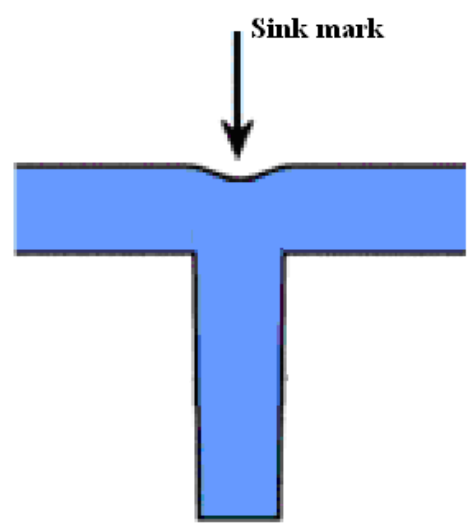

Figure 1-1 Schematic representation of a sink mark due to thick rib on the back of a flat part

In order to manufacture parts containing moulded-in ribs and bosses without sink marks, many techniques have been evaluated. Examples include applying more pressure during injection to minimize shrinkage, using materials with a lower shrinkage or by hiding the sink marks using a textured surface [8,9]. Another alternative being considered by automotive companies is welding. Figure 1-2 shows the principle behind this technique. Rather than mould a rib or boss onto the back of a part having a Class $\mathrm{A}$ surface, the feature is joined to the part to avoid or minimize the deformation on the surface associated with the shrinkage during injection moulding. 

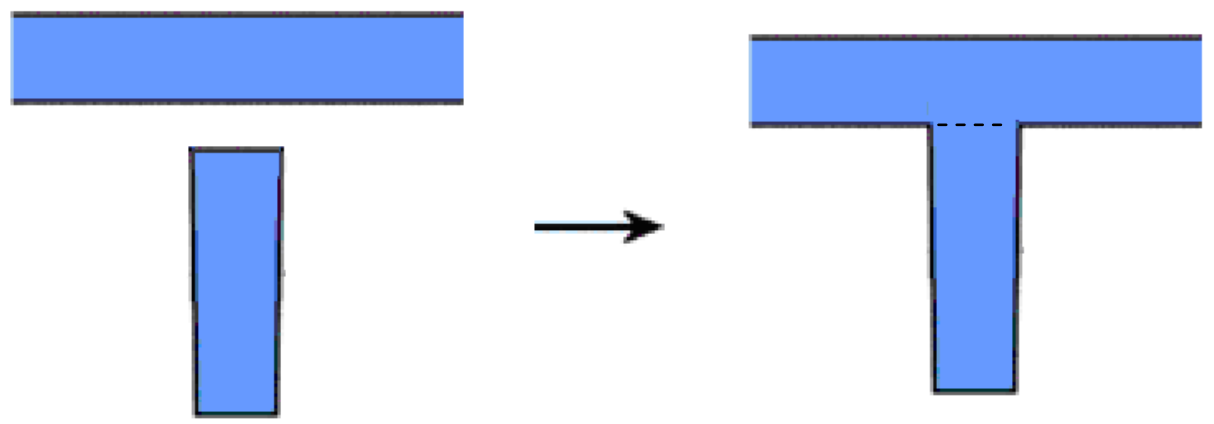

Figure 1-2 Schematic of joining rib-like feature to a simple part

However, gluing or welding structures to the back of automotive Class-A panels can still result in the appearance of aesthetically unacceptable defects on the Class-A side. This is because the curing of the adhesive layer or the cooling of the bonding area can create residual stresses which can lead to the deformation on the surface along the bonding line. This is referred to here as bond-line or weldline read-through $[10,11]$.

This thesis will examine the use of LTW as a means of joining two parts together with a minimum of weldline read-through. As discussed in Section 1.1, the small heataffected zone may result in less residual stresses and less weldline read-through than other joining techniques.

The melting and subsequent solidification of the molten polymer may create internal stresses that cause the polymer to deform at the external surface of the laser-absorbent part. However, through control of the laser welding parameters, carbon black level and material flow, it may be possible to use LTW as a means of joining structures to the back of absorbent Class-A panels. 


\subsection{Objective}

This project will determine the effect of polypropylene homopolymer (PP) material (PP carbon black level), part (thickness of both transparent and absorbent parts) and diode laser (power) on the ability to read the weld through the absorbent part.

The objective will be achieved by:

\subsubsection{Test method development}

In current automotive industry, surface quality is measured visually by human observation of reflected images on the material surface, viewed under controlled lighting conditions [6]. There is no universally accepted standard method to evaluate the surface quality. A profilometer was used to assess the shape of absorbent Class A surface after welding with respect to its shape prior to welding. The test method was developed by the author and will be discussed in Chapter 4 .

\subsubsection{Experimental analysis}

\section{Plate preparation}

Polypropylene plates were prepared by injection moulding at a range of thicknesses and carbon black (CB) levels. A special CB masterbatch and a purpose-built mould insert were developed for this work. Details of this are given in Chapter 3. 


\section{Plate welding}

The plates were welded at a range of powers using a 160W diode laser workstation located at Queen's. Details of this are provided in Chapter 4.

\section{Weld assessment}

A number of techniques were used to assess the welds. The shape of the absorbent Class A surface was assessed using a profilometer. The profilometry results are presented and discussed in Chapter 4. The weld microstructure (cross-sections and fracture surfaces) were visualized using polarized light microscopy of microtomed sections and a Philips XL 30 CP Scanning Electron Microscope (SEM) located at RMC in order to understand the relationship between laser power and weldline read-through. These results are discussed in Chapter 4 and Chapter 6. The lap-shear strength was measured using a universal testing machine in order to determine the trade-off between weldline read-through and weld strength. This will be discussed in Chapter 6 .

\subsubsection{Modeling}

A simplified 2-D thermal-mechanical coupled model was developed to support the read-through mechanism analysis generated from the experimental results. This will be discussed in Chapter 5. 


\section{Chapter 2 \\ Literature Review}

The purpose of this chapter is to review the published scientific and technical papers related to this project. It begins by reviewing the relatively new joining technique Laser Transmission Welding (LTW) (Section 2.1). Related experimental work will be introduced in Section 2.1.1. In this section, the theories relating to transmission, absorption, reflection, and Beer's law will also be discussed. Following this, a brief description of the Finite Element Method (FEM) and other modeling methods will be presented in Section 2.1.2. Finally, the subject of sink marks in injection moulding and in joining will be described in detail (Section 2.2).

\subsection{Laser Transmission Welding (LTW)}

Several Laser Transmission Welding (LTW) techniques were introduced in Chapter 1. Many experimental and modeling studies have been performed on this subject.

\subsubsection{Experimental work}

\section{A. Effect of laser welding parameters}

A number of authors have assessed the effect of LTW parameters on weld strength [13-17]. Although the weld conditions such as laser types (diode [13, 17] and Nd-YAG 
[14 - 16]), welding techniques (quasi-simultaneous [15], contour with multiple scans [14, 16], and continuous heating [17]), and materials (PA [13], PA66 [14], PEEK [15], PC $[15,17]$ and HDPE $[16,17])$ are different, they generally observed a similar result: the weld strength increases with increasing laser power (at a fixed scan speed) and decreasing laser scan speed (at a constant power) until a critical value of line energy (LE) is reached. Line energy is defined as the ratio of laser power and laser scan speed, or laser irradiation energy delivered per unit weldline length [18]. Too low a LE (either too low a power or too high a speed) can result in insufficient heating and limited molecular diffusion between the two parts [18]. At higher LE, thermal degradation of the polymer can occur, which can cause the strength to decrease [18-23].

As will be discussed later, the critical LE value depends on the transmitting material and the carbon black (CB) level. It is generally independent of power and speed as long as the speed is high (for example, the speed should be greater than $50 \mathrm{~mm} / \mathrm{s}$ for PA6 [18]). At low speeds (and correspondingly low powers), the rate of energy loss due to conduction approaches the rate of energy addition by the laser and LE ceases to be a useful parameter. For this reason, it is impossible to weld plastics with a laser pointer!

The LTW parameters such as laser power, laser scan speed, and LE also affect the width of the Heat Affected Zone (HAZ). The weld width increases with: increasing power [24-26], decreasing laser scan speed [24-26], and increasing LE [24, 19]. This has been observed for a range of amorphous [24, 25, 27] and semi-crystalline [26, 27] materials. The reason for this is related to the non-uniform energy distribution of the 
transmitted laser beam. Scattering of light causes the energy density to be highest in the centre of the beam and lowest at edge. At low LE, the edges of the beam do not possess enough energy to cause welding. Increased LE allows a greater fraction of the beam cross-section to cause melting and ultimately welding. This wider beam is able to melt material across a larger area.

\section{B. The effects of transmitting material}

The definitions of transmission, reflection and absorption first need to be provided. The total transmittance $T_{T}$ of a polymer is defined as the ratio of the total transmitted radiant power to total incident radiant power. The total reflectance $R_{T}$ is defined as the ratio of total reflected radiant power to total incident radiant power. Reflection can occur at the boundary between two media (surface reflection) or inside a medium (volume reflection) at the interface between amorphous and crystalline phases. The total absorbance of a polymer $A_{T}$ is defined as the ratio of total absorbed radiant power to total incident radiant power $[28,29]$. Then the relationship between $T_{T}, R_{T}$, and $A_{T}$ satisfies the following equation:

$$
T_{T}+R_{T}+A_{T}=1
$$

Equation 2-1

When the laser beam goes through the part, it can be deviated from its initial path by reflection and refraction at internal interfaces. This is referred to as scattering. Some scattering leads to volume reflection. Some causes increased absorption by increasing the light path length. Scattering also widens the cross-section of the transmitted energy. 
It depends on the phases (crystalline, amorphous, pigments, reinforcements, and so on) in the part. This is shown schematically in Figure 2-1.
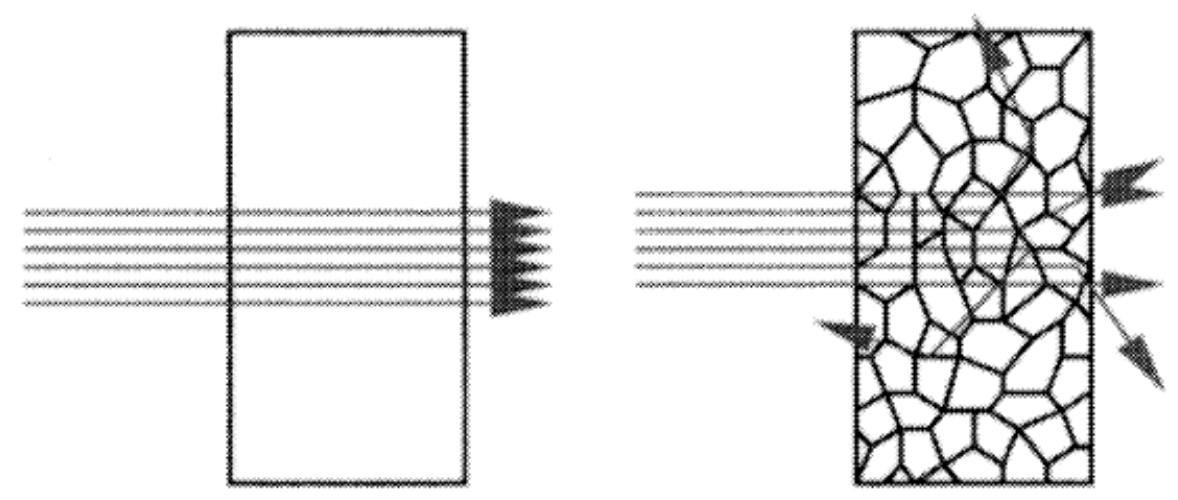

Figure 2-1 Effect of light scattering by crystals (Left: amorphous, right: crystalline) [30]

The amounts of reflectance, absorbance and scattering of a polymer part are dependent on parameters such as:

- Thickness of the part

- Crystal structures

- Additives such as reinforcements, fillers, and pigments

The presence of only one phase in amorphous polymers increases the transmission by reducing laser energy losses due to volume reflection as well as losses due to absorption caused by scattering. This, combined with its low absorption of laser light [17], results in a high level of laser transmission. Rhew et al. [31] found that the transmission of PC did not depend on the thickness. A transmission of $90 \%$ for a diode laser input (wavelength $810 \mathrm{~nm}$ ) was observed for a range of part thickness from 0.37 to 
$12.2 \mathrm{~mm}$. Chen [27] measured the transmission for PC using a diode laser of wavelength $940 \mathrm{~nm}$ and found a similarly high transmission of $85 \%$.

However, the transmittance of light scattering polymer is much lower due to energy losses caused by bulk reflection as well as losses due to absorption caused by scattering of the crystalline phase, pigments, and reinforcements. The influence of part thickness on the transmittance for different materials was studied (nylon-based plastics with different colorant [32], different GF level PA mXD6 [18], PA mXD6 with 50\% GF [33], HDPE [31], PA6 with 30\% GF [34], and PVC [35]). These studies showed that the transmittance decreases with increasing part thickness because the laser beam undergoes reflection, absorption and scattering as it passes through the transparent part.

The light scattering also increases with the increasing part thickness as the path length of the light increases. Wang et al. [33] studied the effect of part thickness on the reflectance for PAmXD6 containing 50\% GF. The reflectance increases with increasing the sample thickness. They explained that it is attributed to the back-scattering of the light caused by the glass fibres distributed throughout the specimen thickness. Thicker specimens cause more back-scatter. Rhew et al. [31] studied the effect of part thickness on the reflectance for HDPE. It was observed that the effect of thickness on transmittance or reflectance is negligible.

The influence of glass fibres on the weld width of PA6 parts after a diode laser scan (wavelength $808 \mathrm{~nm}$ ) was studied by Grewell et al. [36] and Kagal et al. [37, 38]. The 
experiments indicated that the width of weldline increased with the increasing concentration of glass fibres. Haberstroh [39] also reported the influence of glass fibre content on scattering using an infrared camera. Similar results were obtained: increased light scattering was observed with increasing glass fibre content.

Haberstroh et al. [39] also studied the influence of crystallinity on the heat affected area. Three non-filled specimens (PA6, PA 6.6, and PA 12) with different crystallinity levels were investigated in this study. It was observed that the width of the HAZ became smaller with decreasing crystallinity. In other words, crystallinity has an influence on the scattering of the laser beam: the scattering of the laser beam decreases with decreasing crystallinity.

In terms of mechanical properties, using glass fibres will decrease the tensile strength of the joint although it can increase the tensile strength of the plastic. Kagan and Woosman [40] studied the mechanical performance of the PA6. The results are shown in Table 2-1. The tensile strength of joint (T-joints) was tested under optimized welding conditions.

Table 2-1 Mechanical Performance of Thermoplastics, PA6 [40]

\begin{tabular}{|c|c|c|}
\hline GF, wt.\% & Tensile strength of plastic, MPa & Tensile strength of joint, MPa \\
\hline 0 & 82 & $>=82$ \\
\hline 14 & 125 & 77.2 \\
\hline 33 & 185 & 75.4 \\
\hline
\end{tabular}


Colorants are often used in the welding parts. Certain pigments or dyes allow the plastics to be transparent to the laser light while appearing black to the human eye [41]. Generally, the requirements for colorants in laser transparent parts should be high transmission, low reflection, and low absorption values [42]. The colorants used in laser absorbent part will be addressed in detail later. Kagan et al. [32, 43] and Grewell et al. [36] compared the influence of pigments on the transparency of nylon 6. These studies showed that a specific red pigment had no effect on the transparency of the nylon 6 , a yellow pigment had a significant effect, and the green pigment absorbed nearly all laser radiation at near-IR wavelength of $900 \mathrm{~nm}$.

\section{The effects of absorbing material}

The optical properties of the laser absorbent part are also important. From the theory presented earlier, we know that a sufficient quantity of absorbing additives is needed in the absorbent part to absorb the laser energy, which is subsequently converted into heat.

There are many kinds of near-infrared absorbing pigments or dyes such as the cyanine dyes, the squarylium dyes, the croconium dyes, etc [44]. Some pigments or dyes are absorbent to the IR light while appearing invisible to the human eye, so part color is not a limitation for LTW $[45,46]$. Grimm et al. [47] reported that transparent materials colored opaque also could be used as the absorbing layers. However, the most popular laser-absorbing pigment is still carbon black. It absorbs light energy in any wavelength 
and is relatively inexpensive. $\mathrm{CB}$ is usually introduced into the bulk of the resins at a concentration of $0.01 \mathrm{wt} . \%$ to $1 \mathrm{wt} . \%$ [48].

Potente et al. [49] studied the influence of CB level on the melt layer thickness in the transparent part expressed in terms of the melt layer thickness of the absorbing part. The experiments show that if the $\mathrm{CB}$ level is low, then the radiated energy will be absorbed over a greater depth of material. Conversely, if the CB level is high, the energy is absorbed in a very thin layer, and the energy is conducted more equally into both parts. A similar result was also published by Chen et al. [50]. These experimental results are consistent with Beer's law:

$$
I=I_{0} e^{-A y}
$$

where $A$ is the laser absorption coefficient of the material, which is proportional to the concentration of $\mathrm{CB} ; I$ is laser radiation intensity at the depth of $y ; I_{0}$ is laser radiation intensity at the surface of the laser absorbent part $(\mathrm{y}=0)$. The parameters $\left(I, I_{0}, A\right)$ can be rearranged yielding:

$$
y=A^{-1} \ln \left(\frac{I_{0}}{I}\right)
$$

From the equation above, one can see that if we want to get a specific laser radiation intensity $I$, the depth is inversely proportional to the laser absorption coefficient. As $A$ is proportional to the $\mathrm{CB}$ level, the depth is inversely proportional to the CB level. 
For a given LE, the CB level will affect average temperature within the absorbing part. Higher CB levels will cause the energy to be absorbed over a smaller volume potentially resulting in higher average temperatures in a smaller volume. The ratio of LE and $\mathrm{CB}$ level is thus important in order to obtain temperatures sufficiently high for molecular diffusion while avoiding polymer degradation.

Besides CB level, the CB particle size also affects the weld strength. For the same LE, smaller CB particle sizes have been observed to result in higher joint weld strengths $[41,51,52]$. The dependence of the laser absorption coefficient (A) on the CB level $\left(\mathrm{C}_{\mathrm{CB}}\right)$ and diameter of $\mathrm{CB}$ particles was derived by Chen [29]. To simplify the analysis, the laser $\mathrm{CB}$ aggregates are assumed to have a unique diameter D:

$$
A=\frac{3 \rho_{M} C_{C B}}{2 D \rho_{C B}} \frac{1}{100}
$$

where $\rho_{M}$ and $\rho_{C B}$ are the densities of polymer matrix and CB particles respectively.

This equation indicates that higher $\mathrm{CB}$ level and smaller $\mathrm{CB}$ particles result in higher laser absorption coefficients. For the same $\mathrm{CB}$ level, the smaller $\mathrm{CB}$ particles create a larger area of particle surface and will absorb more energy and result in higher temperatures during welding.

In order to disperse low levels of $\mathrm{CB}$ within a polymer matrix, color concentrates often called masterbatch (MB) are used to make the absorbent part. In this technique, carbon black is compounded with a carrier resin to form a concentrated masterbatch 
which is then let down into the base resin during the manufacture of the polymer product or during injection moulding [53].

A technique for quantifying the carbon black morphology in laser welding applications was developed by Wang [54]. In his study, transmission electron microscopy (TEM) followed by image processing were used to assess the microstructure of the $\mathrm{CB}$.

Sometimes, the joining of two visually transparent thermoplastic components is required. A process called Clearweld ${ }^{\mathrm{TM}}$ was developed for this purpose $[40,55,56]$. In this technique, a special coating is placed between the two surfaces to be joined. The coating is transparent to the wavelengths of visible light but absorbent at the wavelengths of commercial near-infrared lasers $[57,58]$. Besides joining two optically transparent thermoplastic components, other advantages of this technique include the elimination of visible markings and weld flash [58]. This is helpful to reduce the surface deformation when joining two parts together and can be considered to be used in future research. However, the Clear-weld material is costly and its application to the weldline introduces another manufacturing step. These factors make this technique unsuitable in some welding applications. 


\subsubsection{Modeling work}

Modeling the LTW process can provide a relatively precise quantitative prediction of temperature and deformation in assemblies without any experimental work. Some of these temperature estimates can be made using only modeling. It also allows one to validate theories after the experimental work.

Much research has been done on thermal and thermal-mechanical modeling of various LTW processes. The following will introduce briefly the past research on LTW modeling.

\section{A. Thermal modeling}

- 1-D modeling

In an early work published in 1998, Potente et al. [49] used a 1-D analytical model to simulate the melt layer thickness in the transparent and absorbent parts for contour LTW of PA 6 with an Nd:YAG laser. It was shown that the calculated melt layer thickness in the transparent and absorbent parts was in good agreement with the experimental values although there were numerous simplifications such as no flash melt flow from the joining zone, ideal material behavior, and constant heat flow.

Kurosaki [59, 60] used a 1-D Finite Difference Method (FDM) to evaluate the temperature profiles in the cross section of LDPE films (the thickness of films: $0.3-1.0$ $\mathrm{mm}$ ) and PS, PMMA, and PC films (the thickness of films: 0.5-1.5 mm) during $\mathrm{CO}_{2}$ laser welding. In their model, the films had different laser absorption coefficients for the laser 
transparent and laser absorbent parts. The properties of the material were temperature independent. They showed that the predicted temperature profiles combined with the melting temperature of LDPE could be used to estimate the weld geometry in the cross section of LDPE films for CO2 laser welds obtained in experiments.

Prabhakaran [5] developed a simplified 1-D FDM to simulate the heat distribution and estimate the minimum line energy required to produce melting at the weld interface during a contour welding of unreinforced nylon 6 . In his model, the power intensity was assumed to be uniform and the thermal properties of the material were temperature independent. The result showed that this simplified model can reasonably estimate the minimum required energy for weld to occur.

- 2-D modeling

Van de Ven [61] used a 2-D numerical model to simulate the transient heat transfer at the weld interface in a LTW between two polyvinyl chloride parts using MATLAB. The model utilizes a thermal contact resistance that was a function of temperature and pressure, a Gaussian laser-power distribution, and many material properties such as absorption coefficients that varied with temperature. Compared to the 1-D models, the parameter settings were more complex and closer to the actual experimental conditions. This resulted in accurate predictions of experimental LTW outputs. For example, in Van de Ven's model, the error of weld widths between the model and the experimental results is less than $5 \%$. 
Becher [62] used a 2-D Finite Element Method (FEM) model to estimate the heat distribution at the weld interface during the Nd:YAG LTW for PP using ABAQUS software. The model was created based on the measured laser intensity distribution and the Lambert-Bouguer law was used to calculate the intensity reduction in the absorbent part due to energy absorption. The modeling results and experimental results agreed very well.

Mayboudi [63] also used a 2-D FEM model using ANSYS software to simulate heat transfer during LTW of PA 6 with a diode laser. They also used Lambert-Bouguer law to calculate the laser beam absorption. Scattering of the laser beam was not considered in the transparent part.

Kritskiy [64] created a 2-D axi-symmetric FEM model in COMSOL to simulate temperature distribution and weld width during the welding of the transparent nylon tube to the absorbent nylon plaque. In his model, heat convection from the specimen to the ambient environment was also accounted for. The beam profile and the specific heat capacity for the transparent part were measured and used in the model. In addition, density, thermal conductivity, and heat capacity were defined as temperature-dependant variables and their expressions were applied to both transparent and absorbent parts. Experimental results agreed with predicted values: at higher laser power (or lower rotational speed) visible onset of degradation occurred earlier. At the same time, at lower laser power (or higher rotational speed), degradation started later, but at a noticeably 
lower temperature. In addition, the experimental results, such as the weld widths, were used to validate the modeling results.

\section{- 3-D modeling}

Mayboudi $[65,66]$ also simulated the heat transfer of contour LTW of PA6 with diode lasers in a 3-D FEM model using ANSYS software. Laser absorption was considered in both the transparent and absorbent parts. The effect of laser beam scattering by the transparent part was also considered. A linear increase of the scattered beam radius as a function of transparent part thickness was used. The solution time of 3D model was much longer than that of 2-D model because of the increased number of elements. In Mayboudi's 3-D model, the CPU time to process and solve this problem was approximately 36 hours on a $2.4 \mathrm{GHz}$ PC with $1.5 \mathrm{~GB}$ of RAM. The time is much longer when compared to the 2-D model (30 min) solution of the same problem [63].

Chen [27] developed a 3-D Quasi-static FEM model to simulate the heat transfer and thermal deformation in contour gap bridging welding of PC, PA6, and PA6GF using COMSOL software. In order to reduce the computing time, a mass flow was introduced in the model so that a time-dependent contour welding process was solved as a timeindependent heat transfer problem. The measured parameters such as densities, heat capacities, thermal conductivities, power intensity distributions, etc. were used in the model. This makes the modeling more precise. Experimental results for the softened/melt widths, the weld widths, the melt pool size, and the maximum bridged gaps were used to validate numerical models and showed good agreement. 


\section{B. Thermal-mechanical modeling}

In order to simulate the temperature profile and deformation in the welding, thermalmechanical coupled models have been used [27, 67-70].

Potente et al. [67-70] used 2-D FEM through ABAQUS software to simulate the temperature profile and polymer melt flow profile of PC and PA6 in simultaneous and quasi-simultaneous welding. The simulation of the temperature profile is similar to thermal modeling. The simulation of the melt flow (thermal deformation) was based on the elastic-plastic material deformation theory. The stress-strain relation depends on the temperature and the time. The heat input was the measured power intensity distributions after the laser-transparent part. The melt flow as a function of clamping pressure was obtained in the modeling, which showed good agreement with the experimental data.

Chen [27] developed a simplified 2-D transient, thermal-mechanical coupled model to simulate the heat transfer and thermal deformation in contour LTW of PC, PA6, and PA6GF using COMSOL software. In his model, the laser power was assumed to be attenuated exponentially along its penetration depth in both the transparent and absorbent polymers based on the Bouguer-Lambert law. The heat input was the measured power intensity distribution from the laser itself. Laser beam scattering in the transparent and absorbent parts was also modelled and accounted for in the thermal-mechanical simulation. The modeling results showed that the maximum gap bridgeable for a given CB level increases with laser power, which showed good agreement with the 
experiments. The modeling results also showed that, for the given laser scan speed range of $25 \mathrm{~mm} / \mathrm{s}$ and above, the 2-D coupled model can be used to adequately describe the temperature rise and thermal expansion of PC and PA6. The simulated thermal expansion for PA6GF is lower than the experimental data.

No simulations of surface deformation during LTW have been reported

\subsection{Sink marks}

To understand the mechanism of sink mark formation, it is important to understand polymer volume changes during injection moulding processing. Referring to the cavity pressure profile and the PVT-diagram (for an amorphous polymer) shown in Figure 2-2 [71], it can be noted that:

- The polymer melt at point (1) in the diagram is at 1 bar pressure. Between (1) and (2), over $90 \%$ of mould filling takes place by injection resulting in pressure build-up.

- At (2), peak cavity pressure is reached during the pressure-control phase of moulding.

- The path from (2) to (3) corresponds to the holding pressure applied to melt. The reduction of the melt's specific volume corresponds to additional melt mass that is transferred to the constant volume cavity from the injection moulding machine barrel.

- The melt is cooled between (3) and (4). Specific volume of melt remains almost constant and the cavity pressure drops to 1 bar. At the point (4) the moulded part can be ejected.

- After demoulding, the moulded part is further cooled to room temperature (at point (6)) outside of the mould. The specific volume decreases between (4) and (6) as the constant mass of plastic in the part cools. 


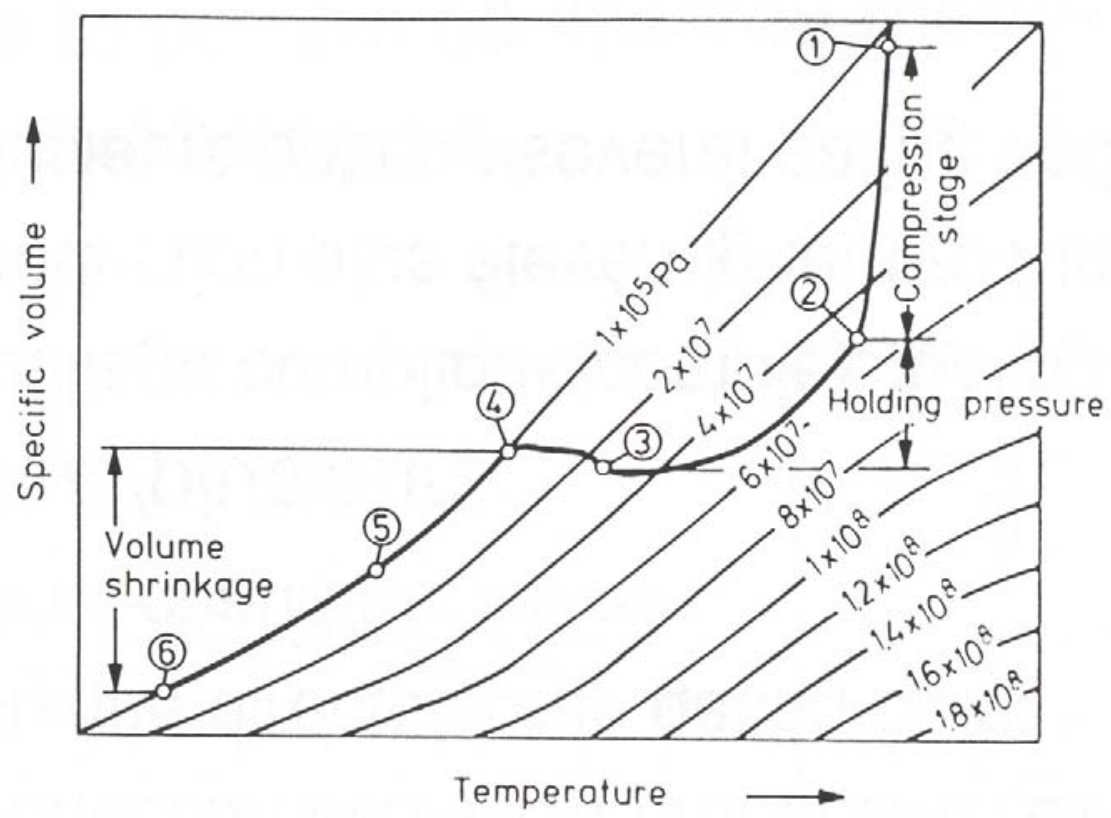

Figure 2-2 Typical PVT profile during Injection Moulding [71]

The above explains how the volume shrinkage takes place theoretically in injection moulded parts. In a real part, volumetric shrinkage will vary throughout due to uneven thickness, uneven cooling and non-uniform holding pressure. This will lead to uneven volume shrinkage. This is most problematic in thicker part sections where the cooling rate and holding pressure are often lower. As a result, sink marks are a common aesthetic effect on injection moulded parts having a smooth surface on one side and rib or other feature on the reverse side. It is often easy to observe this type of surface quality issue using the naked eye because the sink mark depression reflects light in different directions. For some injection molded products, the appearance of the sink mark is obvious. Figure 
2-3 shows examples of sink marks on a surface of the injection-moulded part having a rib on the reverse side.

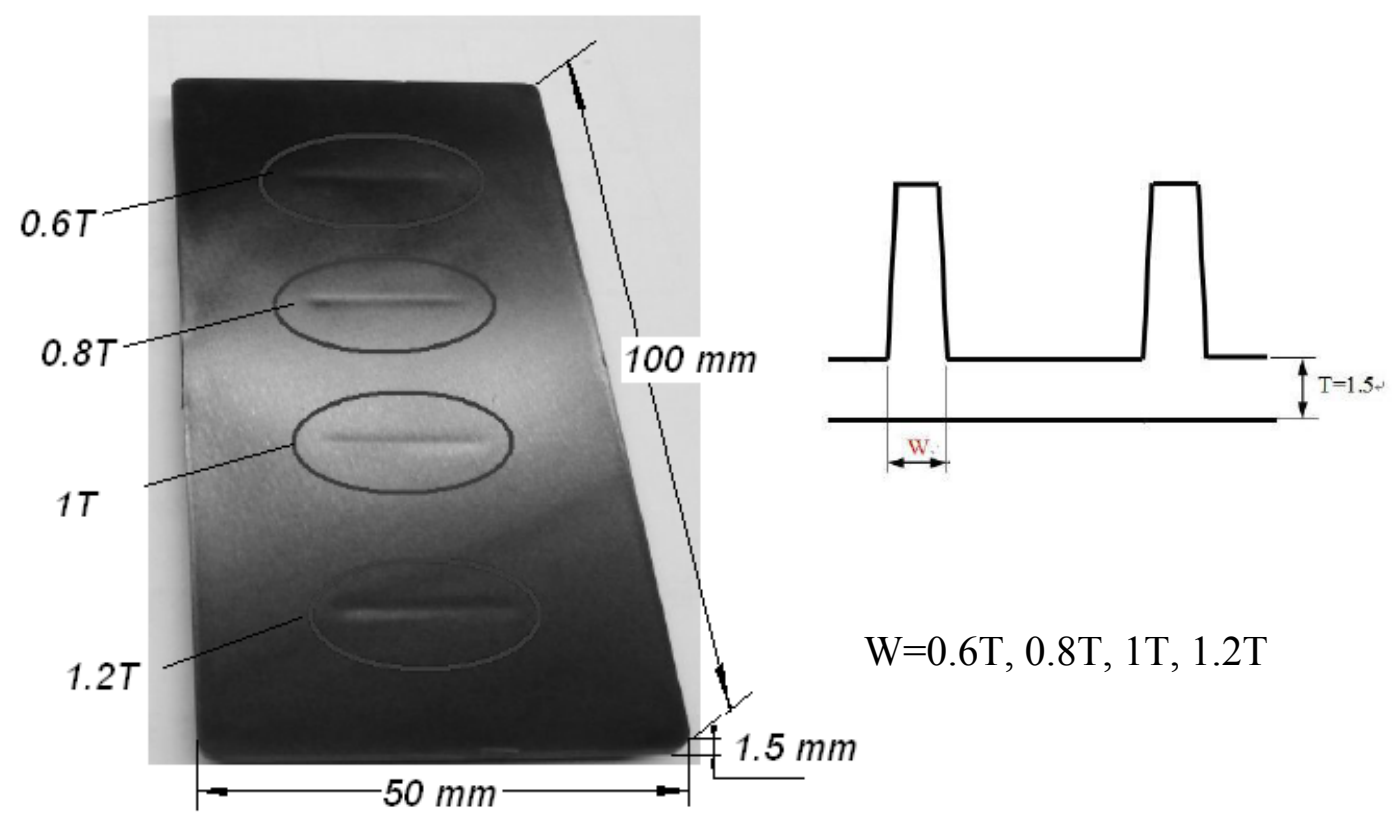

Figure 2-3 Appearance of sink marks with conventional injection moulding [72]

Visible sink marks often exhibit depths measuring hundredths of a millimeter. In other research, sink mark depths of $0.040 \mathrm{~mm}(0.0016$ in. $)$ were not visible to the trained observer, while sink marks deeper than $0.075 \mathrm{~mm}(0.003$ in.) were visible $[8,73]$.

\subsubsection{Sink marks in injection moulding}

One of the typical sources of dimensional instabilities in injection mouldings is the presence of thermally-induced residual stresses which are normally compressive at the surface and tensile at the core [74]. It is common to form sink marks at location of local 
increased thickness. These sink marks are formed when the plastic in the thicker sections solidifies in the absence of packing pressure. The volumetric contraction then pulls the free surface inwards, creating sink marks. A local increase of thickness is dependent on the design of the part such as the presence of a plate-rib type mould geometry part. Figure 2-4 shows a schematic representation of sink mark due to the rib and mould design. It is observed in this figure that the sink mark depth decreases as the rib to wall ratio decreases or the fillet radii decreases. These part geometry changes reduce the volume of material that is solidifying and ultimately reduce the residual stresses.

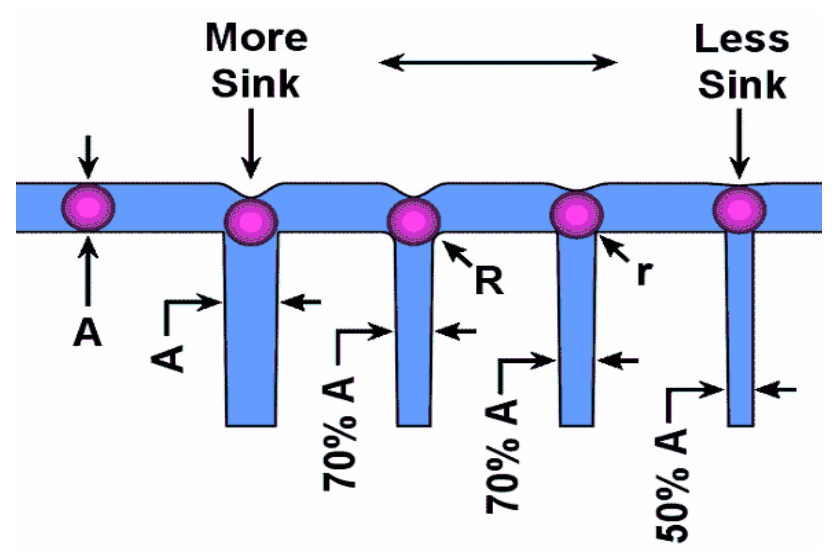

Figure 2-4 A schematic representation of sink mark due to thick rib on the back of a flat part. The image shows is a range of rib/wall ratios and fillet radii. Sink mark depth decreases as the rib/wall ratio decrease [8].

Sink marks are a common defect faced by injection molders [75]. In order to manufacture parts with Class A surfaces without sink marks visible by the naked eye from ribs and bosses, many different moulding techniques have been evaluated. For example, to optimize the parts with ribs, gas assisted injection moulding techniques [72, 
76] have been developed. Gas assist reduces sink marks by injecting the gas into the interior of the part through gas channels. The gas will then establish the pressure inside the part, resisting shrinkage. The control of melt temperature, mold temperature, and pack pressure were often used for optimization [77].

Using materials with a lower shrinkage during the injection moulding is another way to minimize the sink marks. For example, SMC (sheet moulding compound) is a fiberglass reinforced thermosetting compound in sheet form which can reduce shrinkage. The typical SMC compound contains about $30 \mathrm{wt} . \%$ glass fibre, $35 \mathrm{wt} . \%$ powdered inorganic fillers, and about 35 wt.\% resin) is widely used to provide Class A surface for auto panels $[78,79]$.

In addition, surface texture can hide sink marks [8, 9]. Figure 2-5 is a good case to show how the sink marks were hidden by the application of surface texture. From this figure, one can see there are a circle and a cross design and the rest of the part is covered by a lot of small holes. Actually, some ribs exist behind the surface of the picnic table. The place of the ribs is shown in the figure. Given the distortion of these small holes, the sink mark on the surface becomes invisible.

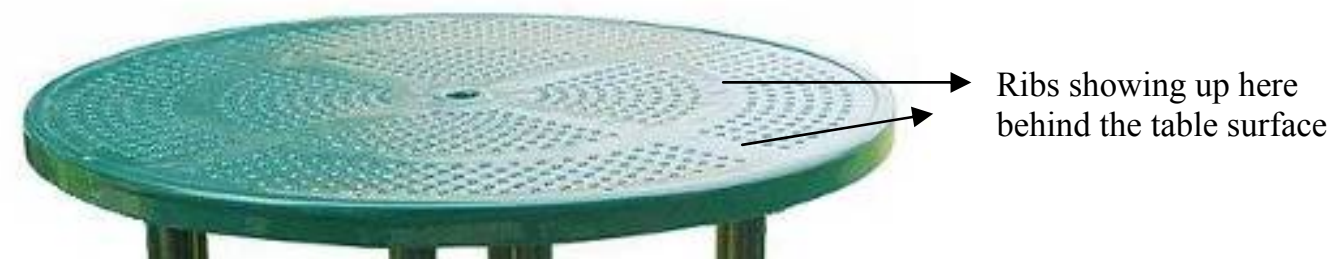

Figure 2-5 An example of hiding the sink marks using the surface texture 


\subsubsection{Sink marks in joining}

One way of avoiding moulded-in features such as a rib or boss on the back of a part having a Class A surface is to join the feature to the part. This will avoid or minimize the deformation on the surface associated with the shrinkage during injection moulding. This is being explored by automotive companies such as Ford [11].

Adhesives or technologies such as hot plate, resistance, vibration, and ultrasonic welding can be used to assemble the plastic parts together [80, 81]. However, gluing or welding structures to the back of automotive Class-A panels can still result in the appearance of aesthetically unacceptable sink-mark-like defects on the Class-A side. This is because the cure of the adhesive layer or the cooling of the bonding area can create residual stresses which can lead to the deformation on the surface along the bonding line. This deformation is referred to here as weldline-read-through [10].

\subsubsection{Evaluation of the defects}

There is no standard for the evaluation of surface quality including sink marks [6]. Wood [6] discussed that, currently in the automotive industry, surface quality is assessed visually by human observation of reflected images on the material surface under controlled lighting conditions. The following will introduce some of the reported evaluation methods.

Wang et al. [82] used 'the relative sink depth' to estimate the sink marks for injection moulding parts. The relative sink depth is defined as: 


$$
y_{i}=\frac{d}{d_{1}+d_{2}}
$$

Equation 2-5

where $y_{i}$ is the relative sink depth, $d$ is the absolute sink depth, $d_{l}$ is the thickness of the plane, and $d_{2}$ is the design height of the boss as shown in Figure 2-6. A movable bridge 3D Coordinate Measuring Machine with a precision of $0.0001 \mathrm{~mm}$ was used to measure the sink mark depth. In their studies, the thickness of the plane, $d_{l}$ and the diameter of the boss were fixed. It was observed from the results that both of the absolute sink depth, $d$ and the relative sink depth, $y_{i}$ increased with the increasing height of the boss, $d_{2}$.

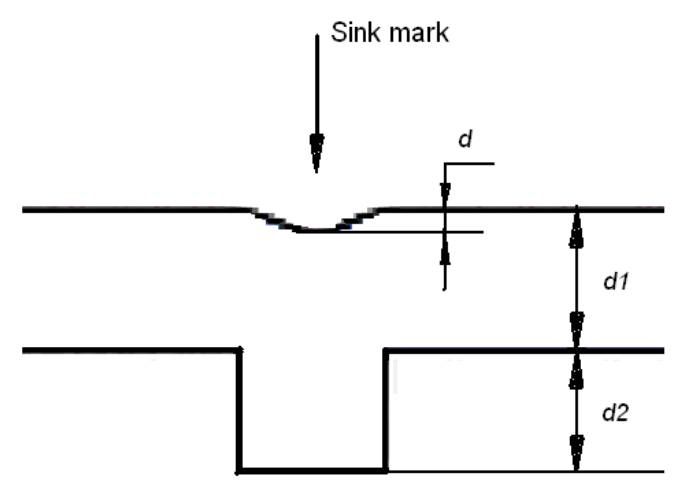

Figure 2-6. Schematic of dimensions of the part [82]

Jeong and Im [83] used the depth of the sink marks directly to evaluate them. In their study, a direct contact-type surface roughness measurement instrument by Mitutoyo Co. was used for determining the sink mark depth of compression molded SMC panels. The range of the measured depths was between 8 and $25 \mu \mathrm{m}$. The results showed that the depth of the sink mark increased with the increasing height of ribs or the increasing width of ribs. 
Chen et al [72] also used the depth to assess sink marks. In their study, a contact surface measurement machine was used to record the surface contour. Its accuracy approached $3.2 \mathrm{~nm}$ in vertical-direction. In their study, a line profile across the region above the ribs was collected. They concluded that, for a given rib height, the depth of the sink mark increased with increasing rib width.

Although the assessment of sink marks by using the depth of sink mark was used in several studies, it is not a universal method as we know that for sink marks with the same depths, their widths, volumes, or shapes may be different. Therefore, the visibility of these defects is also different.

Hsakou [84] discussed this phenomenon. Figure 2-7 shows the plots of two defects with the same depth. The plots, in addition to their height profiles, also show their slopes $(d z / d x)$ and curvatures $\left(d^{2} z / d x^{2}\right)$. It is observed that the first defect is wider than the second one and its curvature is lower than the second one. So the human inspector will be more sensitive to the second defect. Fernholz in a personal communication [11] pointed out that if the width of the defect becomes long enough, one can clearly visualize that the defect will "disappear" because its curvature is too low. Thus, the important factor to assess the visibility of a defect is curvature instead of the depth of the defect. However, if the widths of the two defects are similar, the depth of a defect can be used to assess the defect. This subject will be further addressed in this research. 

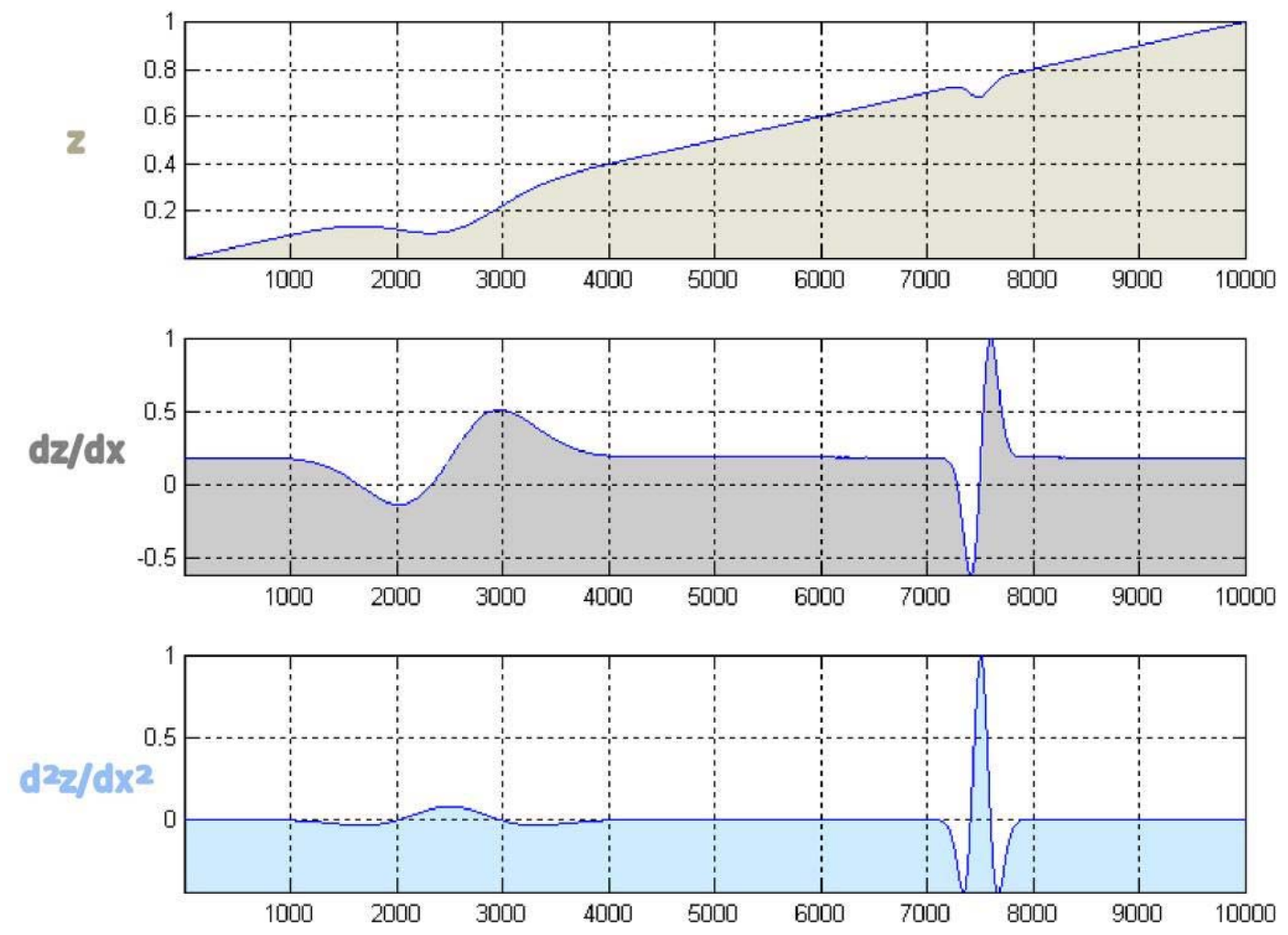

Figure 2-7 Visual relationship between altitude, slope and curvature [84] 


\section{Chapter 3}

\section{Materials}

\subsection{Polymer}

\section{A. Polypropylene (PP)}

The material used in this work was Polypropylene homopolymer, Pro-fax 6323 (supplied by the Basell Polyolefins Company). Although polypropylene-based thermoplastic olefins (TPO) materials are widely used in the automotive industry in the applications targeted by this research, PP homopolymer was selected for this work. Typically TPOs contain significant fraction of PP homopolymer in addition to elastomer and some filler. For the purposes of this exploratory study, PP homopolymer was used. Typical properties of Pro-fax 6323 are found in Table 3-1.

Table 3-1 Typical properties of Pro-fax 6323 [85]

\begin{tabular}{|c|c|}
\hline Property & Value \\
\hline Density, $\mathrm{g} / \mathrm{cm}^{3}\left(23^{\circ} \mathrm{C}\right)$ & 0.900 \\
\hline Melt Flow Index, g/10min & 12 \\
\hline Flexural Modulus, MPa & $1448(210000 \mathrm{psi})$ \\
\hline${\text { Melting Point, }{ }^{\circ} \mathrm{C}}$ & $168\left(334^{\circ} \mathrm{F}\right)$ \\
\hline
\end{tabular}




\section{B. $C B$ masterbatch (MB)}

To make the laser absorbent part, carbon black in the form of masterbatch was added to PP during injection moulding. This CB masterbatch was supplied by the Color Master Inc. In this technique, carbon black (Monarch 880 which is supplied by Cabot Corporation) was compounded with a linear low-density polyethylene (LLDPE) carrier resin to form a $2.6 \mathrm{wt}$ \% concentrated masterbatch which is then let down into the base resin PP to get absorbent parts with CB levels in the range $0.2,0.1$, and 0.05 wt. $\%$.

The CB level will affect the penetration of the laser into the absorbent part. Based on studies of Chen [50] who assessed the effect of carbon black on gap-bridging, it would appear that a relatively high $(>0.1$ wt. \%) $\mathrm{CB}$ would be most appropriate in order to minimize the volume of molten material in the weld zone. Material that flows or expands from the weld zone as flash may not flow back after cooling. This may generate residual stresses and cause surface deformation. In order to determine the effect of $\mathrm{CB}$ level on the ability to read the weld through both the transparent and absorbent part, the CB level should be varied. In addition, Becker [62] mentioned that 0.1 wt. $\%$ and 0.3 wt. $\% \mathrm{CB}$ level were used to weld PP. So $0.05,0.1$, and 0.2 wt. \% CB level were selected in this research. 


\subsection{Geometry of specimens}

A lap weld configuration was used to simulate typical contour welds in order to simplify welding, to minimize the effect of weld geometry on experimental results, and to be consistent with previous work.

Although the lap weld is different from joining a rib to a plate, as an exploratory test, it is still meaningful. In order to laser weld a rib to a laser-absorbing plate, we need to pass the beam through the rib material. The rib normally is too thick (more than a few millimetres) to allow the laser beam to reach the joint surface without excessive energy loss. Thus, we need to change the geometry of the rib as shown in Figure 3-1. This geometry makes the rib-plate weld similar to a lap weld configuration.

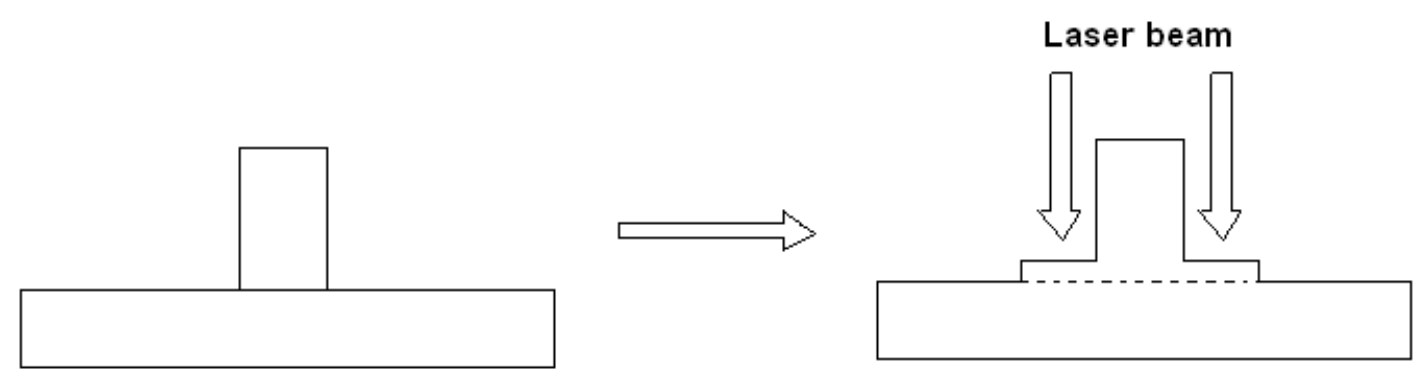

Figure 3-1 Schematic of changing the rib-plate weld to lap weld

The part thickness for both transparent part and absorbent part should be $3 \mathrm{~mm}$ in order to simulate industrial conditions. However, in order to find the effect of part thickness on the ability to read the weld through both the transparent and absorbent part, 
two part thicknesses were selected: $3 \mathrm{~mm}$ and $2 \mathrm{~mm}$ for both transparent part and absorbent part.

Most exterior automotive components are considered Class A. A Class A surface finish facilitates observation of defects on welded assemblies and they were therefore used in this research. In order to get Class A surface, a mould insert was made of brass and then polished to a mirror finish by Mr. Clarence McEwen of RMC. The polished mould insert is shown in Figure 3-2. The insert is divided into two equal halves: one half is $4 \mathrm{~mm}$ and the other is $3 \mathrm{~mm}$ thick.

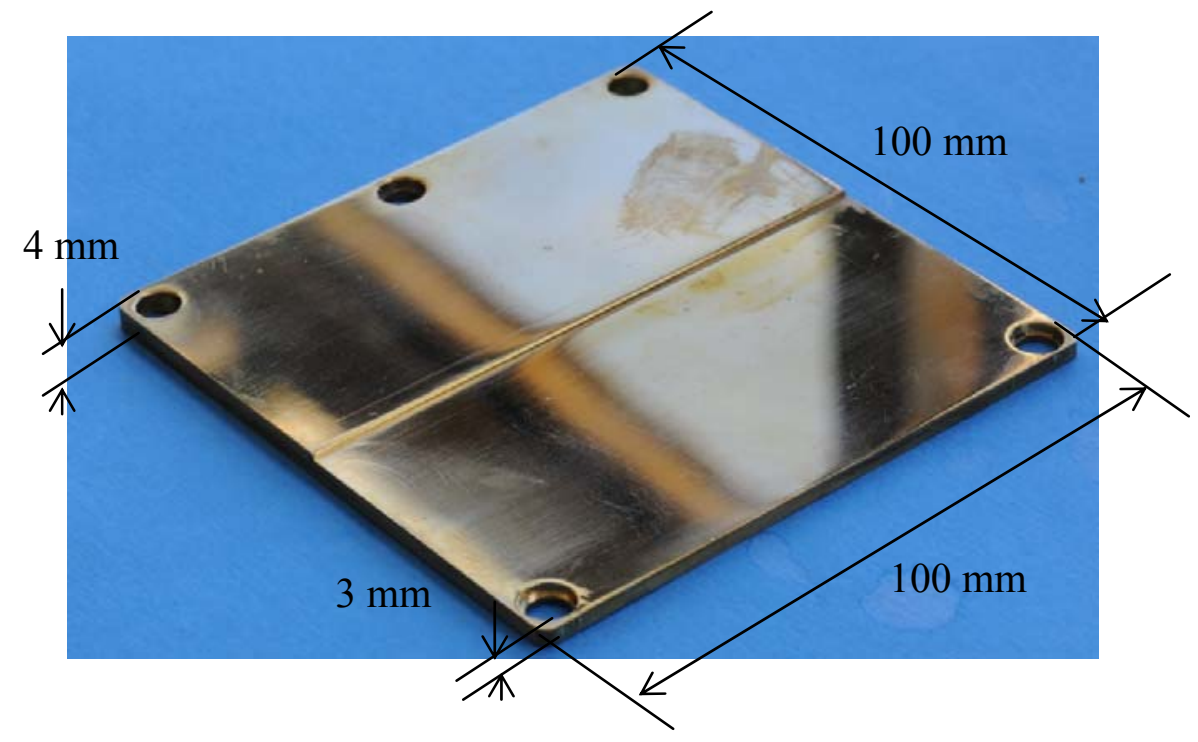

Figure 3-2 Polished mould insert made of brass

The mould insert was used in an existing $100 \times 100 \times 6 \mathrm{~mm}^{3}$ mould cavity to produce half-plaque that were $3 \mathrm{~mm}$ thick and $2 \mathrm{~mm}$ thick, as shown schematically in Figure 3-3. The plaques were moulded in a 55-ton Engel injection moulding machine 
located at RMC. The moulding conditions are shown in Table 3-2. After moulding, the plaques were cut into $35 \mathrm{~mm} \times 70 \mathrm{~mm} \times 2 \mathrm{~mm}$, and $35 \mathrm{~mm} \times 70 \mathrm{~mm} \times 3 \mathrm{~mm}$ parts for testing.

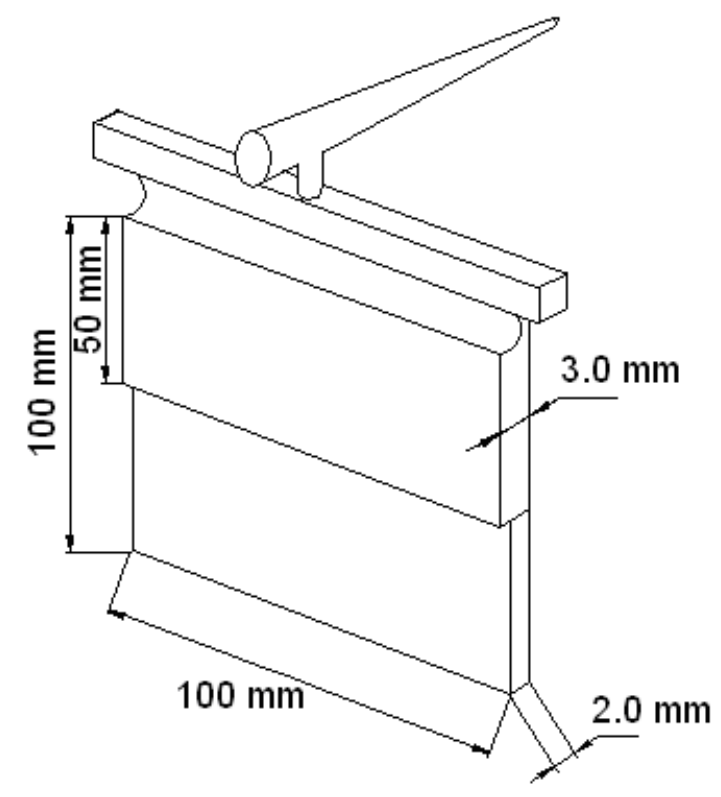

Figure 3-3 Schematic of the moulded plaque

Table 3-2 Injection moulding conditions

\begin{tabular}{|l|c|}
\hline \multicolumn{1}{|c|}{ Injection moulding variable } & Value \\
\hline Hold pressure & $30-40$ bars \\
\hline Hold time & $10 \mathrm{~s}$ \\
\hline Cooling time & $30 \mathrm{~s}$ \\
\hline Cycle time & $48 \mathrm{~s}$ \\
\hline Tool temperature, ${ }^{\circ} \mathrm{C}$ & 40 \\
\hline Barrel temperature, ${ }^{\circ} \mathrm{C}$ & $205-198-185$ \\
\hline Nozzle temperature, ${ }^{\circ} \mathrm{C}$ & 205 \\
\hline
\end{tabular}




\subsection{Optical properties of transmitting part}

$\mathrm{PP}$ is semi-crystalline polymer. The total transmittances of PP were measured by a Coherent ${ }^{\circledR}$ PM10 10W power meter using a setup shown in Figure 3-4. The $2 \mathrm{~mm}$ lasertransparent part made of PP has a total transmittance of $84 \%$, and the $3 \mathrm{~mm}$ PP has a total transmittance of $75 \%$.

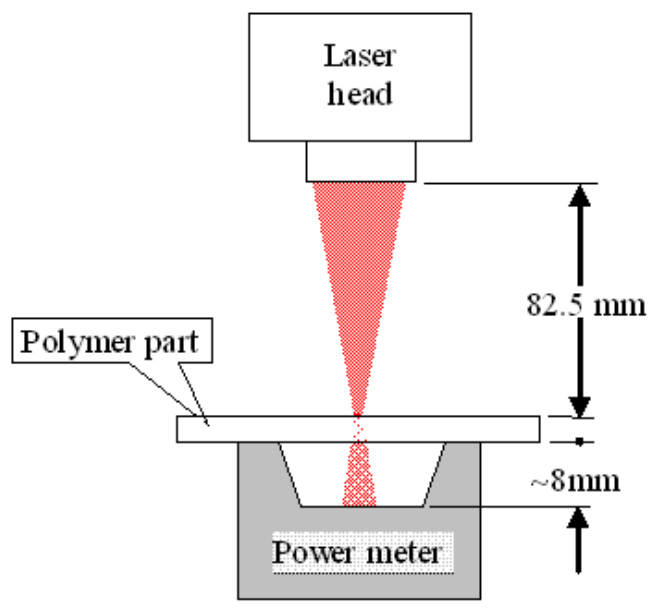

Figure 3-4 Setup for transmittance measurement of polymers (drawn by M. Chen) 


\section{Chapter 4}

\section{Surface Defect Characterization}

The experimental study of contour LTW presented in this chapter investigated the effect of polypropylene homopolymer (PP) material (PP carbon black level), part (thickness of both transparent and absorbent parts) and diode laser (power) parameters on the ability to see the weld through the absorbent part. This is often referred to as 'weldline read-through'. A profilometer was used to measure the deformation on the absorbent sample surfaces. The cross-sectional microstructure also was assessed using polarized light microscopy of microtomed sections. The chapter will describe the equipment and general methodology (Section 4.1), the assessment of surface quality (Section 4.2), and the experimental results (Section 4.3).

\subsection{Method}

\subsubsection{Contour LTW}

\section{A. Equipment}

The equipment used in this study was a $160 \mathrm{~W}$, continuous-wave Rofin-Sinar diode laser DLx16 (wavelength $940 \mathrm{~nm}$ ) equipped with CCD camera. Its focal distance is 82.5 $\mathrm{mm}$. At this distance, the spot size of the laser is approximately $0.6 \mathrm{~mm} \times 1.4 \mathrm{~mm}$ [86]. The system is shown in Figure 4-1. From this figure, we can see that the laser and the 
fixture are set in the cabinet for safety reasons. The laser system can be operated manually or controlled by the computer program. The motion system inside the workstation allows for linear movement of the fixture in the horizontal plane along the $\mathrm{x}$ and z-axes and vertical movement of the laser head along the y axis. The maximum horizontal translation speed is $9000 \mathrm{~mm} / \mathrm{min}$. The laser head is positioned above the fixture. The laser beam is delivered by a lens through the laser head, and then focused on the weld interface between the parts. The parts are held stationary and indexed with respect to the laser in the fixture.

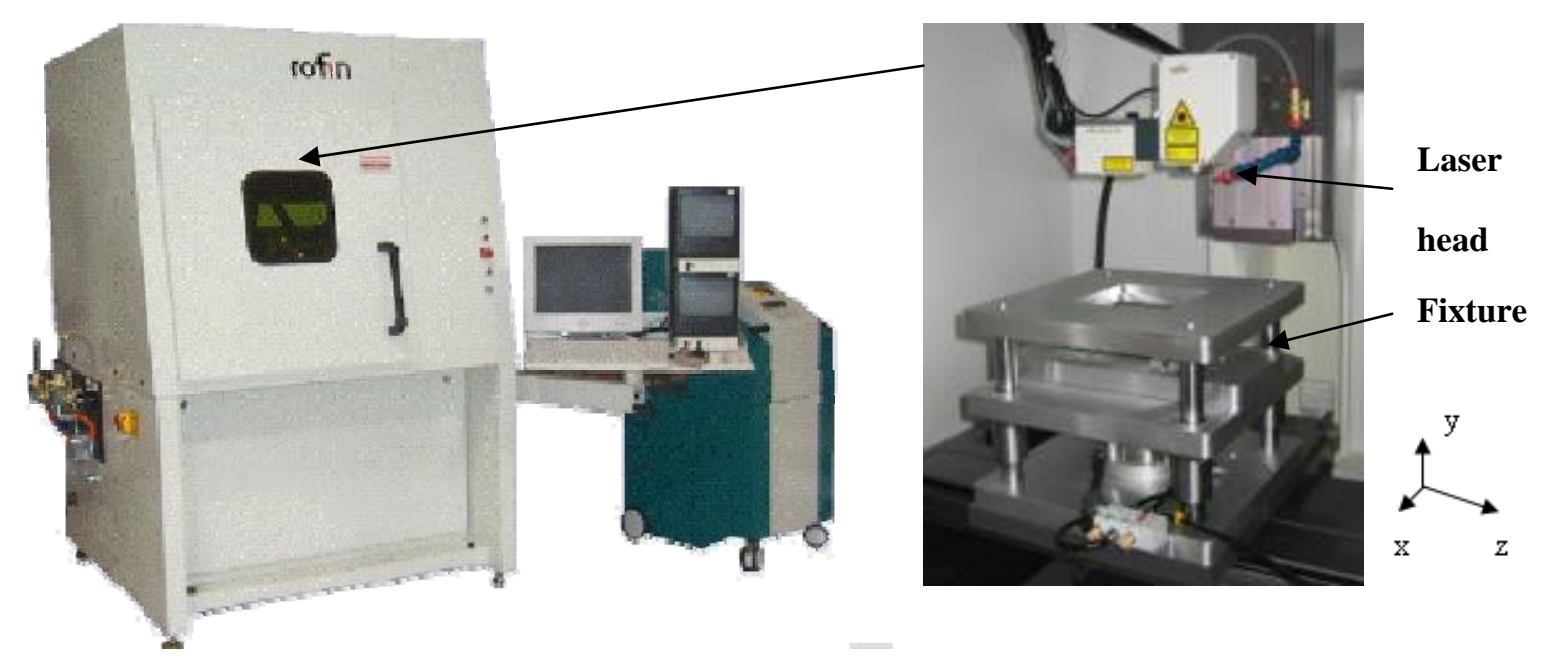

Figure 4-1 Rofin-Sinar diode laser cabinet (left) and close-up view of the DLx16 laser head and the welding fixture (right).

The power profile of the laser beam has been measured by Mayboudi et al. [87] and is shown in Figure 4-2. In order to obtain a wide and relatively evenly distributed heating 
area, the laser always scans over specimens along the z-axis. That is to say that, during welding, the fixture moves along z-axis under the stationary beam.

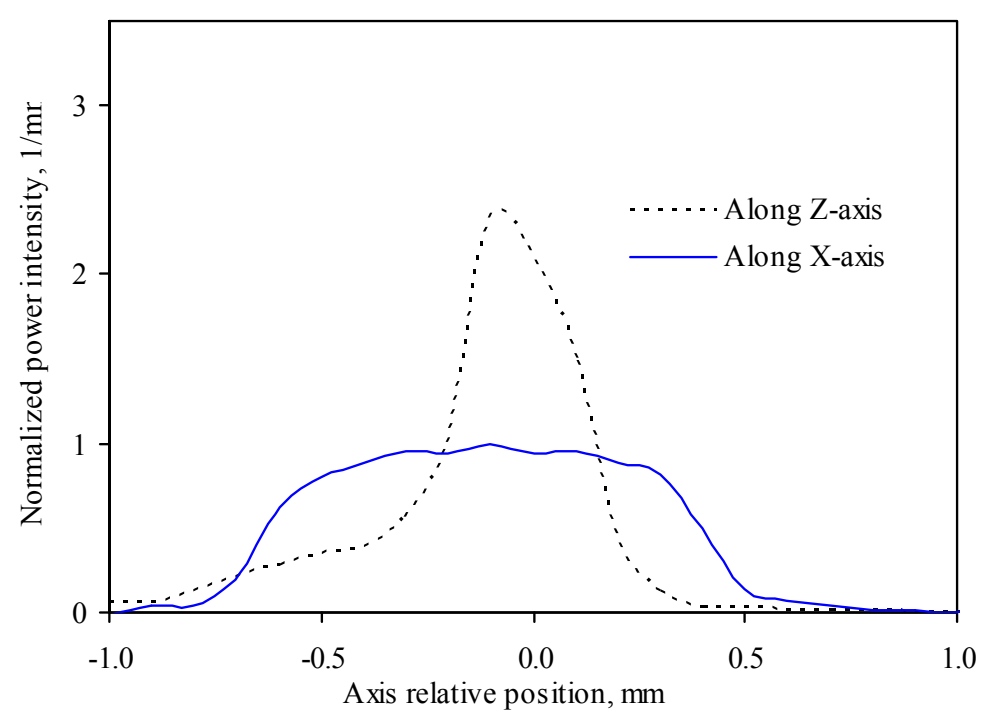

Figure 4-2 Typical 1-D laser beam profile at a work distance of $82.5 \mathrm{~mm}$ for DLx16 HP diode laser [27]

\section{B. Welding procedure}

The parts to be welded are placed inside the welding fixture shown in Figure 4-1 and represented schematically in Figure 4-3. The welding fixture was designed and assembled by M.L. Chen. The fixture was installed on and driven by the x-z linear motion system in the workstation. Two aluminum plates with an open slot were used to hold the parts in the fixture. A pneumatic cylinder moves the bottom plate along the yaxis to generate the specified weld pressure to hold parts together for welding. 


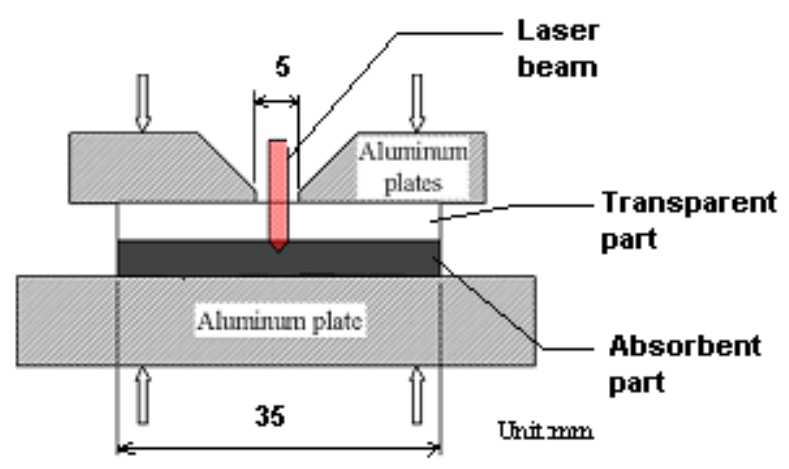

Figure 4-3 Schematic of the welding fixture

The dimensions of the parts and the weld direction are shown schematically in Figure 4-4. The weld length for each specimen is $35 \mathrm{~mm}$. The weld seam was located in the center of the part, approximately $17 \mathrm{~mm}$ from each edge.

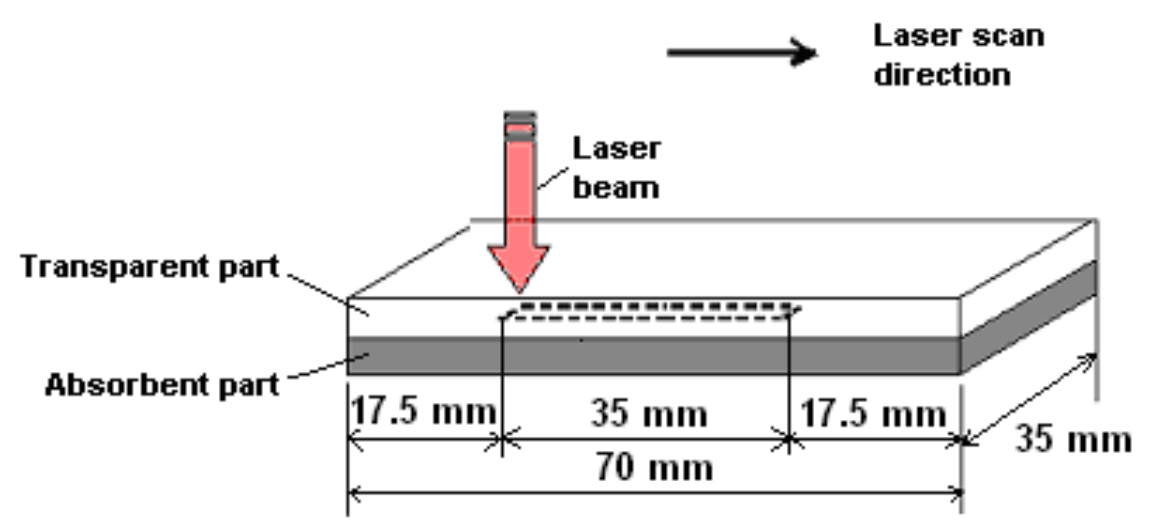

Figure 4-4 Schematic of an over-lap joint specimens

The specimens were put into the fixture and centred along the middle of the open slot. The fixture was then positioned under the laser head using an $\mathrm{x}-\mathrm{z}$ motion system 
and the CCD camera. In order to control the length of the weld seam, two metal masks were placed over the slots to obscure the area that was not to be irradiated.

\section{Process parameters investigated}

The main process parameter studied was the laser power. For a given scan speed, the laser power determines the total energy delivered by the laser to the specimens. The laser power settings were between 6 and 23 Watts. These operating ranges were determined by the non-contact welding method [88] described in Appendix A. It is important to note here that the range of minimum-maximum powers was different for each $\mathrm{CB}$ level. This was due to the fact that, for different $\mathrm{CB}$ level, the ability to absorb the laser energy is different. For example, if $12 \mathrm{~W}$ is applied to parts containing 0.05 wt. \% CB and 0.2 wt. \% CB, the parts containing 0.05 wt. \% CB can just be welded together. However, parts with 0.2 wt. \% CB level parts begin to degrade.

The laser scan speed was fixed at $1500 \mathrm{~mm} / \mathrm{min}$ for all tests. In order to reduce the number of runs, the laser scan speed was selected based on previous work in our research group. Previous work $[88,89]$ has shown that, as a first approximation, the temperature at the weld depends on line energy (ratio of laser power to scan speed). Thus, the results presented here are expected to be comparable to those that would have been obtained at higher scan speeds and correspondingly higher laser powers.

The air pressure in the clamping unit used was $300 \mathrm{psi}$. This corresponds to a weld interface pressure of $385 \mathrm{KPa}$. It is selected based on previous work in our group. Table 
4-1 summarizes the material and process parameters in detail. For each material and welding condition, 3 replicate tests were performed.

Table 4-1 Process parameters in the study

\begin{tabular}{|c|c|c|c|c|c|c|}
\hline \multirow{2}{*}{$\begin{array}{c}\text { CB level } \\
\text { (Wt. \%) }\end{array}$} & Part thickness & \multicolumn{5}{|c|}{ Laser power } \\
\hline \multirow{2}{*}{0.05} & 2 & 12 & 14 & 16 & 18 & 20 \\
\cline { 2 - 7 } & 3 & 15 & 17 & 19 & 21 & 23 \\
\hline \multirow{2}{*}{0.1} & 2 & 7 & 8 & 10 & 12 & 14 \\
\cline { 2 - 8 } & 3 & 9 & 10 & 11 & 13 & 15 \\
\hline \multirow{2}{*}{0.2} & 2 & 6 & 7 & 8 & 10 & 12 \\
\cline { 2 - 8 } & 3 & 6 & 7 & 8 & 10 & 12 \\
\hline
\end{tabular}

- clamping pressure of 300 psi

- 3 replicates

- Scan speed of $1500 \mathrm{~mm} / \mathrm{min}$

\subsubsection{Profilometer}

\section{A. Equipment}

In order to assess the deformation of the black surface opposite the weld line, a profilometer was used. All the data were taken from the surface of absorbent parts because in almost all foreseeable cases, the Class A surface will be laser absorbing [11].

The profilometer used in this research is the KLA-Tencor P-15 Profiler (Figure 4-5), which is located at the Queen's University Human Mobility Research Centre (HMRC). 
The P-15 system uses stylus-based tracing to achieve high resolution. It is a highly sensitive surface profiler that measures step height, roughness, and waviness on sample surfaces. Roughness can be measured with up to a $0.0005 \mu \mathrm{m}$ resolution over short distances. Waviness can be measured over the entire surface of a sample whose trace area is less than $200 \times 200 \mathrm{~mm}$.

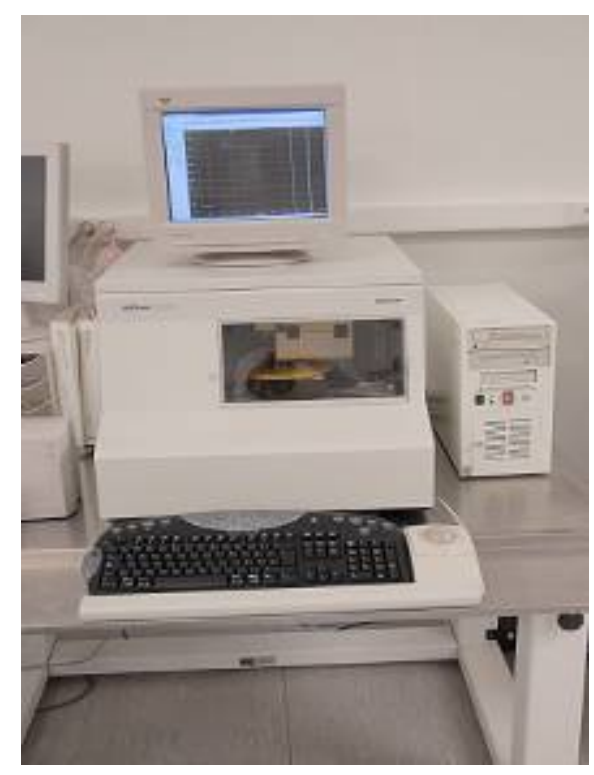

Figure 4-5 The KLA-Tencor P-15 Profiler

The P-15 system is capable of high-resolution traces in 2D or 3D formats. Both formats use trace data. The 3D scan uses a combination of parallel traces. The length of the traces, the distance between parallel traces, and the frequency of data point collection can be defined by the user. The $2 \mathrm{D}$ trace is a collection of data points made at a specified frequency either as one trace, or a specified number of traces over the same trace 
position, which are then averaged. The data are then presented in either a two- or threedimensional graphical format for observation and analysis.

In our case, nine traces were taken for each specimen. Figure 4-6 shows schematically how the profiler traced the surface of the absorbent part. The stylus traced across the weld seam along the yellow lines in the trace direction (green arrow) shown in the figure. The parallel traces were equally spaced over the $35 \mathrm{~mm}$ long weld line.
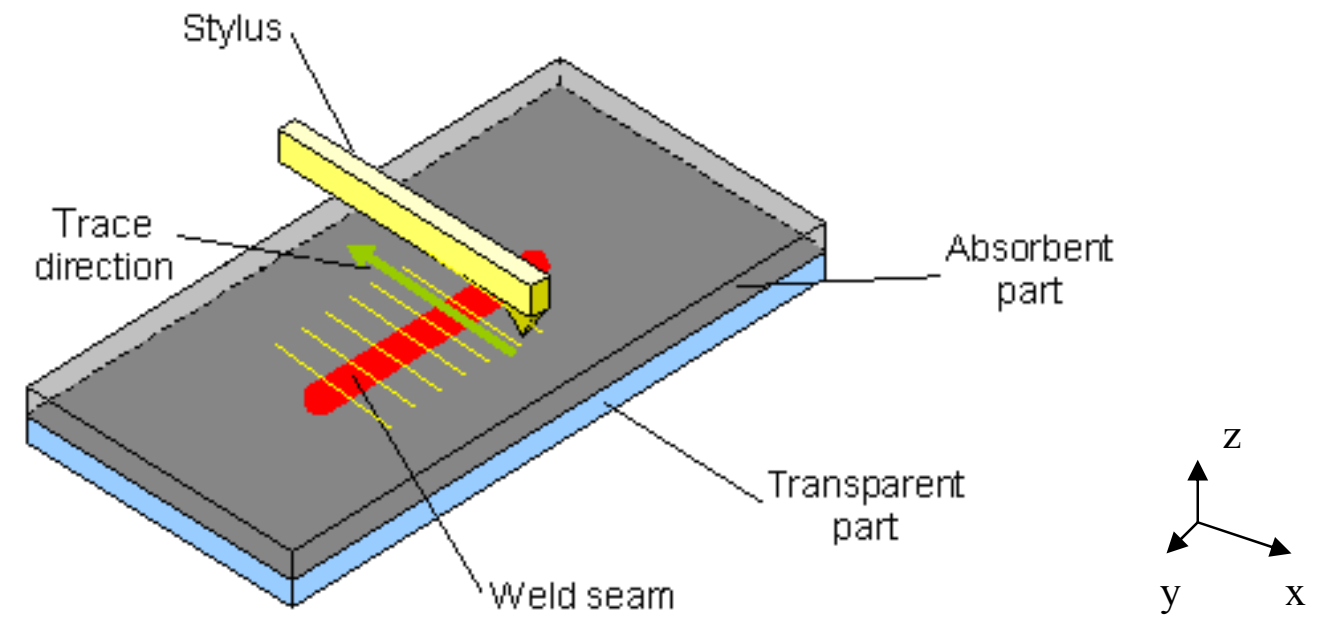

Figure 4-6 Schematic of 3D profilometer trace using the P-15 profiler

In order to keep each specimen indexed with the profilometer, a spring-loaded fixture was designed and used. It is shown in Figure 4-7. This fixture was attached to the measurement stage, and then the specimen was placed between two plates as shown in Figure 4-7 (b). This ensures that the specimen was placed in the same position in the center of the stage for each measurement. 


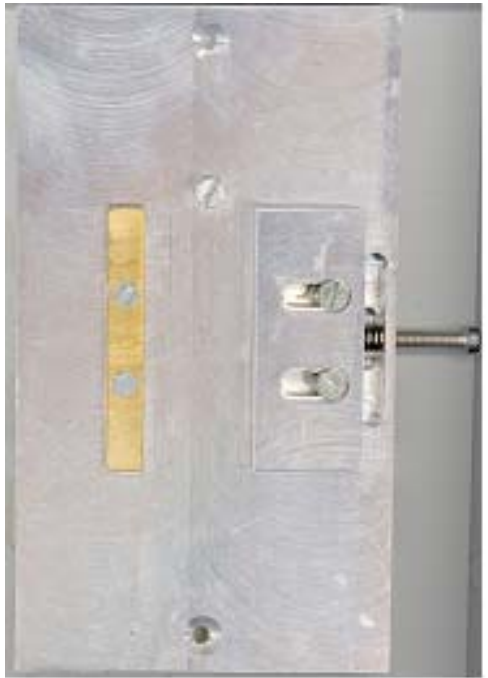

(a)

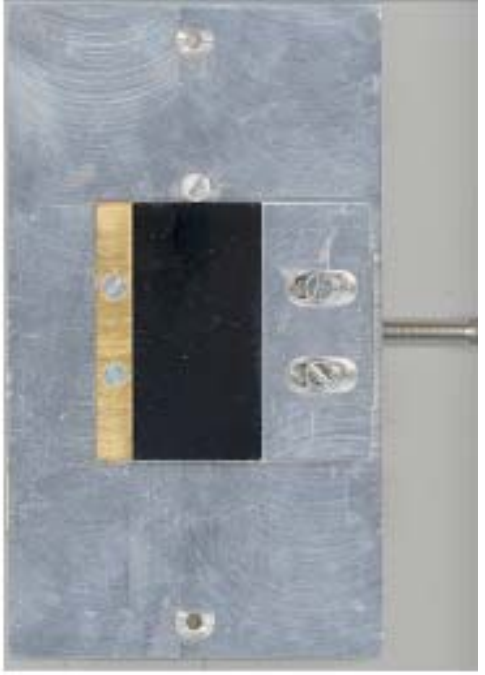

(b)

Figure 4-7 Specimen holding fixture used in profiler trace, (a) the fixture without specimen, (b) the fixture with the specimen

\section{B. Process parameters investigated}

The profilometer trace speed was $1000 \mu \mathrm{m} / \mathrm{s}$ at a sampling rate of $10 \mathrm{~Hz}$, giving a spatial resolution of $10 \mathrm{samples} / \mathrm{mm}$. The trace length perpendicular to the weld was 10

$\mathrm{mm}$. A total of 9 traces were made for each weld, with traces spaced $4.5 \mathrm{~mm}$ apart. Under these conditions, 101 data points were collected for each trace. In order to determine a suitable spatial resolution, several preliminary tests were performed in which 10,001, 1,001, and 101 measurements were collected for each trace line. By comparing the three results, 101 data points were judged to be sufficient to differentiate the various welding conditions used in this research while at the same time minimizing the data storage and handling requirements. 


\subsubsection{Microstructure}

The weld microstructure was obtained by observing microtomed slices of the assembly cross-section at the weld interface under a polarized light optical microscope. Given the width of assembly used in this study $(35 \mathrm{~mm})$, it was first cut to a $10 \mathrm{~mm}$ wide section using a Buehler Isomet 1000 precision sectioning saw. Care was taken not to damage the weld seam during machining. Then a Leica RM 2155 microtome was used to cut the specimens into 40 -micron thick slices. The slices were then observed under a polarized light microscope. The images were photographed and saved for further analysis. The sectioning and microscopic equipment used here was located at RMC.

\subsection{Assessment of weld read-through}

Currently, there is no tool capable of quantifying the severity of a surface defect on a Class-A surface in a way that correlates to visual assessment [11]. Profilometers can provide a numeric output related to defect dimensions but do not provide information related to how noticeable the defect might be to the consumer. For automotive applications, the consumer's perception of the defect is the ideal output. In the absence of such a tool, our research focused on quantifying the defects using the profilometer mentioned above. The treatment of the profilometer data in order to provide a rational means of assessment for weld read-through is discussed below.

Figure 4-8 shows a plot of surface height (relative to the profilometer's frame of reference) as a function of trace distance. It presents typical raw data taken from $2 \mathrm{~mm}$ 
thick parts containing a CB level of 0.05 wt. $\%$ and welded at a power of $18 \mathrm{~W}$. It is observed that the slope of the curve undergoes a noticeable change around $5.5 \mathrm{~mm}$. This suggests that the defect is there. We can also see from this figure that there is an angle between the curve and the x-axis. That is because the specimen could not be placed absolutely parallel to the trace direction (x-axis). This angle does not affect the accuracy of measurement but does present some difficulties in determining the height and width of the defect from the raw data.

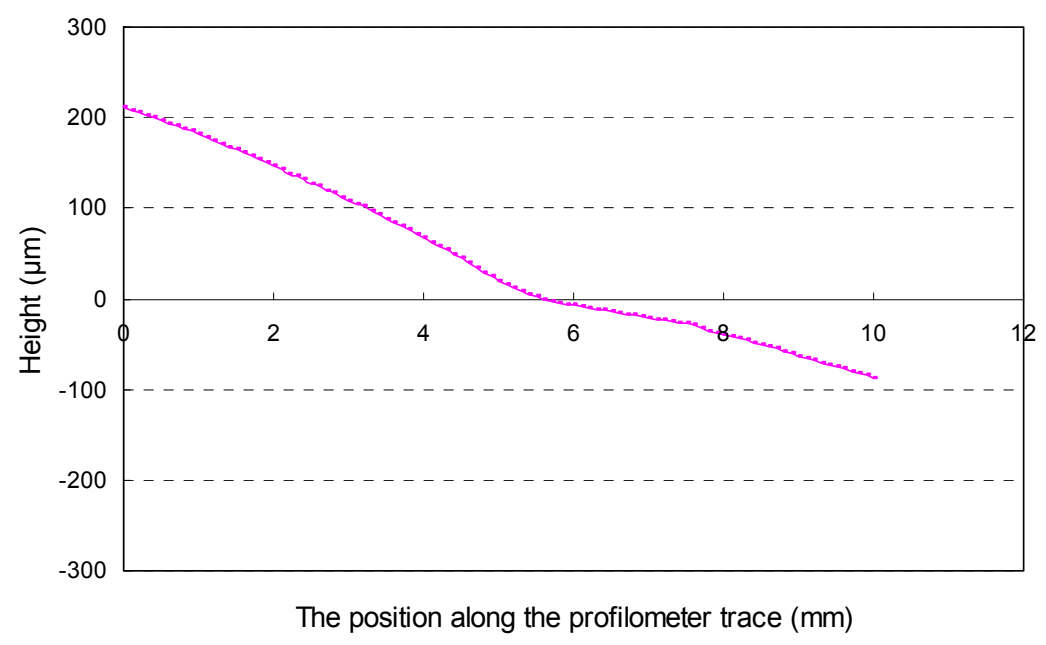

Figure 4-8 An example of raw data taken from P-15 profiler (Thickness of parts: $2 \mathrm{~mm}$ CB level : 0.05 wt.\%, Laser power: $18 \mathrm{~W}$, Clamp pressure: 300 psi, Laser scan speed: $1500 \mathrm{~mm} / \mathrm{min}$, Profilometer trace speed: $1000 \mathrm{um} / \mathrm{s}$, Sampling rate: $10 \mathrm{~Hz}$ )

In order to differentiate between the "ambient" curvature of the part and that in the defect, the second derivative of the height as a function of the position along trace was calculated. This is often referred to as curvature. The term "ambient curvature" refers to 48 
the background curvature of the plate in the absence of the defect. In other words, it is the curvature of the surrounding area which comes into contact with the defect. It is generally accepted that a defect on a surface will be visible if the local surface curvature is substantially greater than the "ambient" curvature $[11,84]$.

In order to reduce the noise, the data were filtered using the moving average method. The moving average method is defined as:

$$
\begin{gathered}
x 1=\frac{1}{n}\left(x_{1}+\cdots+x_{n}\right) \\
x 2=\frac{1}{n}\left(x_{n}+\cdots+x_{n+1}\right) \\
x m-n+1)=\frac{1}{n}\left(x_{m-n+1}+\cdots+x_{m}\right)
\end{gathered}
$$

where $\mathrm{m}$ is the total number of data points in the curve (this was approximately 90 to 101 for each data set), and $n$ is the number of the data averaged in each period. Figure 4-9 and Figure 4-10 show the second derivative as a function of the position along trace for $n=10$ and 15 respectively. The results show that increasing the value of $n$ smoothes the data. A value of $n=15$ was selected for filtering of other data sets as the ratio of noise amplitude to the magnitude of the second derivative in the vicinity of the defect was small. 


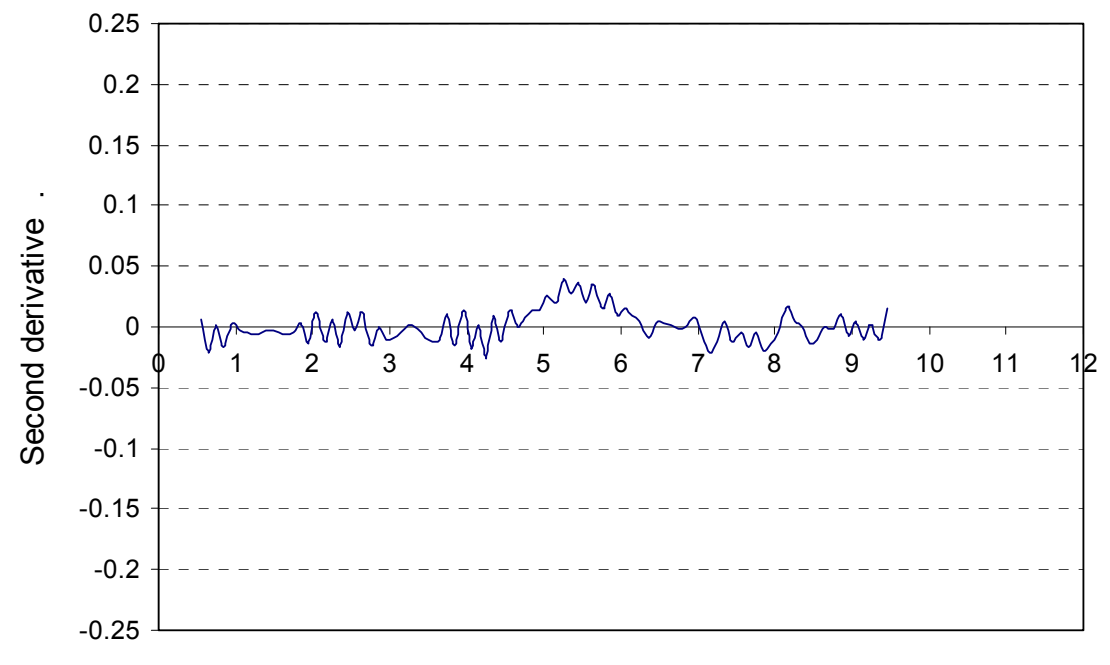

The position along the profilometer trace $(\mathrm{mm})$

Figure 4-9 Curvature of smoothed data with $n=10$

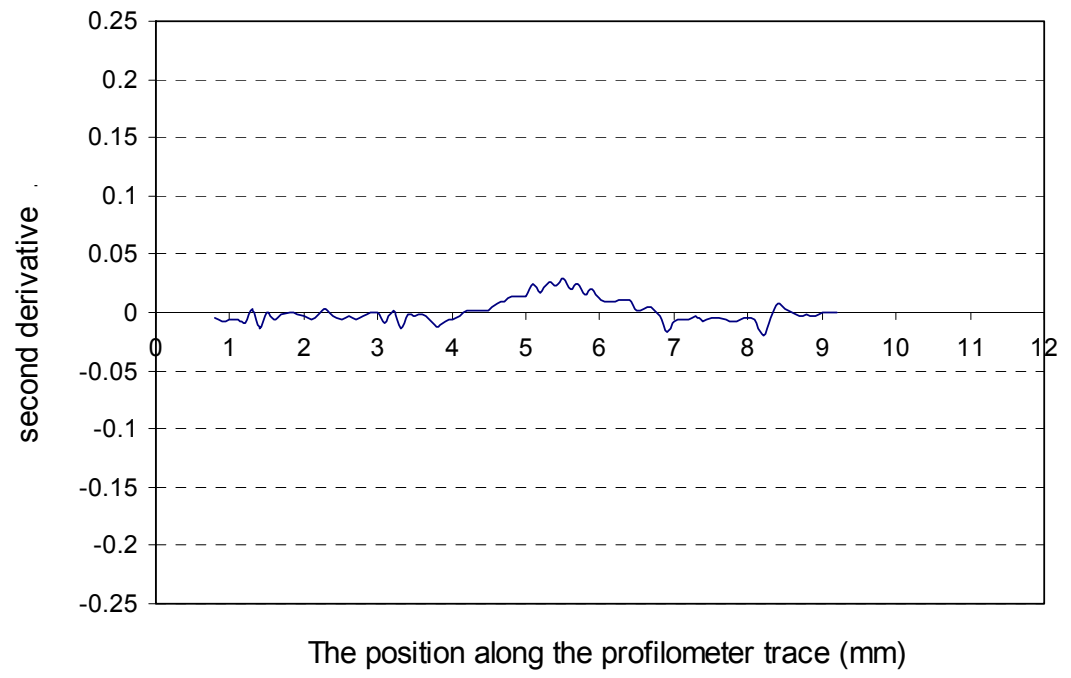

Figure 4-10 Curvature of smoothed data with $n=15$

The data in Figures 4-9 and 4-10 show that the calculation of curvature is a good way to differentiate between the curvature associated with the plate itself and any curvature 
related to the surface defect. It allows one to calculate two important parameters. First, it allows one to clearly differentiate between two types of defects: if the centre section of the curvature is greater than that of base line, the defect is a depression referred to here as a sink mark. If the curvature is largely negative, the defect is protruding outward and is referred to as a rib. Figure 4-11 shows the schematic of curvatures for sink mark and rib. Secondly, the curvature also allows one to estimate the defect width. From the Figure 4-11, one can see the defect width is same as the width of curvature changes (the grey line). In this research, the defect width is observed to vary between 5 and $6 \mathrm{~mm}$. This width will be used later to further data treatment.
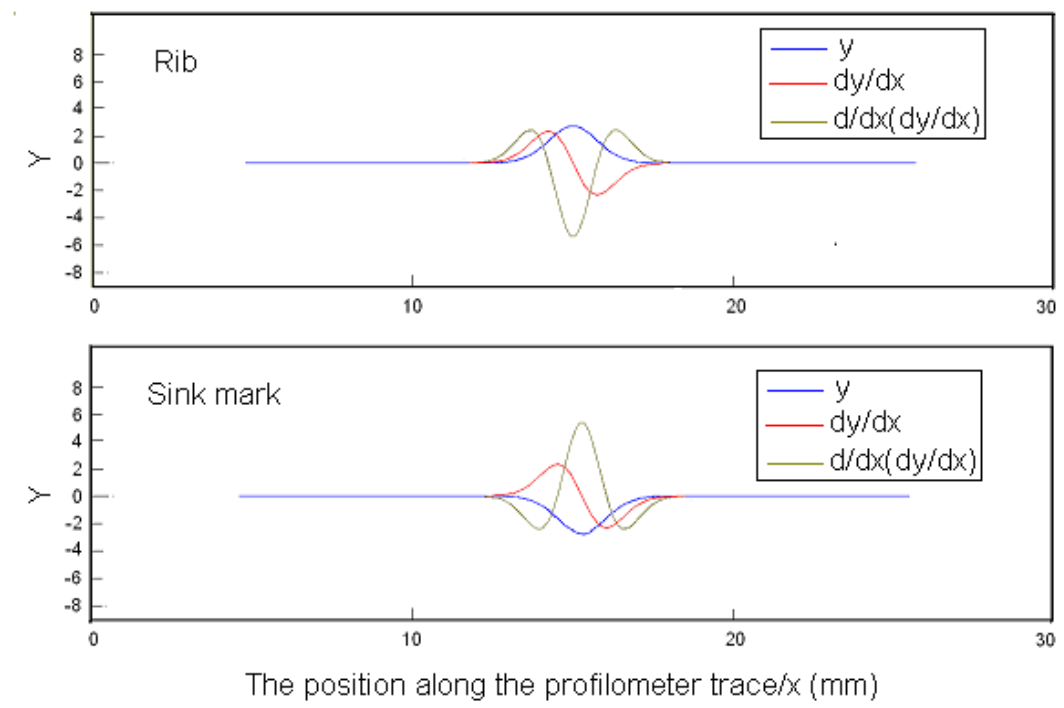

Figure 4-11 Schematic of the curvature of the sink mark and rib 
Figure 4-12 shows typical second derivative data from $2 \mathrm{~mm}$ thick parts containing $0.1 \% \mathrm{CB}$ as a function of the position along trace for a number of laser powers. It is observed that the widths of these defects are all approximately 5-6 mm. Similar results were found for other part thicknesses and carbon black levels. It would therefore appear that defect width was not a parameter that could be easily used to differentiate between welding conditions.

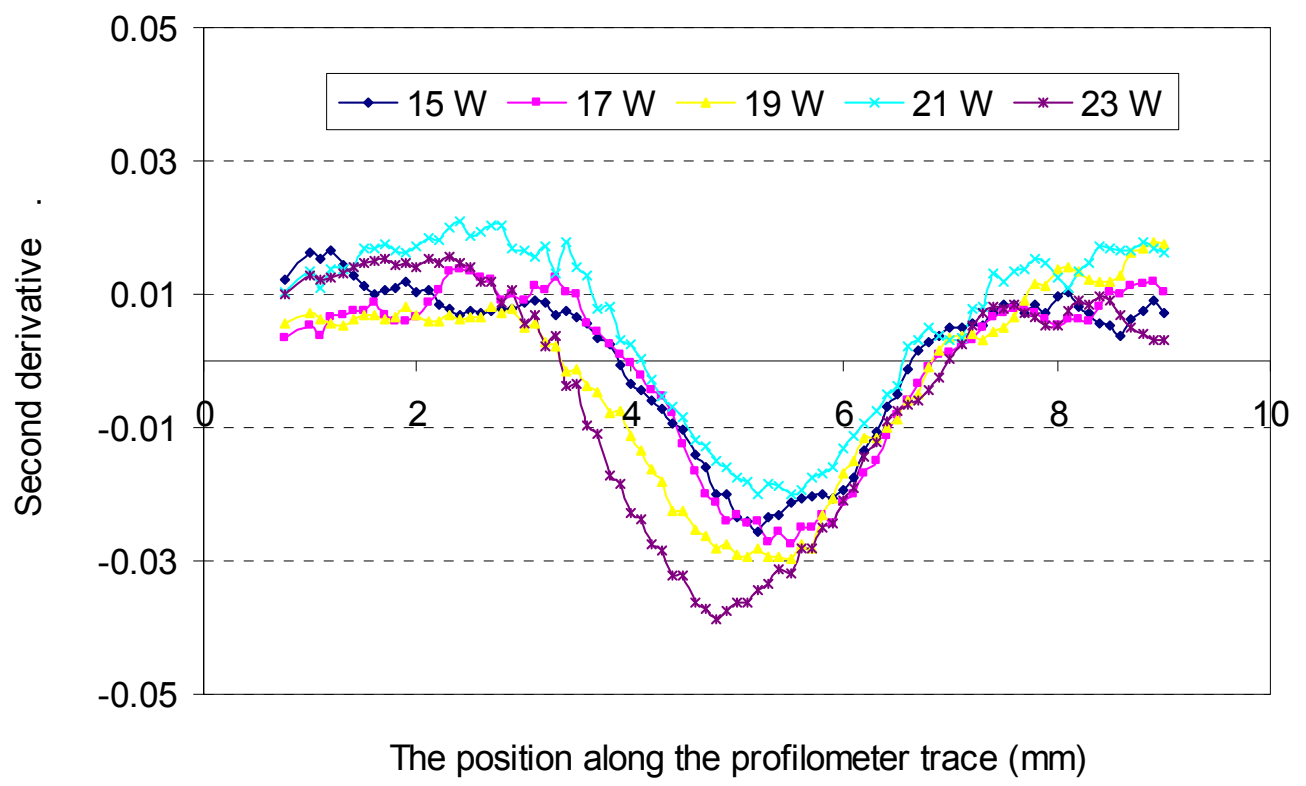

Figure 4-12 The curvature for the parts with the same thickness (2mm), CB level (0.1 wt.\%) and different weld power

In order to calculate the height of the defect relative to the background shape of the plate, the following approach was used. The distance along the trace for any given 
assembly was divided into two parts. The width data determined using the radius of curvature calculation was used to define the interval containing the defect. The remainder of the distance along the trace (the segment immediately preceding the defect and that just after the defect) was used to define the base or natural curvature of the plate. The surface height of the plate in the interval not including the defect was fit to a quadratic equation as a function of the horizontal $\mathrm{x}$-location. The resulting model was then subtracted from the entire height versus $x$-location data set. The entire data set includes the defect.

The raw data from Figure 4-8 is again used as an example to illustrate this procedure. From Figure 4-10 the width of the defect is approximately $5 \mathrm{~mm}$. That is to say, about $2.5 \mathrm{~mm}$ on each side of the defect centre has the shape of the initial plate and was largely not deformed by the welding operation. Therefore, approximately 15-20 data points on each side from the defect centre were used to make the regression curve.

The software JMP 7.0 was used to fit the data. Initial tests were performed on unwelded plates whose height as a function of x-position was measured using the profilometer. It was found that these data could be adequately fit using a $3^{\text {rd }}$ order quadratic equation of the form:

$$
y=a x^{2}+b x^{2}+c x+d
$$


where y represents the height or the depth of the surface relative to the profilometer's plane of reference, $\mathrm{x}$ represents the trace length and $\mathrm{a}, \mathrm{b}, \mathrm{c}$, and $\mathrm{d}$ are constants dependent on the particular plate being tested.

Figure 4-13 shows a plot of the surface height as a function of position along trace for the entire raw data set and for the curve fit to the surface-depth data outside of the defect region. Figure 4-14 shows the result of subtracting the two plots. The defect on the surface becomes easier to identify. The depth of the defect can be read on the curve directly by observing the height of the defect's lowest point. In this case the defect represents a sink mark of $36 \mu \mathrm{m}$ depth.

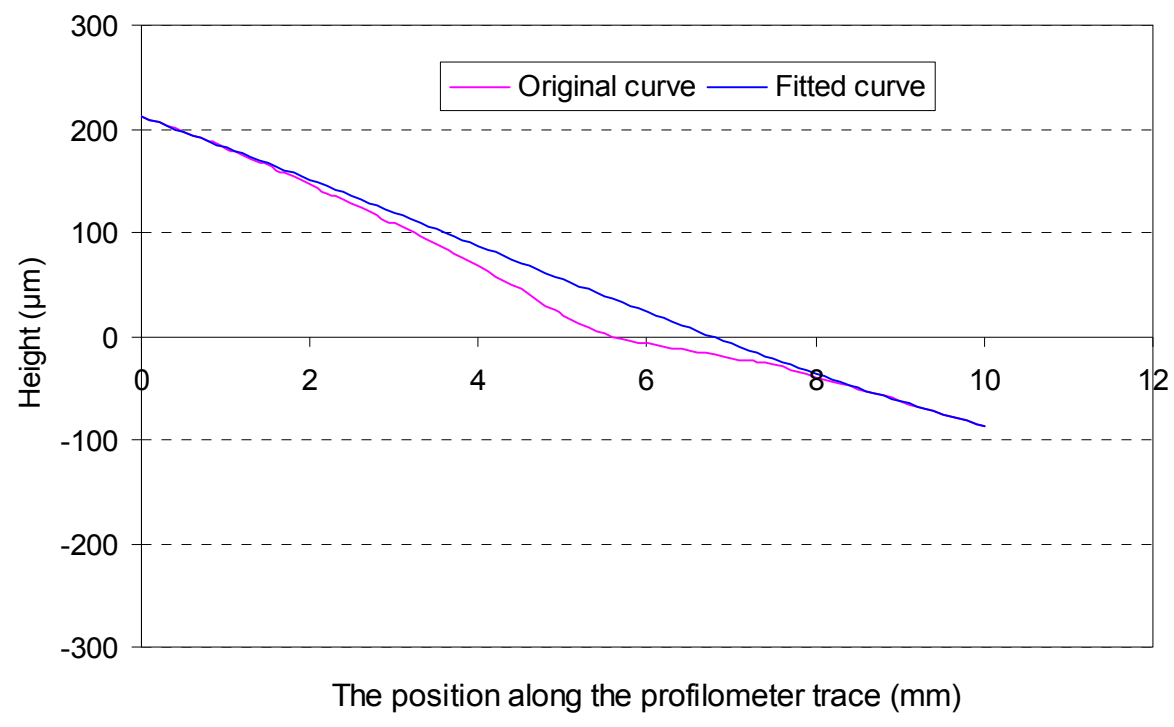

Figure 4-13 Raw data and its fitted curve 


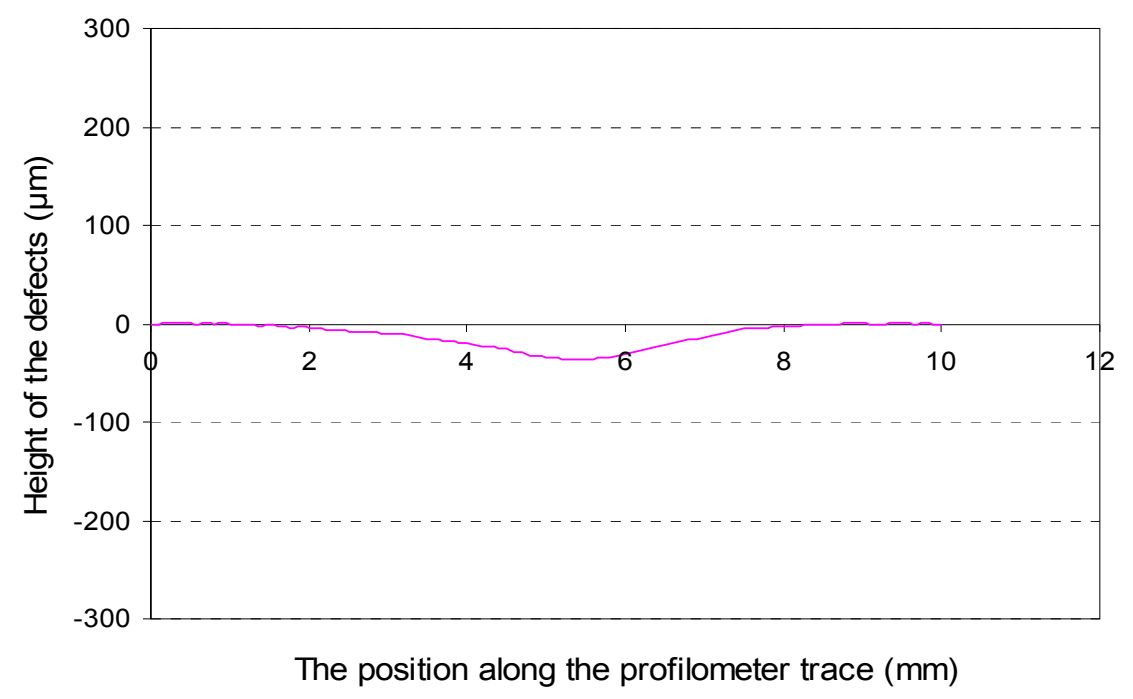

Figure 4-14 Fitted data in Figure 4-13 subtracted from the raw data

This technique was applied to all experimental data in order to extract the maximum height, in the case of ribs, or depth, in the case of sink marks. The next section will discuss the effect of welding and material parameters on the magnitude and direction of these different defects.

\subsection{Results and discussion}

\subsubsection{The welding experiments and profiler traces}

This section presents and discusses the results of the welding experiments and the resultant defects measured by the profilometer. The height and depth dimensional data for each CB level, power setting and thickness are found in Appendix B. 
The data in this section are presented as the deformation relative to the plane of the black specimen. Figure 4-15 and Figure 4-16 show typical results for profilometer traces in the vicinity of a rib and sink mark respectively.

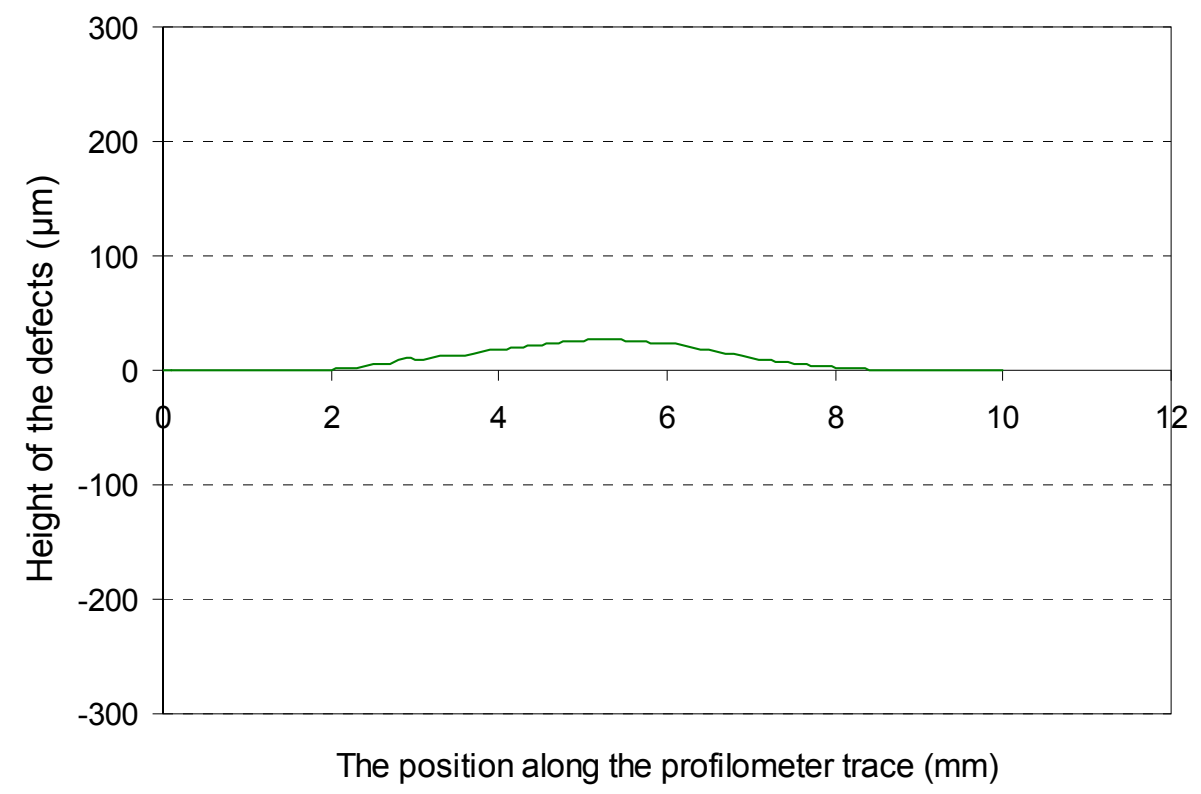

Figure 4-15 A typical shape of ribs obtained using the method in Section 4.2. This data is for a 2 $\mathrm{mm}$ thick part containing a CB level of $0.05 \mathrm{wt}$ \% and welded at a power of $18 \mathrm{~W}$ (this defect was created near the beginning of the "weld seam") 


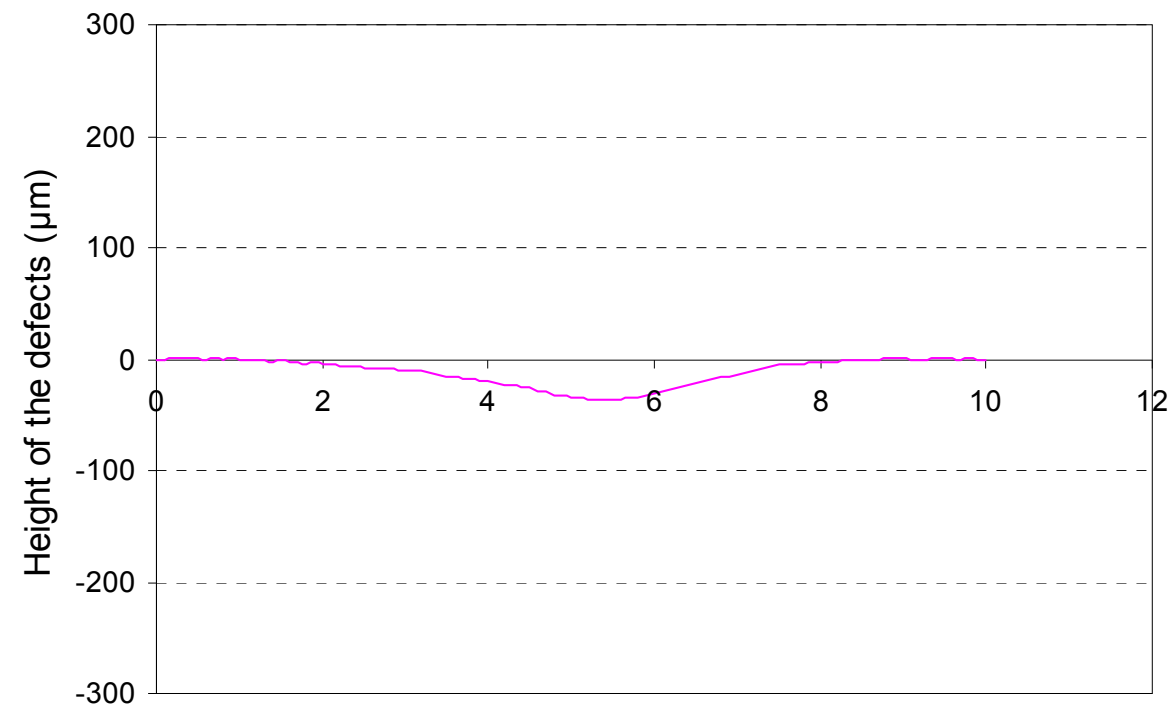

The position along the profilometer trace $(\mathrm{mm})$

Figure 4-16 A typical shape of sink marks obtained using the method in Section 4.2. This data is for a $2 \mathrm{~mm}$ thick part, $\mathrm{CB}$ level $0.05 \mathrm{wt} . \%$ and welded at a power of $18 \mathrm{~W}$ (this defect was created near the end of the "weld seam")

All specimens exhibited one or both of these defects. In order to simplify the analysis of this data, only the relative height or depth around a profilometer trace position of $5 \mathrm{~mm}$ will be discussed further. This corresponds to the defect height at nine discrete points at the surface of the black part along the centre of the laser weld line. This is shown schematically in Figure 4-17. 


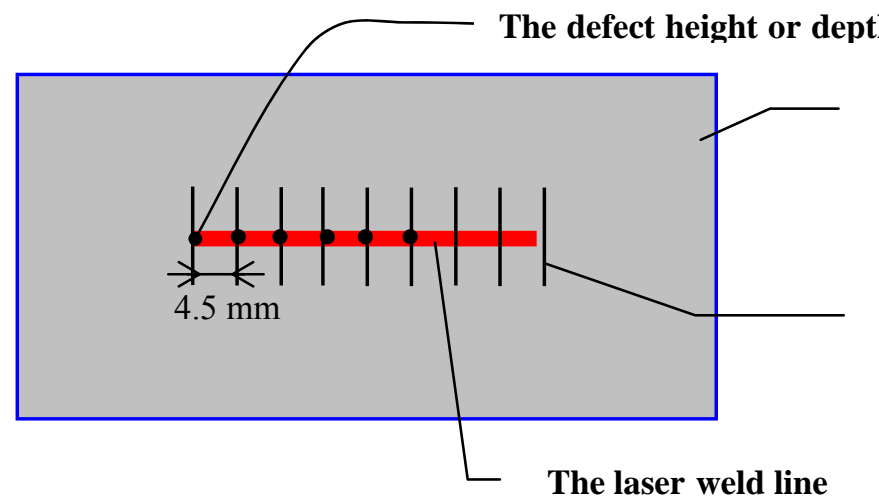

is taken at the centre of each trace Absorbent part

Profilometer trace line

Figure 4-17 A 2D schematic of the tracing position

The defect height along the laser weld line is shown in Figure 4-18 for a $2 \mathrm{~mm}$ thick part welded at $18 \mathrm{~W}$ and a CB level of $0.05 \mathrm{wt} . \%$. In this Figure, the laser scanned along the part from left to right. It is observed that the height of the defects $(H)>0$ (ribs) over the sections that were first welded and that $\mathrm{H}<0$ (sink marks) towards the end of the weld seam. That is to say, both sink marks and ribs were obtained in one part. This behavior was typical for all $2 \mathrm{~mm}$ thick parts that were welded. The transition from rib to sink was observed to be approximately 15 to $20 \mathrm{~mm}$ from the start point for all $2 \mathrm{~mm}$ thick pats welded in this study regardless of power or CB level. 


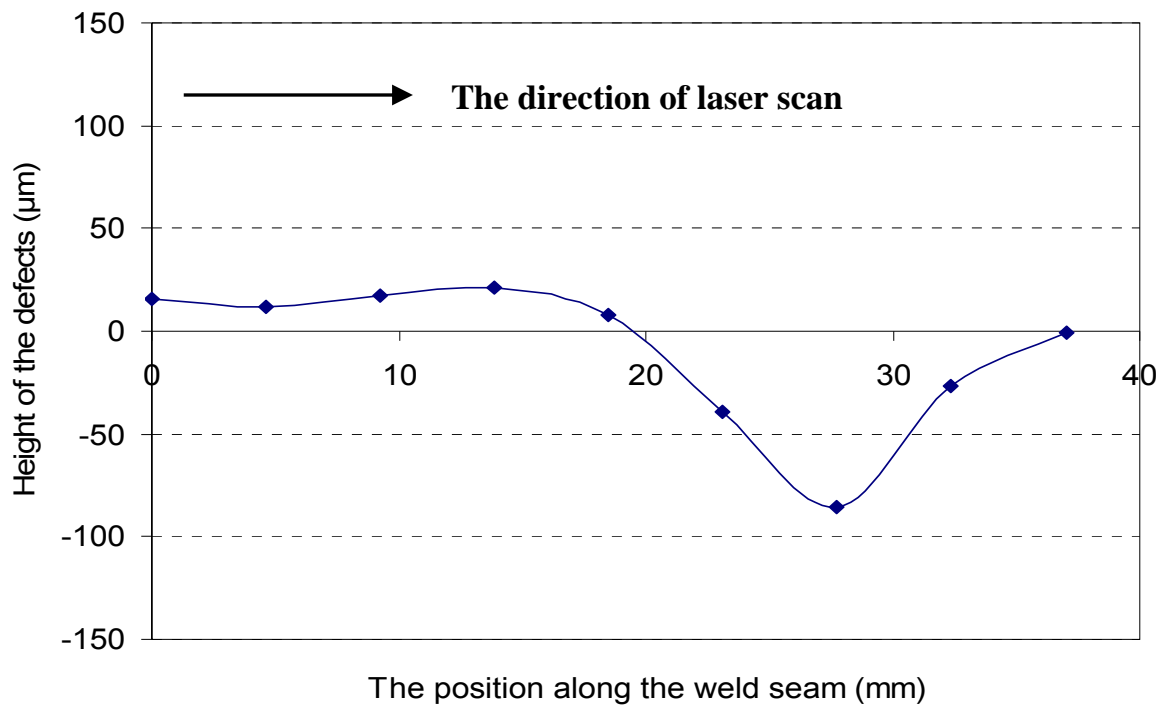

Figure 4-18 Height or depth of the defects as a function of the position along the weld seam (the part thickness is $2 \mathrm{~mm}$, laser power is $18 \mathrm{~W}$, laser scan speed is $1500 \mathrm{~mm} / \mathrm{min}$, and concentration of $\mathrm{CB}$ is $0.05 \mathrm{wt} . \%)$

Figure 4-19 shows the height of defects as a function of position along the laser scan direction for a $3 \mathrm{~mm}$ thick specimen welded at $23 \mathrm{~W}$ and a $\mathrm{CB}$ level of 0.05 wt. \%. Similar to the results in Figure 4-18, the laser scanned along the part from left to right. It is observed that the height of the defects is always positive throughout the weld line. Only ribs are obtained along the entire weld line. For all other laser powers and carbon black levels, $3 \mathrm{~mm}$ thick parts only exhibited rib-like deformations. This is very different from the results of $2 \mathrm{~mm}$ thick specimens. 


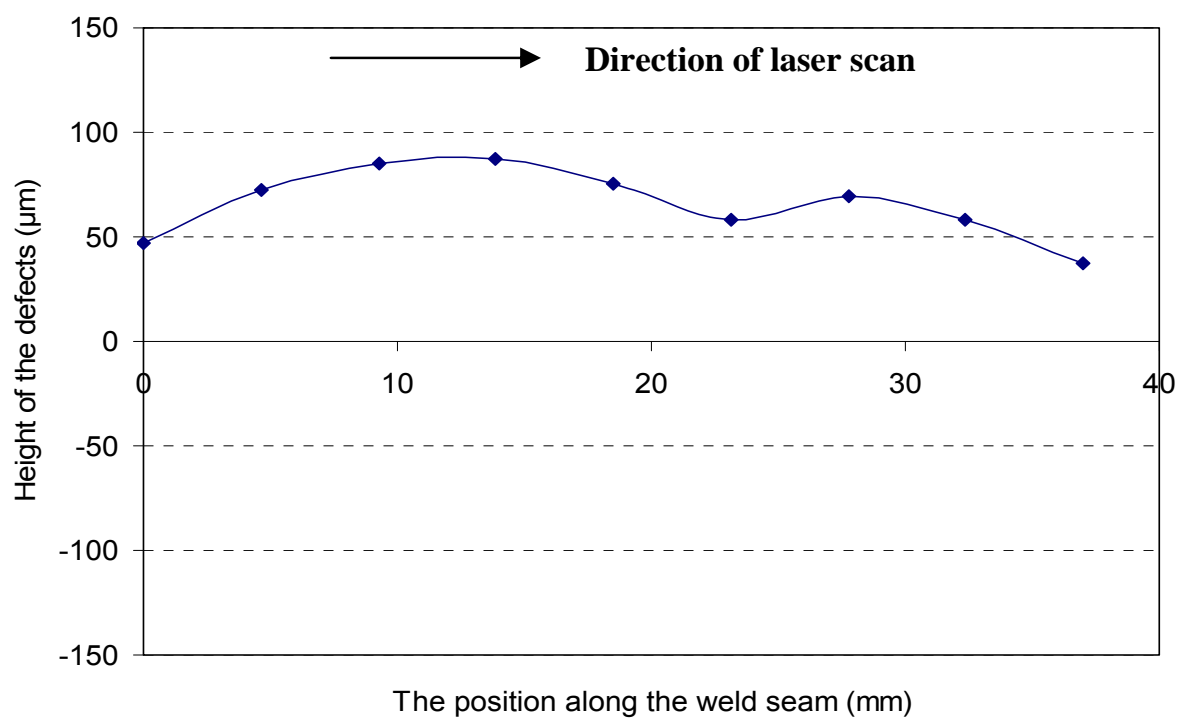

Figure 4-19 The height of the defects as a function of the position along the weld seam (the part thickness is $3 \mathrm{~mm}$, laser power is $23 \mathrm{~W}$, laser scan speed is $1500 \mathrm{~mm} / \mathrm{min}$, and concentration of $\mathrm{CB}$ is 0.05 wt.\%)

The effect of power and CB-levels on defects in both $2 \mathrm{~mm}$ and $3 \mathrm{~mm}$ thick specimens will be discussed before any mechanism will be proposed to explain the sinkrib phenomenon. We will first focus on $2 \mathrm{~mm}$ thick parts. Figure 4-20 shows a plot of the maximum observed sink mark depth as a function of laser power for the three $\mathrm{CB}$ levels $(0.05,0.1$, and 0.2 wt. \%). This figure shows that, for each $\mathrm{CB}$ level, the depths of the sink mark increases with the increasing laser power. When the laser power is increased, the energy delivered to the absorbent part increased too. This results in either higher temperatures and/or larger volumes of molten material. The melting and subsequent solidification of the molten polymer likely creates internal stresses that cause 
the polymer to deform at the external surface of the laser-absorbent part. The higher temperatures and/or larger melt volume will result in the larger internal stresses which will lead to the larger deformation on the surface.

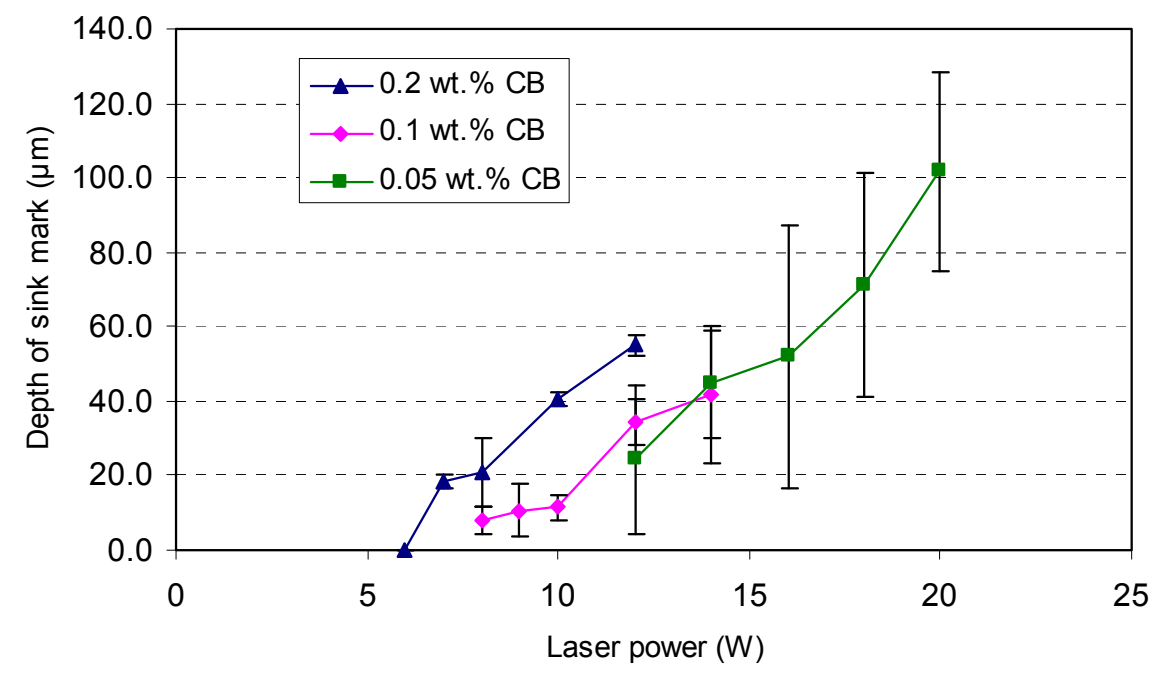

Figure 4-20 Depth of sink marks as a function of laser power (part thickness is $2 \mathrm{~mm}$ ).

Figure 4-20 also shows that when laser power is the same, the depth of the sink marks generally increased with the increasing of CB level. For example, when the laser power is $12 \mathrm{~W}$, the depth of the maximum sink marks for $0.05,0.1$, and $0.2 \mathrm{wt} . \% \mathrm{CB}$ levels are 19, 34, and $54 \mu \mathrm{m}$ respectively. From the theory in Chapter 1, we know that the black part absorbs the heat through the $\mathrm{CB}$. If the concentration of $\mathrm{CB}$ is higher, that means laser light penetrates less deeply into the laser absorbent part and the volume of heated material is smaller. At a fixed value of power and speed, higher CB levels will 
cause this energy to be absorbed over a smaller volume - potentially resulting in higher average temperature in a smaller volume. The experimental observations suggest that the residual stresses resulting from these higher temperatures result in greater deformations. The data also suggest that higher CB levels combined with low powers create the smaller defects. High CB levels, when combined with low power, minimize the heated volume, which would appear to affect residual stresses.

Figure 4-21 shows a plot of the maximum height of ribs on $2 \mathrm{~mm}$ thick parts as a function of laser power for CB levels of $0.05,0.1$, and $0.2 \mathrm{wt} . \%$. It is observed that for the two highest $\mathrm{CB}$ levels of 0.1 and 0.2 wt. \%, the heights of ribs increase with the increasing laser power. Similar to the results presented earlier, higher powers cause higher temperatures/heated volumes. During cooling, the resulting stresses ultimately lead to rib-like deformations. Unlike what was observed with sink marks on $2 \mathrm{~mm}$ thick plates, the CB level does not appear to affect the size of rib-defects at levels of 0.1 and $0.2 \mathrm{wt} \%$ at the same power level. This suggests a different mechanism for the formation of ribs. At the lowest $\mathrm{CB}$ level of 0.05 wt. \%, the maximum heights of ribs decrease slightly with power. A possible reason for this observation will be discussed later. Similar to the data presented in Figure 4-20, high CB levels combined with low powers are again observed to cause the smallest observed defect. 


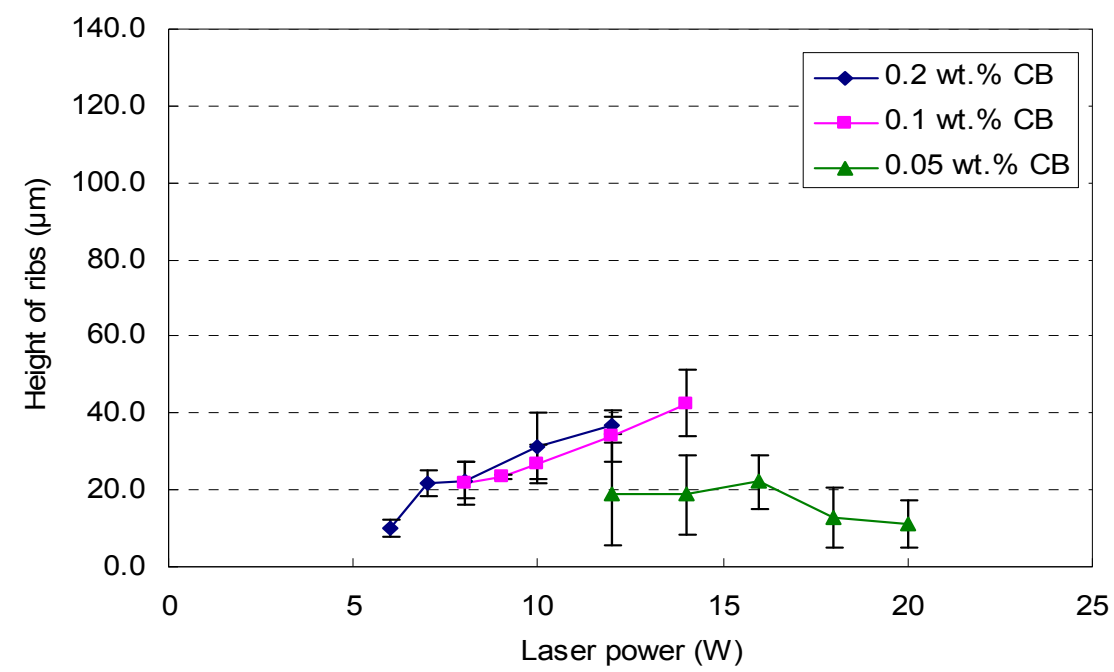

Figure 4-21 Height of ribs as a function of laser power (part thickness is $2 \mathrm{~mm}$ ).

Figure 4-22 shows the maximum height of ribs on $3 \mathrm{~mm}$ thick plates as a function of laser power for three different CB levels $(0.05,0.1$, and $0.2 \mathrm{wt} \%$ CB). Similar to the results obtained on $2 \mathrm{~mm}$ thick plates, the maximum heights of ribs are observed to increase with the increasing laser power. As explained previously, at any carbon black level, higher powers lead to higher temperatures and/or larger heated volumes that, upon cooling ultimately result in higher residual stresses causing greater part deformation.

The rib-height as a function of laser power appears to lie along the same line for all three CB levels. This is similar to what was observed during the formation of ribs in 2 mm thick parts at $\mathrm{CB}$ levels of 0.1 and 0.2 wt. \% CB. This would again suggest that the mechanism for rib formation is significantly different than that for sink formation. In order to better elucidate the underlying reasons for sink and rib formation, one needs to 
examine the microstructure of the weld interfaces. This is addressed in the next section. Finally, it is again seen that high $\mathrm{CB}$ levels combined with low powers create the conditions for the low defect size.

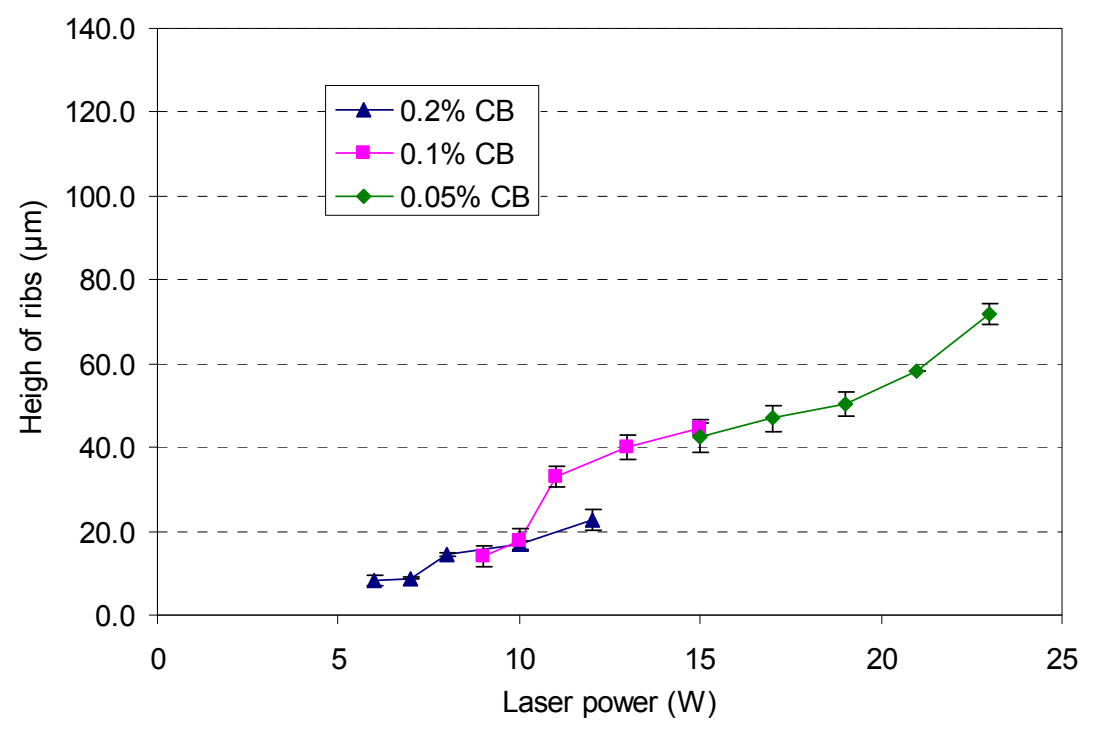

Figure 4-22 Height of ribs as a function of laser power (part thickness is $3 \mathrm{~mm}$ ).

\subsubsection{Microstructure}

The microstructure will provide additional information on the mechanism of surface deformation. Before examining the microstructure resulting from various power settings, part thickness and CB levels, it is useful to discuss a typical polarized light micrograph. Figure 4-23 shows a joint ( $3 \mathrm{~mm}$ plates and $\mathrm{CB}$ level $0.1 \mathrm{wt}$. \%) processed at a laser power of $10 \mathrm{~W}$ and a scanning speed of $1500 \mathrm{~mm} / \mathrm{min}$. The image shows the large semicircular heat-affected zone (HAZ) at the weld interface. This occurs as a result of 
the melting and resolidification of the polypropylene during welding. Most of the HAZ is found in the absorbent part. This is reasonable since the transparent part does not absorb significant laser energy. Most of the energy from the laser beam is dissipated as heat in the absorbent part and then conducted further into both parts.

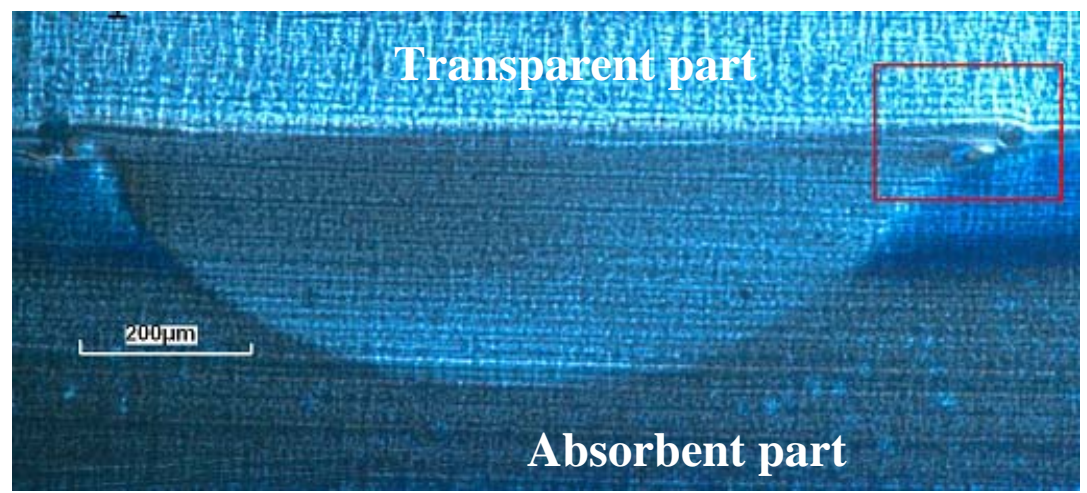

Figure 4-23 Micrograph of a weld interface showing heat affected zone (HAZ) and flash. Laser power is $10 \mathrm{~W}$ and scanning speed is $1500 \mathrm{~mm} / \mathrm{min}$. The thickness for both transparent and absorbent parts is $3 \mathrm{~mm}$. CB level is $0.1 \mathrm{wt}$. \%

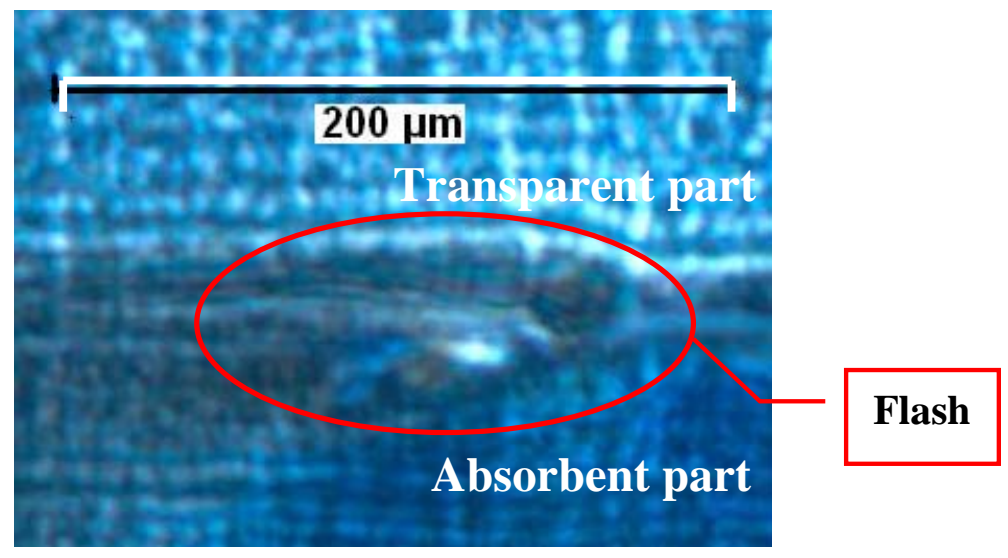

Figure 4-24 Magnified image taken near the edge of the HAZ in Figure 4-23 as shown in the square. 
From Figure 4-24, the magnified image taken near the edge of the HAZ, one can see that, for these welding conditions, some material was squeezed out of the weld interface into the space between the two parts. This is called flash. In theory, the clamping pressure should have minimized any space between the two parts. However, as the CB in absorbent part absorbs laser energy, the material close to interface is heated up and melts. This causes the material to expand. The pressure generated by this thermal expansion causes the plates to move apart allowing the material to flow laterally. In this case, the "leakage" consists of a lateral flow from the weld zone where it will solidify and not flow back into the HAZ. As will be shown later, not all welding conditions exhibited this "leakage" phenomenon.

The micrographs in Figure 4-25 show the HAZ of assemblies containing $2 \mathrm{~mm}$ thick plates at three different $\mathrm{CB}$ levels and at a constant laser power of $12 \mathrm{~W}$. All the microtomed slices were taken from the position where the largest sink mark defect was observed. Qualitatively, they show that both the total HAZ thickness at center and the width of the HAZ increase slightly with increasing CB level. 
(a)

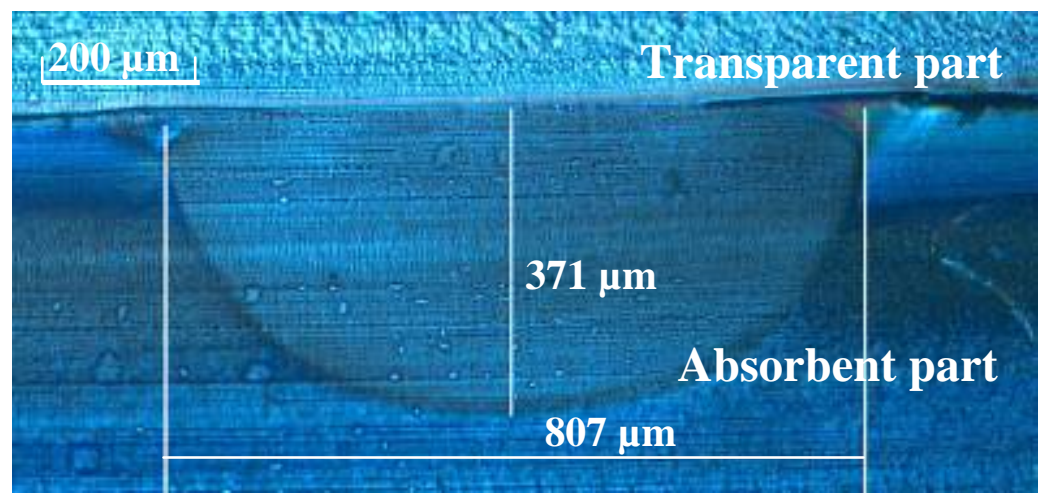

(b)
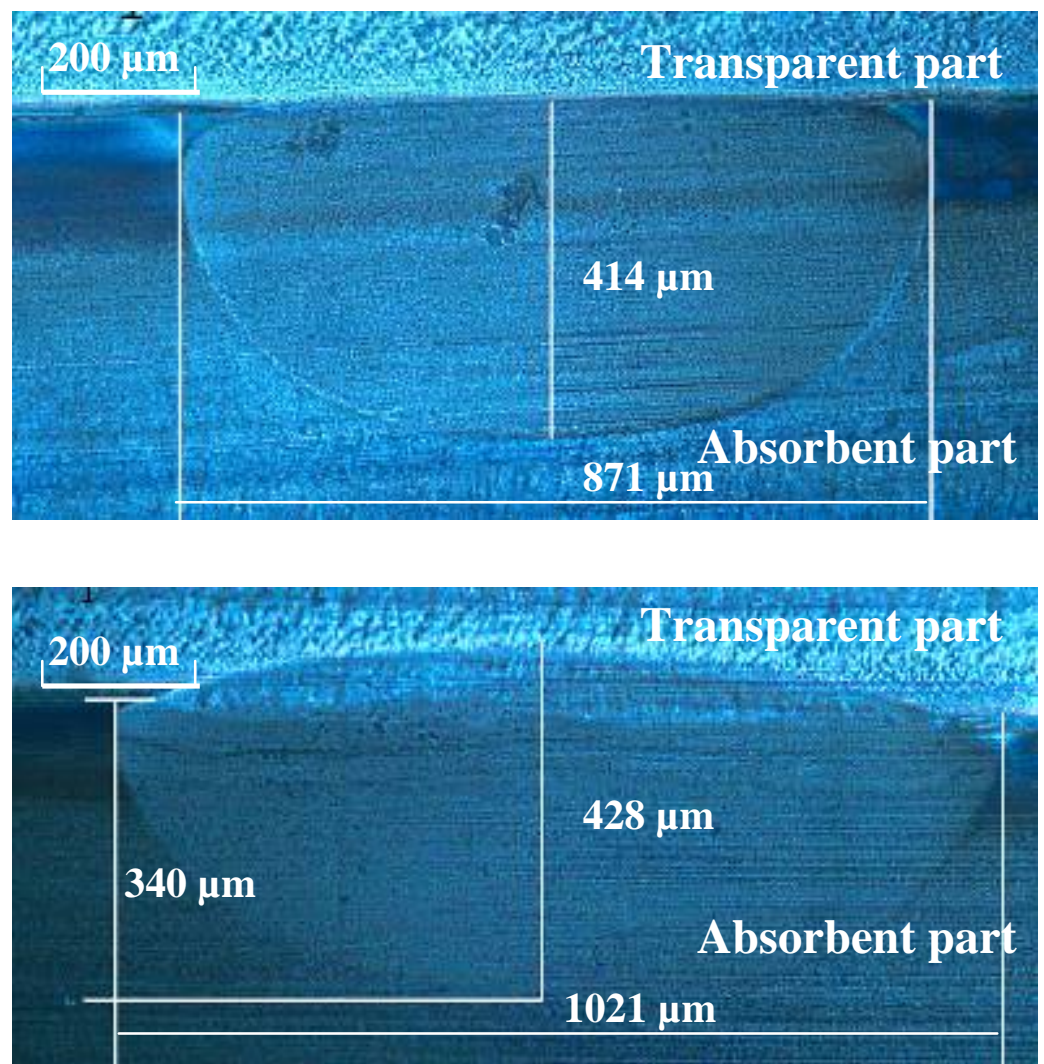

Figure 4-25 Heat Affected Zone geometry viewed under polarized-light microscope for a PP joint processed with $12 \mathrm{~W}$ laser power, $2 \mathrm{~mm}$ thickness for both transparent and absorbent parts. (a)

CB level is 0.05 wt.\% (b) CB level is $0.1 \mathrm{wt.} \%$ (c) CB level is $0.2 \mathrm{wt} . \%$. The defect type associated with this microstructure is a sink mark. 
The effect of CB-level and power on the heat-affected zone thickness is related to the thermal history of the polymer during welding. Qualitatively, if the concentration of CB is lower, that means laser light penetrates deeper into the laser absorbent part and the volume of heated material is larger. For a constant power and speed, the same amount of energy will be absorbed but, at low CB levels, it will be absorbed over a larger volume and will result in a lower average temperature. For parts containing higher $\mathrm{CB}$ levels, the energy is absorbed over a smaller volume leading to higher average temperatures. This allows more heat to be conducted further into both the transparent and absorbent parts. This results in a larger volume of heat-affected material that is observed in Figure 4-25 (c).

In addition to examining the dimensions of the HAZ, it is also important to examine the presence or absence of flash in $2 \mathrm{~mm}$ thick plates in the region where sink marks were present. A typical polarized light micrograph of the weld microstructure below a sink mark is shown in Figure 4-26. Figure 4-26 (a) shows an assembly made of $2 \mathrm{~mm}$ thick plates containing a CB level of $0.1 \mathrm{wt} . \%$ and processed at a laser power of $14 \mathrm{~W}$. Figure 4-26 (b) shows an assembly made of $2 \mathrm{~mm}$ thick plates containing a CB level of 0.05 wt. $\%$ and processed at a laser power of $18 \mathrm{~W}$. Both images show the large semicircular heat-affected zone (HAZ) at the weld interface similar to other images. Again, most of the HAZ is found in the absorbent part. From the magnified image (the image in Figure 4-27) taken near the edge of the HAZ, the edge of the HAZ is round and no flash is 
visible. Furthermore, no gap between transparent part and absorbent part is observed. It would therefore appear that the absence of flash is associated with sink-mark defects.

(a)

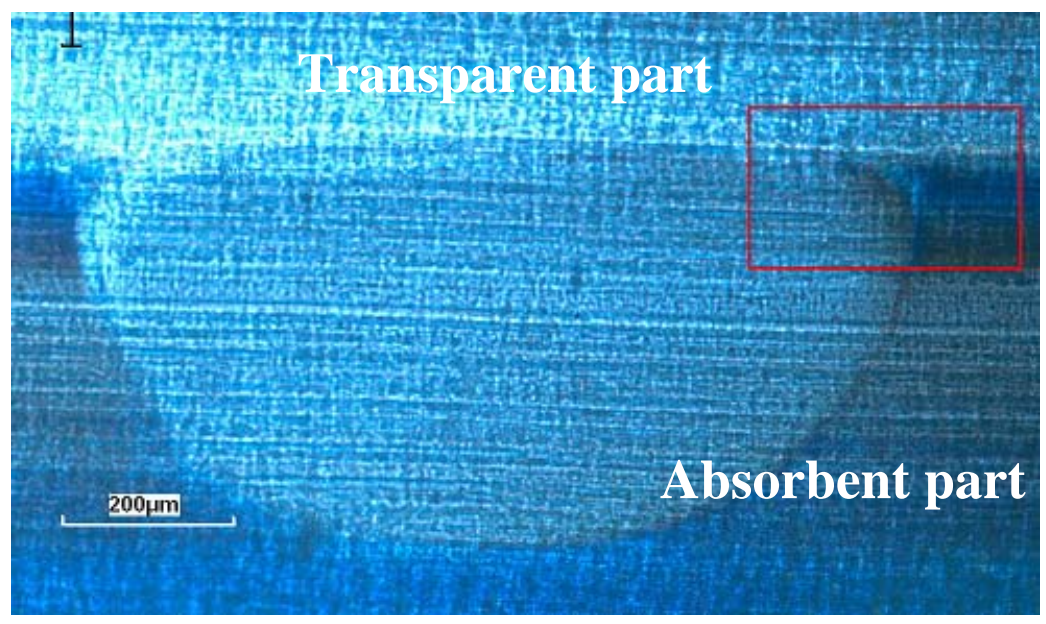

(b)

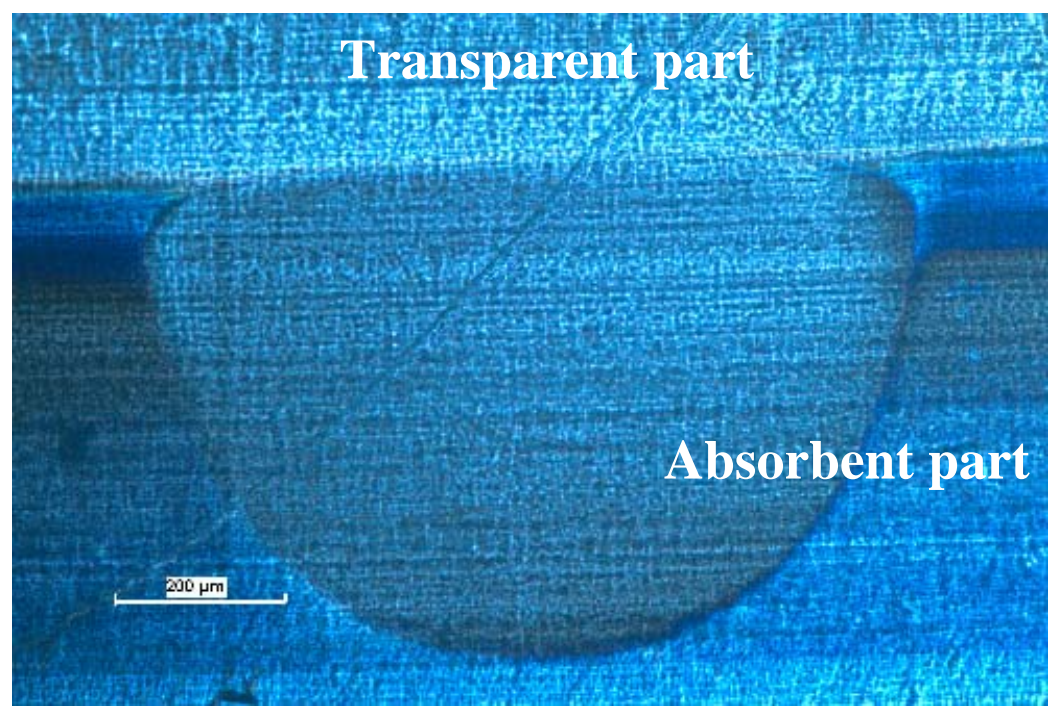

Figure 4-26 Micrograph of a weld interface showing heat affected zone (HAZ) (a) Laser power is $14 \mathrm{~W}$. The part thickness is $2 \mathrm{~mm}$. CB level is $0.1 \mathrm{wt} . \%$. (b) Laser power $18 \mathrm{~W}$, the part thickness $2 \mathrm{~mm}$ and the CB level $0.05 \mathrm{wt} . \%$. The defect type associated with this microstructure is a sink mark. 


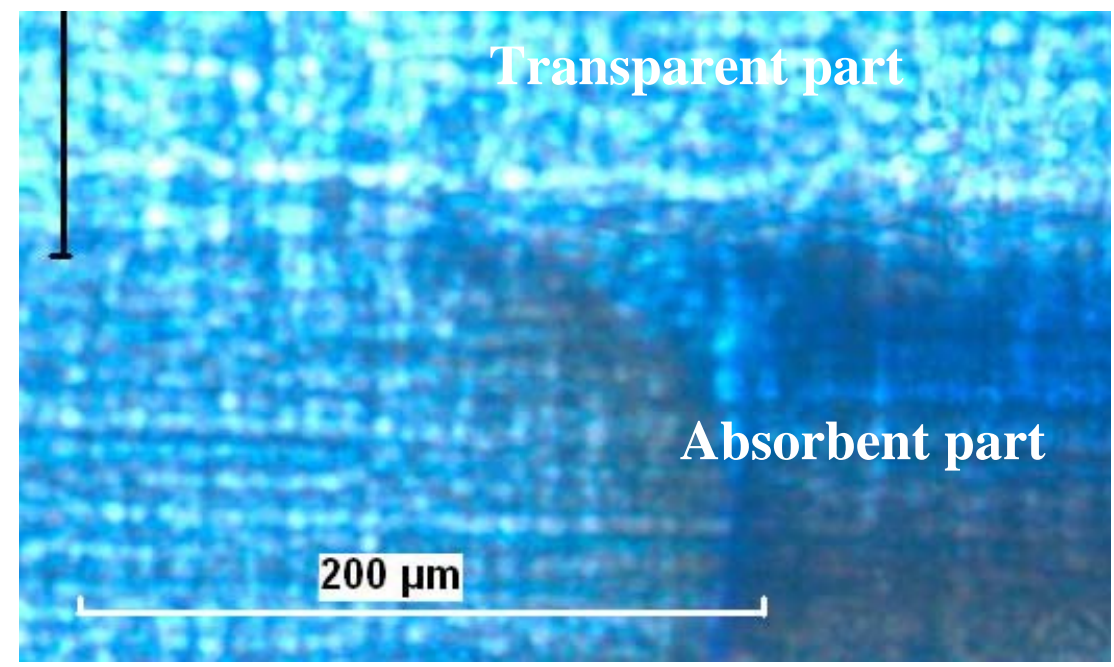

Figure 4-27 Magnified image taken near the edge of the HAZ in Figure 4-26 as shown in the square.

Figure 4-28 shows the microstructure in a $2 \mathrm{~mm}$ thick specimen in the region of a riblike defect at a power of $18 \mathrm{~W}$ and a CB level of $0.05 \mathrm{wt} . \%$. The general shape of the HAZ is comparable to that shown in Figure 4-26 (b) for the same conditions but in the region of a sink mark. One notable difference is the presence of flash at the edge of the HAZ. 


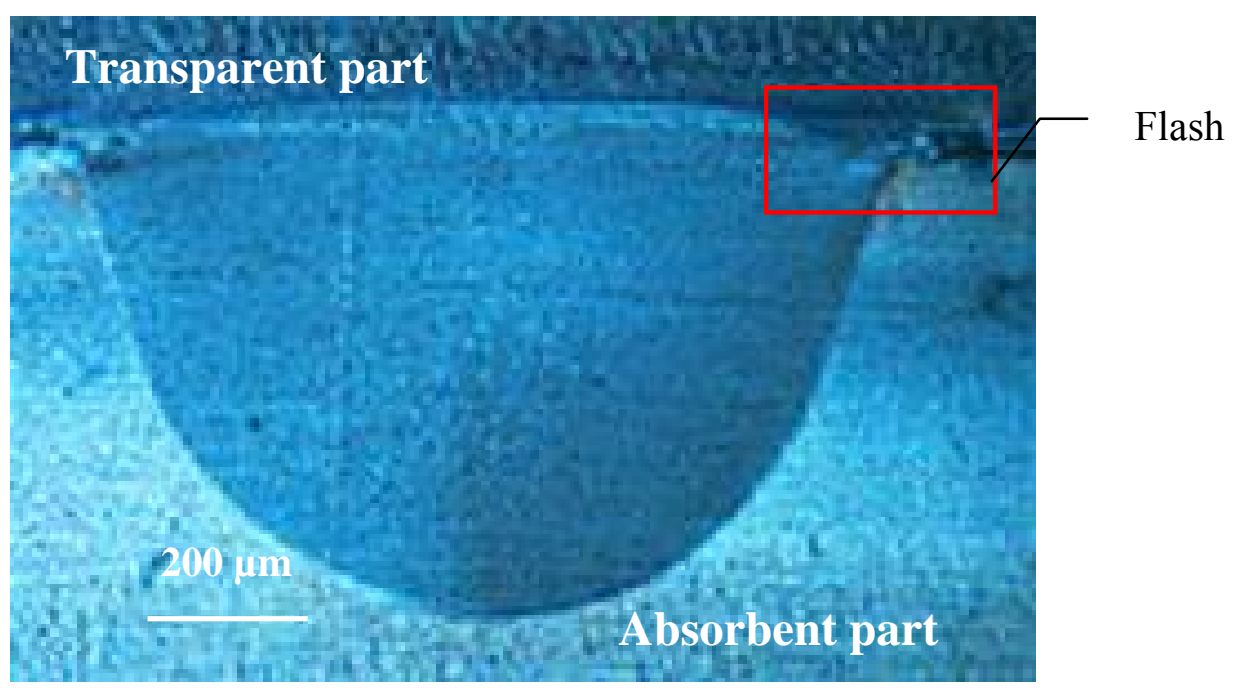

Figure 4-28 Micrograph of a weld interface showing heat affected zone (HAZ) and flash for a power of $18 \mathrm{~W}$ and a CB level of $0.05 \mathrm{wt} . \%$ at apart thickness of $2 \mathrm{~mm}$. The defect type associated with this microstructure is a rib.

The micrographs of weld cross-sections in $3 \mathrm{~mm}$ thick assemblies are discussed next. Figure 4-29 shows the HAZ of an assembly containing $3 \mathrm{~mm}$ thick plates at two different CB levels $(0.1$ and $0.2 \mathrm{wt} \%)$ and at a constant laser power of $10 \mathrm{~W}$. Similar to the results of Figure 4-25, they show qualitatively that both the total HAZ thickness at center and the width of the HAZ increased with increasing CB level. The reason for this was discussed previously.

Compared to the images shown in Figure 4-25, we can see that the depths of HAZ in Figure 4-29 are smaller for the same CB level yet the widths are greater. Part of the reason for the lower HAZ depth is the lower laser power used to weld these assemblies. In addition there is a difference in laser transmission. The transmission of 2 and $3 \mathrm{~mm}$ 
transparent parts were treated by M.L. Chen. The laser transmission was found to be $75 \%$ for $3 \mathrm{~mm}$ parts and $84 \%$ for $2 \mathrm{~mm}$ parts [91]. This suggests that, under the same weld condition, less energy will reach the weld interface for assemblies using $3 \mathrm{~mm}$ thick parts compared to $2 \mathrm{~mm}$ parts. In addition to transmission losses, it is expected that the scattering of the laser beam in $3 \mathrm{~mm}$ thick parts should be more than in $2 \mathrm{~mm}$ thick parts.

(a)

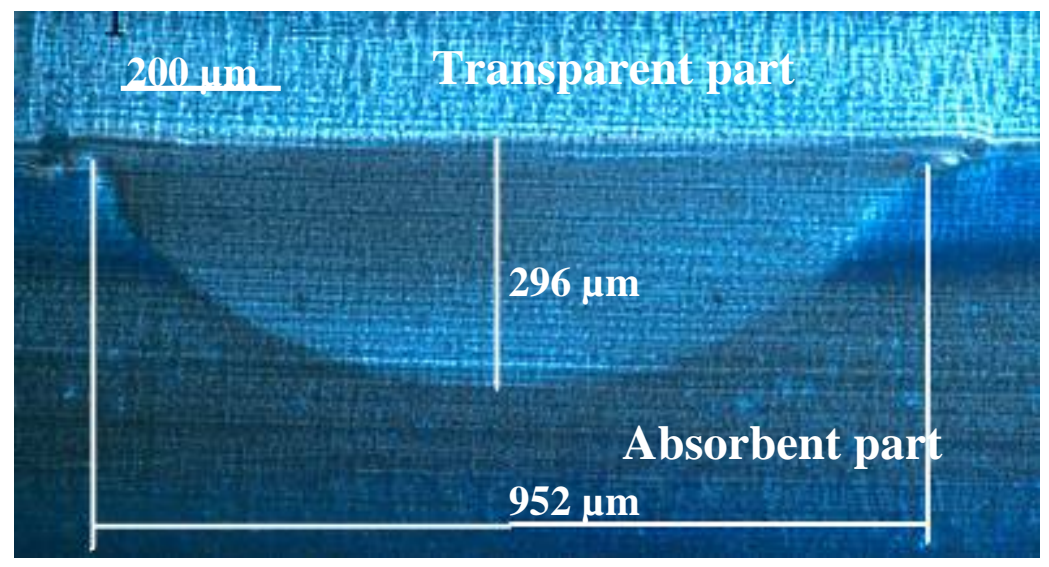

(b)

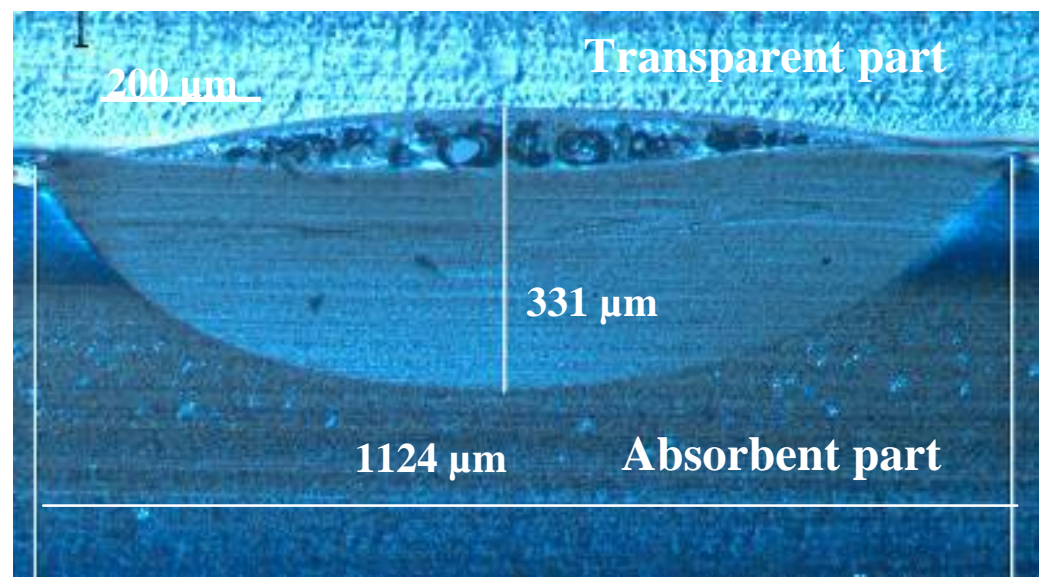

Figure 4-29 Heat Affected Zone geometry viewed under polarized-light microscope for a PP joint processed with $10 \mathrm{~W}$ laser power. The thickness for both transparent and absorbent parts is 3 mm. (a) CB level is 0.1 wt. \% (b) CB level is 0.2 wt. \%. 
It is interesting to note that, like the image shown in Figure 4-23, the edge of HAZ shown in the Figure 4-29 has flash. Additional micrographs showing the presence of flash in $3 \mathrm{~mm}$ thick assemblies are shown in Figure 4-30. The surface defects associated with Figure 4-29, Figure 4-30 as well as Figure 4-28 are ribs. That is to say that when ribs were observed, flash was consistently visible in the weldline micrographs.

(a)

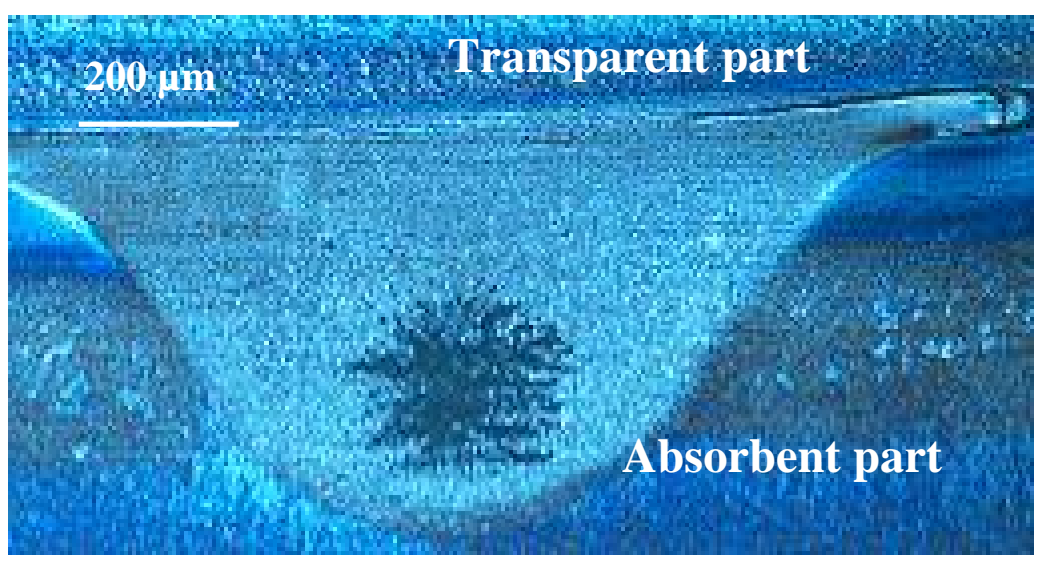

(b)

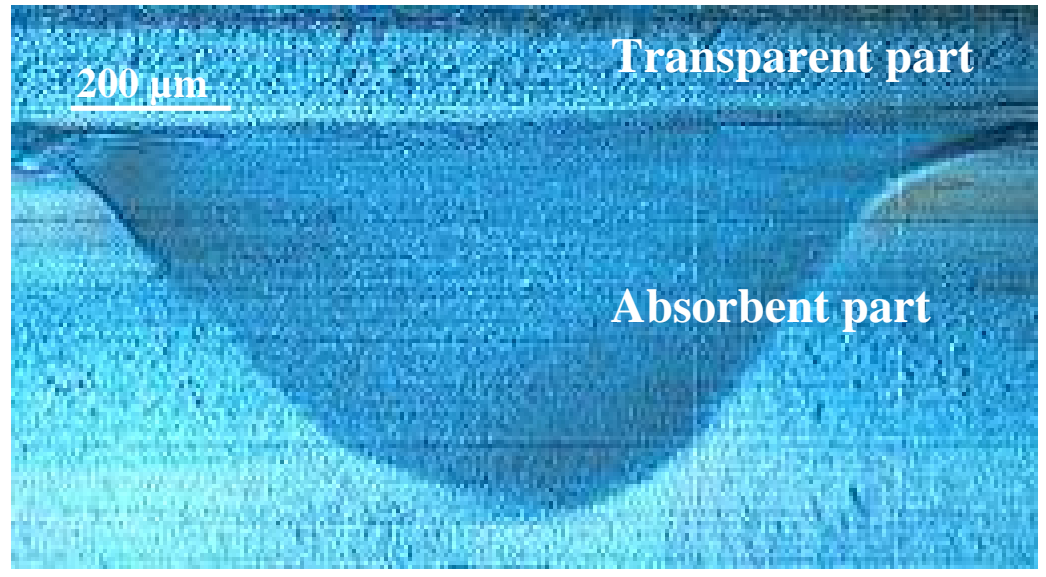

Figure 4-30 Micrograph of a weld interface showing heat affected zone and flash. Laser power $23 \mathrm{~W}$, CB level $0.05 \mathrm{wt} . \%$, part thickness $3 \mathrm{~mm}$. (a) the defect was created near the beginning of the weld seam; (b) the defect was created near the end of the weld seam. The direction of the laser scan is shown in Figure 4-19 
In addition to microscopic examination of weld cross-sections, it is also useful to visually examine the weld interface through the transparent part. Figure 4-31 shows the image of the weld seam taken from a $2 \mathrm{~mm}$ specimen welded at a laser power of $18 \mathrm{~W}$ and a CB level of 0.05 wt. \%. In this figure, the weld seam appears as a thick black line. The laser beam scanned the part from left to right. It is observed that the left side of the weld seam is wider and it appears to contain some small ripples along its edges. The ripples are most likely the flash that periodically flows into the space between the absorbent and transparent parts. Recall from Figure 4-18 and Figure 4-28, that the riblike defects were associated with this region. On the right side of the assembly the seam is narrower and straighter. The absence of ripples likely corresponds to the absence of flash in this region. Again, recall from Figure 4-18 and Figure 4-26(b), that this region was associated with sink mark surface defects. These observations, together with the cross-sectional micrographs, again suggest that ribs are formed when flash is present at the weldline and that sink marks occur in the absence of flash. 


\section{Ripples}

The direction of laser scan

Figure 4-31 Weld seam visible through the transparent part (laser power is $18 \mathrm{~W}$, CB level is 0.05 wt. \%, and the thickness of both transparent part and absorbent part is $2 \mathrm{~mm}$ )

The visual examination of the weld interface through the transparent part can also be performed for the $3 \mathrm{~mm}$ thick assemblies. Figure 4-32 shows the image of the weld seam taken from a $3 \mathrm{~mm}$ specimen welded at a power of $23 \mathrm{~W}$ and a CB level of $0.05 \mathrm{wt}$. $\%$. The laser beam scanned the parts from left to right. It is observed that there are some ripples throughout the weld seam. Again, the ripples likely correspond to flash in the space between the two parts that was observed in the weld cross-sections presented earlier. This data is also consistent with the observation that flash at the interface leads to rib-like surface defects shown in Figure 4-19. 


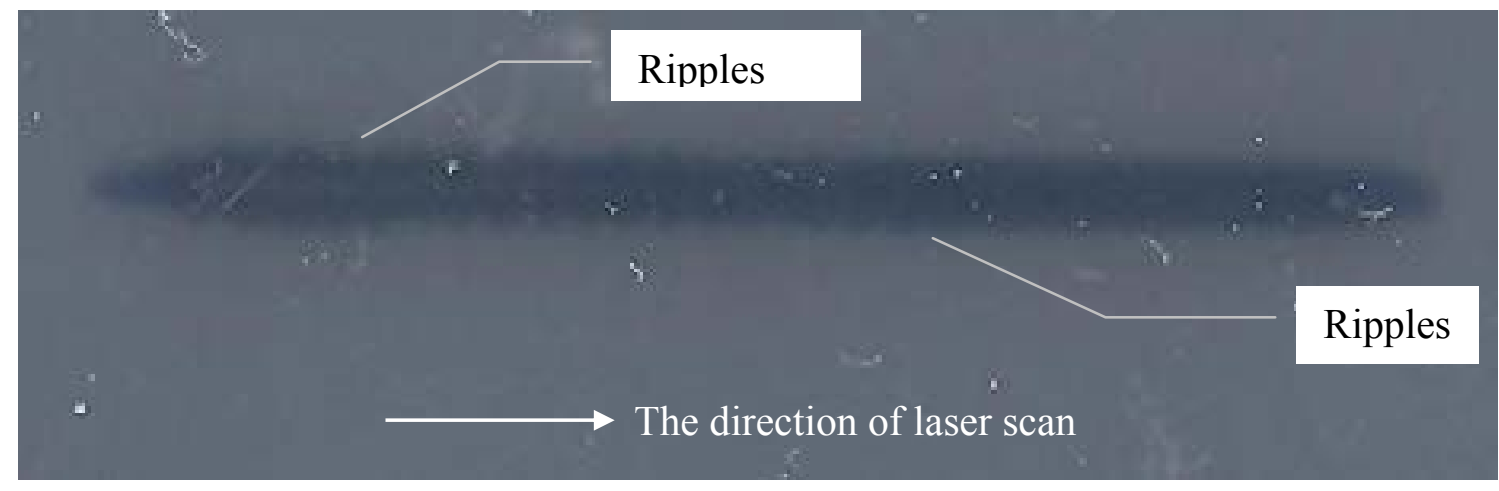

Figure 4-32 Weld seam visible through the transparent part: (laser power is $23 \mathrm{~W}$, CB level is 0.05 wt. \%, and the thickness of both transparent part and absorbent part is $3 \mathrm{~mm}$ ).

\subsubsection{Possible mechanism}

Before we discuss the possible mechanism, it is necessary to understand how the residual stresses are created. When welding, the laser beam passes through the transparent part and is dissipated as heat in the absorbent material. The material at interface is heated up, melts, expands, potentially flows out of the weld zone and ultimately solidifies. This process may cause a volume change within the material due to irreversible material loss from the heated zone. The molten material can flow into the spaces between the transparent and absorbent parts, it can push the transparent part upward to create space between the two parts, or the material can flow back along the "tunnel" of molten material in the heat affected zone. Upon solidification this material may not return to its original position. This decrease in density will create an inward stress within the cooling material. This stress will pull on the surrounding solid polymer in all directions causing it to deform. 
The nature of the deformation will depend on the contact conditions between the transparent and absorbent parts after solidification. There are two possible extremes of contact conditions: Figure 4-33 shows the schematic drawing of internal stresses between HAZ and the parts when the two parts are in contact. Figure 4-34 shows the schematic drawing of internal stresses when the parts are separated by material that has flowed into the space between the transparent and absorbent parts.

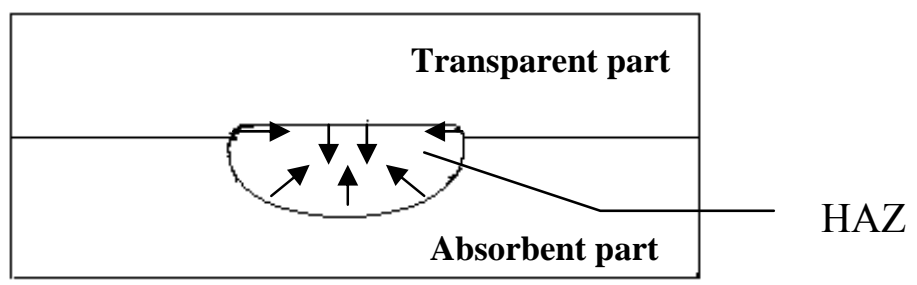

Figure 4-33 Schematic drawing of internal stresses on a simple laser transmission joint when there is no gap between transparent part and absorbent part (the top bulk is transparent part, the bottom bulk is the absorbent part, and the semi-circle in the middle is the HAZ)

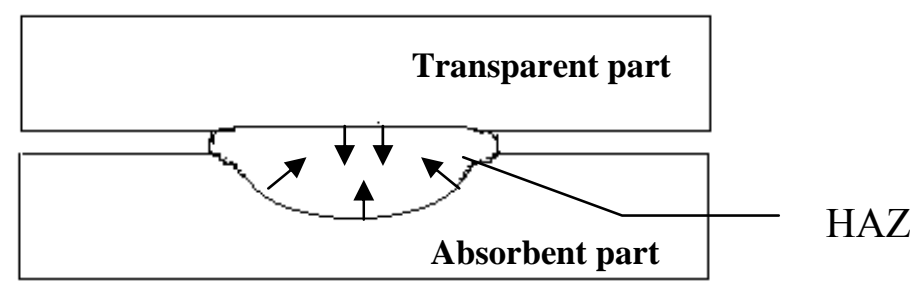

Figure 4-34 Schematic drawing of internal stresses on a simple laser transmission joint when there is gap between transparent part and absorbent part (the top bulk is transparent part, the bottom bulk is the absorbent part, and the semi-circle in the middle is the HAZ) 
In both cases, the horizontal component of the inward stresses is expected to cause the absorbent part to buckle outward. If this is the only deformation, ribs will be observed on the part surface. The reaction of the vertical stresses will be different in Figure 4-33 and Figure 4-34. When the absorbent and transparent parts are in contact with each other (as in Figure 4-33), these stresses will likely pull the outer surfaces of the parts inwards. When a gap is present between the parts due to flash (as in Figure 4-34), the vertical component of the stress will cause the parts to move closer together without necessarily causing any deformation on the external surfaces.

The relative magnitude of these different deformations will determine what type of defect is visible on the surface. If the horizontal stresses predominate, then ribs will be formed. If the vertical stresses predominate, then sink marks will be created. Chapter 5 will discuss a finite element model that will show how the schematic geometries shown in Figure 4-33 and Figure 4-34 lead to sink marks and ribs.

This analysis would suggest that when flash forms and part separation occurs, a geometry like that shown in Figure 4-34 is created. As explained above, this then results in rib-like defects on the surface. When there is no flash or part separation, the residual stresses cause a sink-mark to form. This is consistent with the observations presented in the previous sections. The remainder of this section is devoted to a discussion of how these two geometries are created during welding of $2 \mathrm{~mm}$ and $3 \mathrm{~mm}$ thick parts. 
Specifically, one needs to explain why flash always occurs early along the weld seam for every condition, and why, for the case of $2 \mathrm{~mm}$ thick parts, it then disappears. Referring to Figure 4-31 and Figure 4-32, as the laser beam is traveling from left to right, the left section is heated first. The material at interface heats-up and melts causing it to expand. There is nowhere for this expanding material to go but up. This expansion causes the transparent part to deform upward (no downward deformation is possible given the fixture and clamping force) and allows some material to squeeze into this space between the two parts. Once it is squeezed out, it cannot flow back to its original position upon cooling and flash is formed.

As the laser continues to move, the material to the right starts to heat-up, melt and expand. The expanding material in this section still has to go somewhere. There are now two possibilities. It can expand upward, deform the transparent part and flow out as flash, or, if the melt pool is large enough, the molten material can flow back along the melt pool toward the left section. For $2 \mathrm{~mm}$ thick plates, the molten polymer may have flowed back along the melt pool into the section that was first heated by the laser. Here there is free volume created by the initial thermal expansion of the polymer. For $3 \mathrm{~mm}$ thick plates, it would appear that the polymer expanded upward to create flash. One possible explanation as to why the flow occurred into the spaces between the two parts along the entire weld seam for $3 \mathrm{~mm}$ thick parts is their greater waviness compared to 2 $\mathrm{mm}$ thick parts. Figure 4-35 and Figure 4-36 show plots of surface height (relative to the profilometer's frame of reference) of unwelded parts as a function of trace distance for 3 
$\mathrm{mm}$ and $2 \mathrm{~mm}$ thick parts respectively. From these figures, one can see the greater waviness of $3 \mathrm{~mm}$ thick plates when compared with the data taken from $2 \mathrm{~mm}$ plate. That means that, before the weld processing, two $3 \mathrm{~mm}$ thick plates cannot mate very well, i.e. there is some gap between two parts before welding, which can provide spaces for expanding molten plastic to flow out and form flash. This effect does not imply that the thicker parts always lead to flash formation but that parts with uneven surface are the cause.

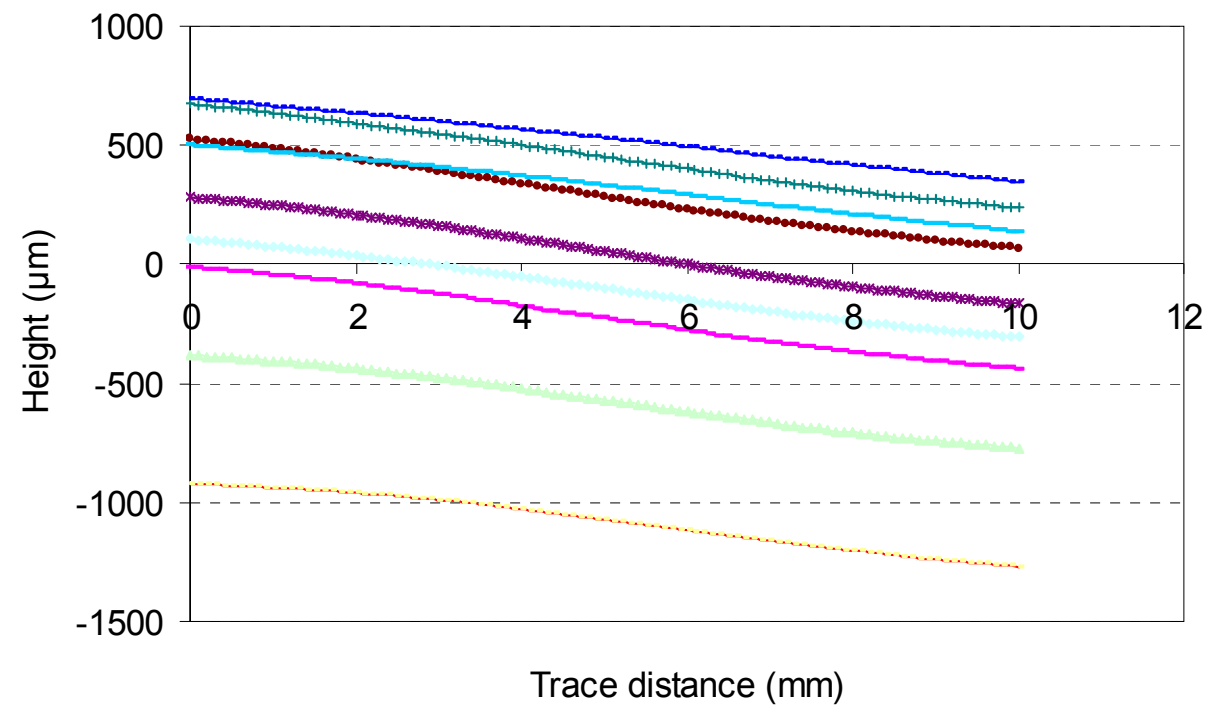

Figure 4-35 Profilometer traces for a $3 \mathrm{~mm}$ thick unwelded plate 


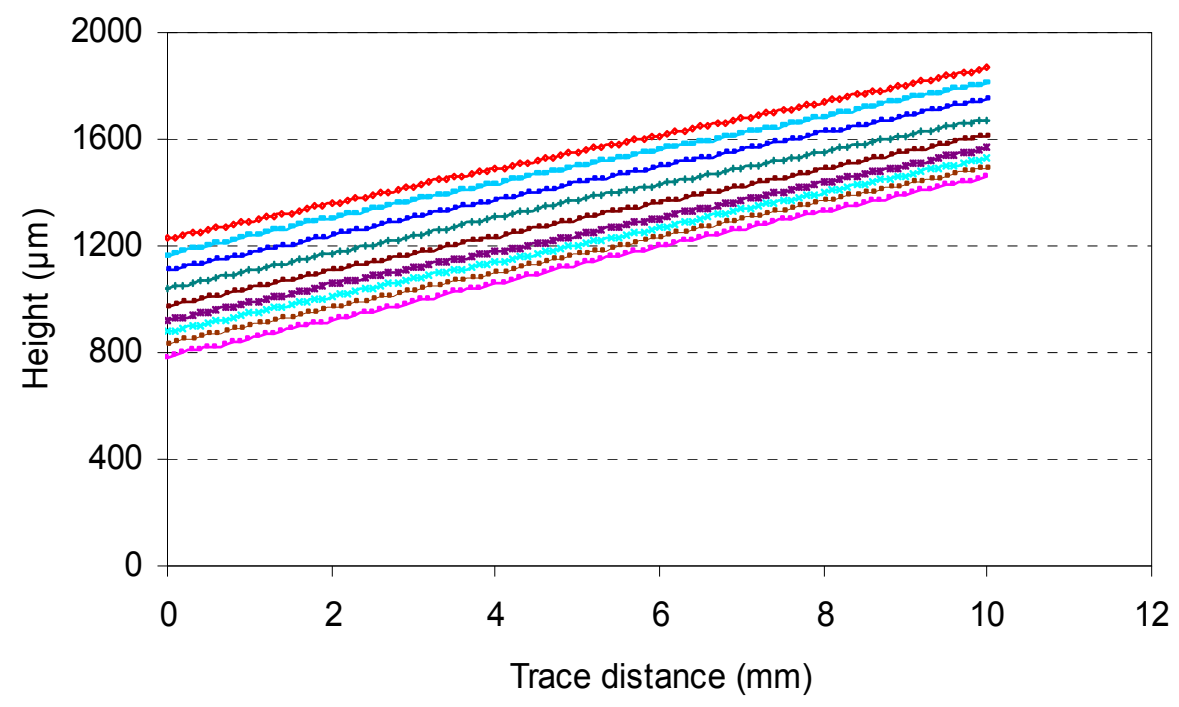

Figure 4-36 Profilometer traces for a $2 \mathrm{~mm}$ unwelded plate

Similar observations have been made by Chen [27]. In his case, for the lap-joint test configuration used, both ends of the weld seam were open as shown in Figure 4-37. This joint design allows the resin to flow out from the two ends to form flash.

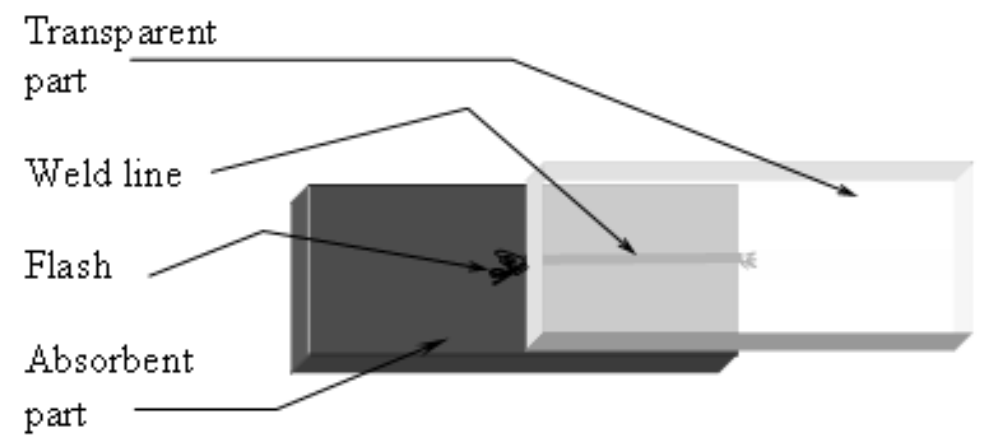

Figure 4-37 Schematic of a lap-joint specimen in Chen's thesis 
Figure 4-38 shows Chen's experimental results. In this figure, the laser beam is travelling from the left to right. When the artificially added gap between transparent part and absorbent part was zero, the expanding resin in left section flowed out the left end to form flash (Figure 4-38(a)). When the artificial gap was increased, the size of the flash decreased and the width of weld seam increased (Figure 4-38 (b) and (c)). This suggests that the gap provides the space for the expanding resin to flow out and the flash along the weld seam is formed.

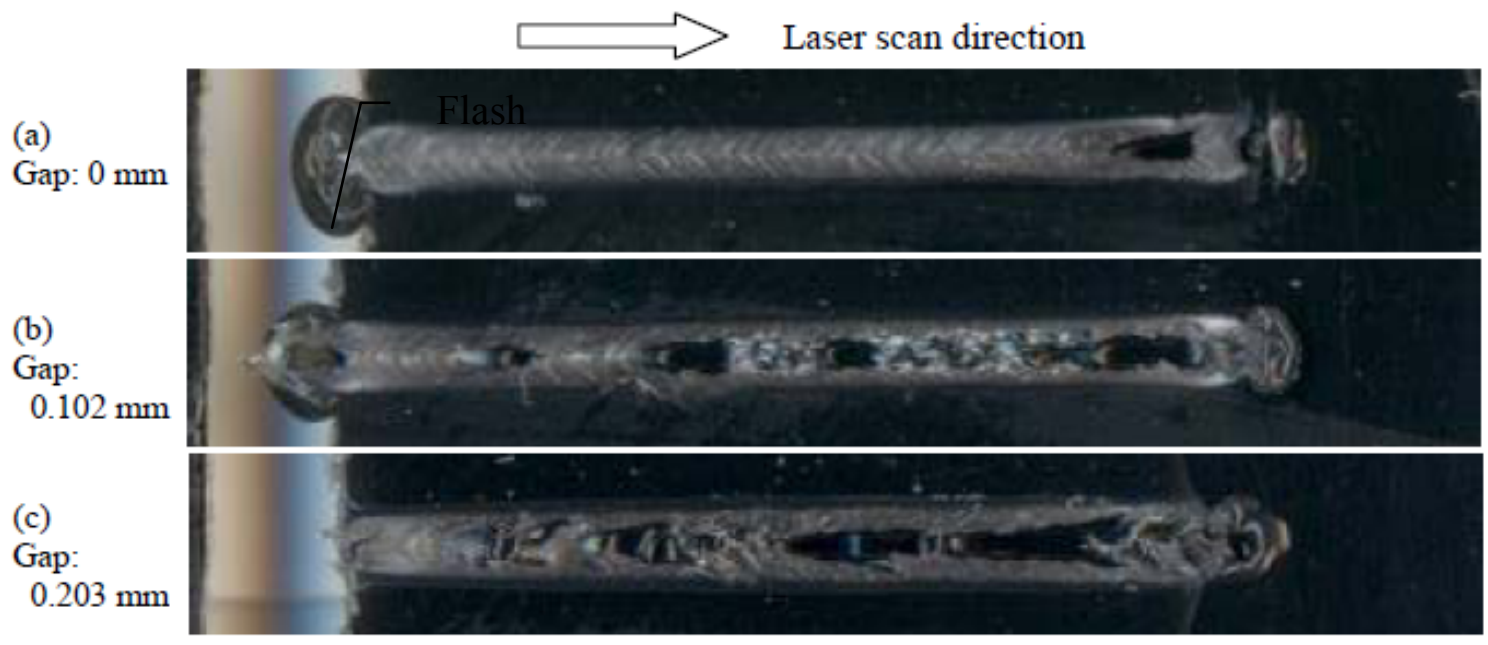

Figure 4-38 Weld fractures of laser-absorbent PA6 parts after pull test $(0.025$ wt.\% CB, power 92 $\mathrm{W}$, speed $25 \mathrm{~mm} / \mathrm{s}$ ) [27]

In addition, the cross-sectional images in Chen's thesis also show similar results. It is observed that the top image in Figure 4-39, which corresponds to the top image in Figure 4-38, has no visible flash as the expanding resin flows out of the weld seam ends. 
However, the bottom image in Figure 4-39, which corresponds to the bottom image in Figure 4-38, shows flash because there is a gap between the two parts. These results are consistent with the results described in this thesis and explain why the flash occurs first and then disappears.

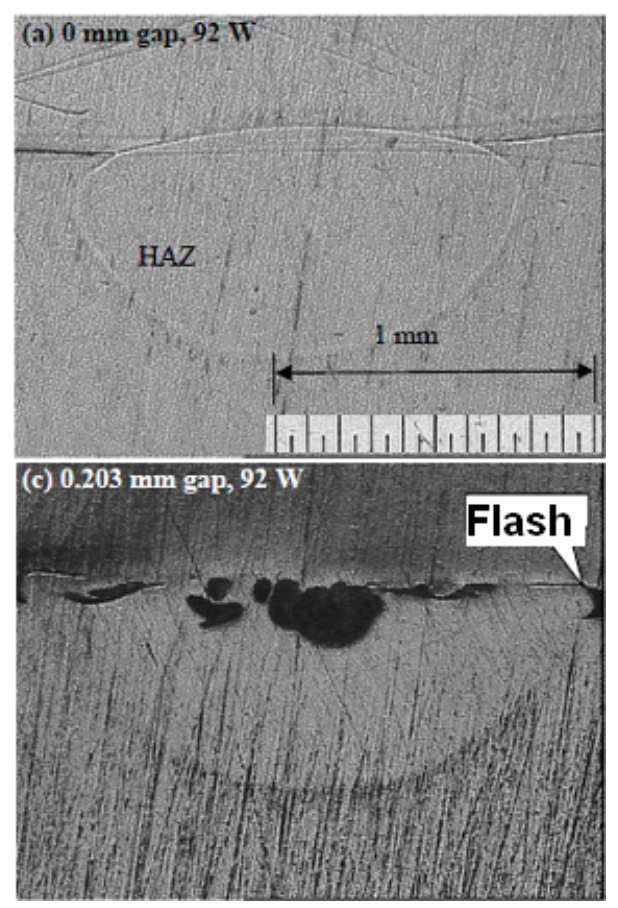

Figure 4-39 Cross-section views of the PA6 welds under microscope for different power and gap setting; Top material is laser-transparent and bottom material is laser-absorbent. (0.025 wt.\% CB, speed $25 \mathrm{~mm} / \mathrm{s}$ ) [27]

Now it is possible to propose an answer to question raised in section 4.3.1. Figure 4-21 on page 63 shows a plot of the maximum height of ribs on $2 \mathrm{~mm}$ thick parts as a 
function of laser power for $\mathrm{CB}$ levels of $0.05,0.1$, and $0.2 \mathrm{wt} \%$. It is observed that for the two highest $\mathrm{CB}$ levels of 0.1 and 0.2 wt.\%, the heights of ribs increase with the increasing laser power. This is similar to the results in Figure 4-20 and Figure 4-22. However, at the lowest CB level of 0.05 wt.\%, the maximum height of ribs decreases slightly with power. At high laser power and lower CB level, the melt pool is much larger (see Figure 4-28 and Figure 4-26 (b)) and so the molten material heated later along the laser scan has less resistance to flowing back along the melt pool into the section that was first heated by the laser. So although there is larger free volume created by the initial thermal expansion of the polymer, it is filled out by the molten polymer heated later. That decreases loss of the material to the sides of the weld seam as flash so that the residual stresses also decrease. Thus, the deformation on the surface becomes smaller as well. Therefore, at the lowest $\mathrm{CB}$ level of 0.05 wt. $\%$, the maximum height of ribs decreases slightly with power. 


\section{Chapter 5}

\section{Modeling}

This chapter describes a 2-D thermal-mechanical coupled model to simulate the surface deformation in contour welding of PP. The purpose of the modeling is to determine what type of surface deformation (sink or rib) would be created as a function of material shrinkage and part contact conditions at the interface and to compare these simulated results with experimental observations. The software used in this simulation is COMSOL Multiphysics ${ }^{\circledR}$ 3.3a. The weld structure used in the modeling is based on the experiments described in Chapter 3 (Material). The material properties used in the modeling, such as thermal conductivity and heat capacity, will be described in section 5.1. Then the modeling strategy (section 5.2), the construction of the model (section 5.3) and the results and discussion (section 5.4) will be presented.

\subsection{Material properties}

Polymer thermal properties such as thermal conductivity, heat capacity, thermal expansion coefficient, and density are needed for heat transfer simulation. In addition to thermal properties, mechanical properties such as Young's modulus are needed for strainstress simulation. For this exploratory simulation, all the material properties are taken from data sheets of typical PP homopolymer [85, 92-95] and are assumed to be temperature independent. They are given in Table 5-1. 
Table 5-1 PP homopolymer material properties used in the model

\begin{tabular}{|l|c|}
\hline \multicolumn{1}{|c|}{ Property } & Value \\
\hline Density & $0.9 \mathrm{~g} / \mathrm{cm}^{3}$ \\
\hline Melting point & $168^{\circ} \mathrm{C}$ \\
\hline Thermal conductivity, $x 10^{-4}$ & $1171.52 \mathrm{~W} /(\mathrm{m} \cdot \mathrm{K})$ \\
\hline Heat capacity & $1900 \mathrm{~J} /(\mathrm{kg} \mathrm{K})$ \\
\hline Thermal expansion coefficient, $\times 10^{-7}$ & $1.9 \mathrm{~mm} / \mathrm{mm} /{ }^{\circ} \mathrm{C}$ \\
\hline Young's modulus & $34 \mathrm{MPa}$ \\
\hline
\end{tabular}

\subsection{Modeling strategy}

The purpose of this model is to predict the type of surface deformation (i.e., a sink or a rib) that would be created due to material shrinkage and part contact conditions at the interface and to qualitatively compare these simulated results with experimental observations. As discussed in section 4.3.3, the shrinkage of a small volume of molten polymer in the HAZ (shrinkage due to increased density or material losses due to flow) in the middle of a much larger solid volume creates internal stresses that result in small defects (ribs or sink marks) on the outer surfaces of the larger volume.

One of the issues is how to simulate volume shrinkage in HAZ using COMSOL software. The density changes cannot be used because the governing equations for structural analysis do not consider the density during the analysis; it is only there for 
post-processing. In other words, the mass balance is not enforced strictly by the governing equations [96]. In order to simulate the volume changes of HAZ in this exploratory modeling study, it was assumed that only the HAZ is initially above room temperature and the rest of the specimen is at room temperature $\left(23^{\circ} \mathrm{C}\right)$. That is to say, the cooling of the $\mathrm{HAZ}$ from $168^{\circ} \mathrm{C}$ to $23^{\circ} \mathrm{C}$ caused the volume of $\mathrm{HAZ}$ to shrink. Different levels of shrinkage, corresponding to more or less volume loss, were obtained by adjusting the coefficient of thermal expansion. It is acknowledged that this technique does not reflect the true physical phenomena in the process. However, for the purposes of this exploratory study, it will allow one to examine qualitatively the type of surface deformation as a function of the boundary condition at the interface. A more detailed study would involve material heating by the laser, heat transfer by conduction in the parts as well as material flow due to thermal expansion in a transient $3 \mathrm{D}$ simulation. Such work, although very useful, is very complex and clearly beyond the scope of this Master's thesis.

\subsection{Structure of the 2-D coupled model}

In order to reduce the simulation time, only 2-D simulations were performed. In the experiments, both ribs and sink marks were observed on $2 \mathrm{~mm}$ welded parts, whereas, only ribs were observed on $3 \mathrm{~mm}$ parts. In order to test the mechanism analysis in section 4.3.3, the modeling was only performed for the $2 \mathrm{~mm}$ parts. Based on the experiments, two heat transfer conditions at the weld interface were simulated: 
(a) The "no-gap" model - the laser-transparent and laser-absorbent parts are stacked together with contact at the interface of transparent and absorbent parts. This model condition was used to analyze the internal stresses under contour welding conditions where no gap exists. Recall, that this situation was observed experimentally for $2 \mathrm{~mm}$ thick plates in the latter half of the laser scan. Based on the dimensions of the parts shown in Figure 4-4, the model mesh is shown in Figure 5-1. This 2-D coupled model is a cross section of the weld assembly in the $x-y$ plane. Both transparent part and absorbent part are $35 \mathrm{~mm}$ wide and $2 \mathrm{~mm}$ thick. Based on the experiments (CB level is 0.1 wt. $\%$, laser power is $14 \mathrm{~W}$ ), the heat affected zone is located in the middle of the model. The width of the heat affected zone is $984 \mu \mathrm{m}$. Its depth in absorbent part is 387 $\mu \mathrm{m}$ and the depth in transparent part is $97 \mu \mathrm{m}$. The model is symmetrical in the $\mathrm{x}-$ direction.

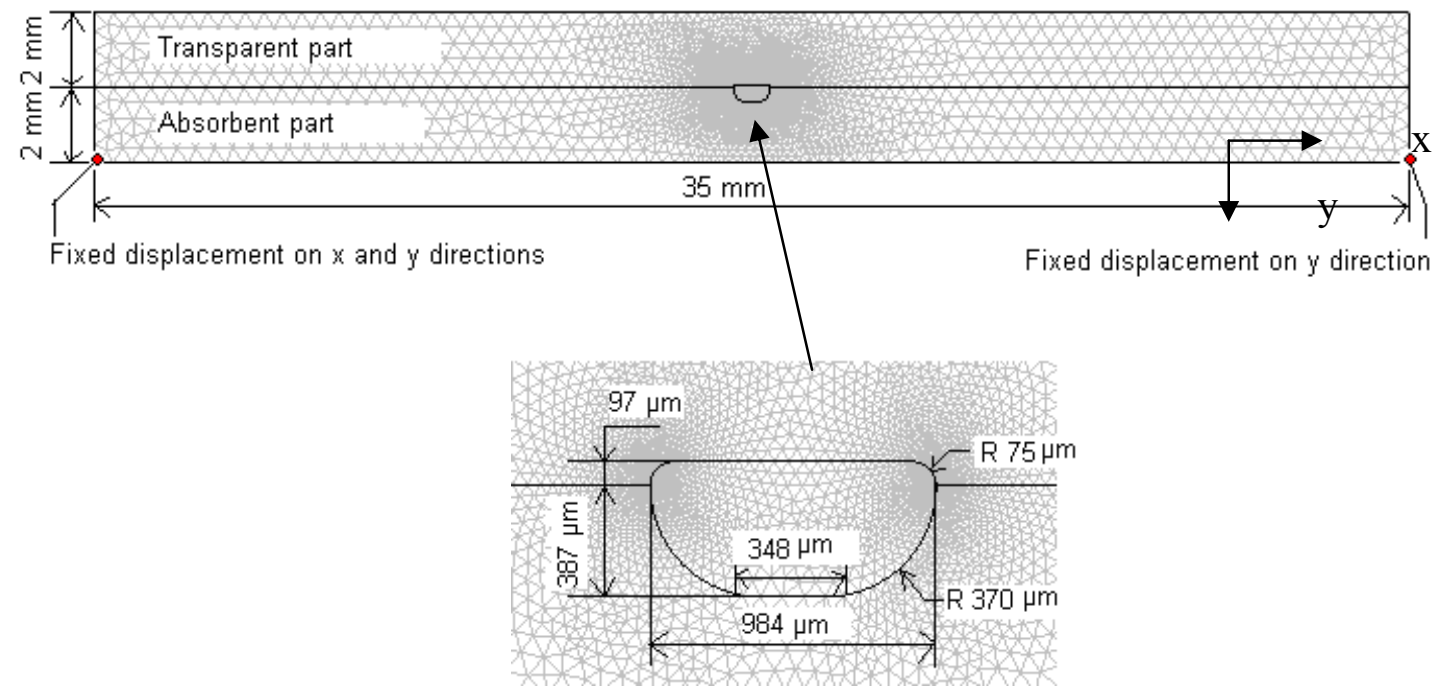

Figure 5-1 Model mesh of the 2-D thermal-mechanical coupled FE model without gap. 
In the heat transfer-mechanical deformation simulation, Lagrange-linear elements (tetrahedral, first order/linear shape function) were selected in the thermal modeling. The boundaries at the weld interface were set to continuity, the other boundaries were set to a constant heat flux. The ambient temperature is $23{ }^{\circ} \mathrm{C}$. Two points at the bottom were fixed in space: the left point was fixed in both $\mathrm{x}$ and $\mathrm{y}$ directions, and the right point was fixed only in the y direction. All other points were free as shown in Figure 5-1. The fixed displacement point provides a reference for the relative movement of the parts. A plain strain model was selected for the stress modeling. There were 9289 elements with 56274 degrees of freedom for the model with a maximum mesh size of $0.5 \mathrm{~mm}$ and a mesh growth rate of 1.1. The computing time for this model was $227 \mathrm{~s}$.

(b) The "gap" model - In this case the laser-transparent and laser-absorbent parts are in contact only through the HAZ at the weld interface as shown in Figure 5-2. A small $0.036 \mathrm{~mm}$ gap separates the two parts along the remainder of the interface. This simplified model condition was used to analyze the internal stresses under contour welding conditions where a gap exists. Based on the dimensions of the parts shown in Figure 4-4, the model mesh is shown in Figure 5-2. This 2-D coupled model is a cross section of the weld assembly in the $x-y$ plane. Based on the experiment (CB level is 0.1 wt.\%, laser power is $14 \mathrm{~W}$ ), the heat affected zone is located in the middle of the model. The width of the heat affect zone is $1028 \mu \mathrm{m}$. Its depth is $477 \mu \mathrm{m}$ in the absorbent part and $51 \mu \mathrm{m}$ in the transparent part. The model is symmetrical in the $\mathrm{x}$-direction. Except for the gap between two parts, all other settings are same as for the "no-gap" model. 


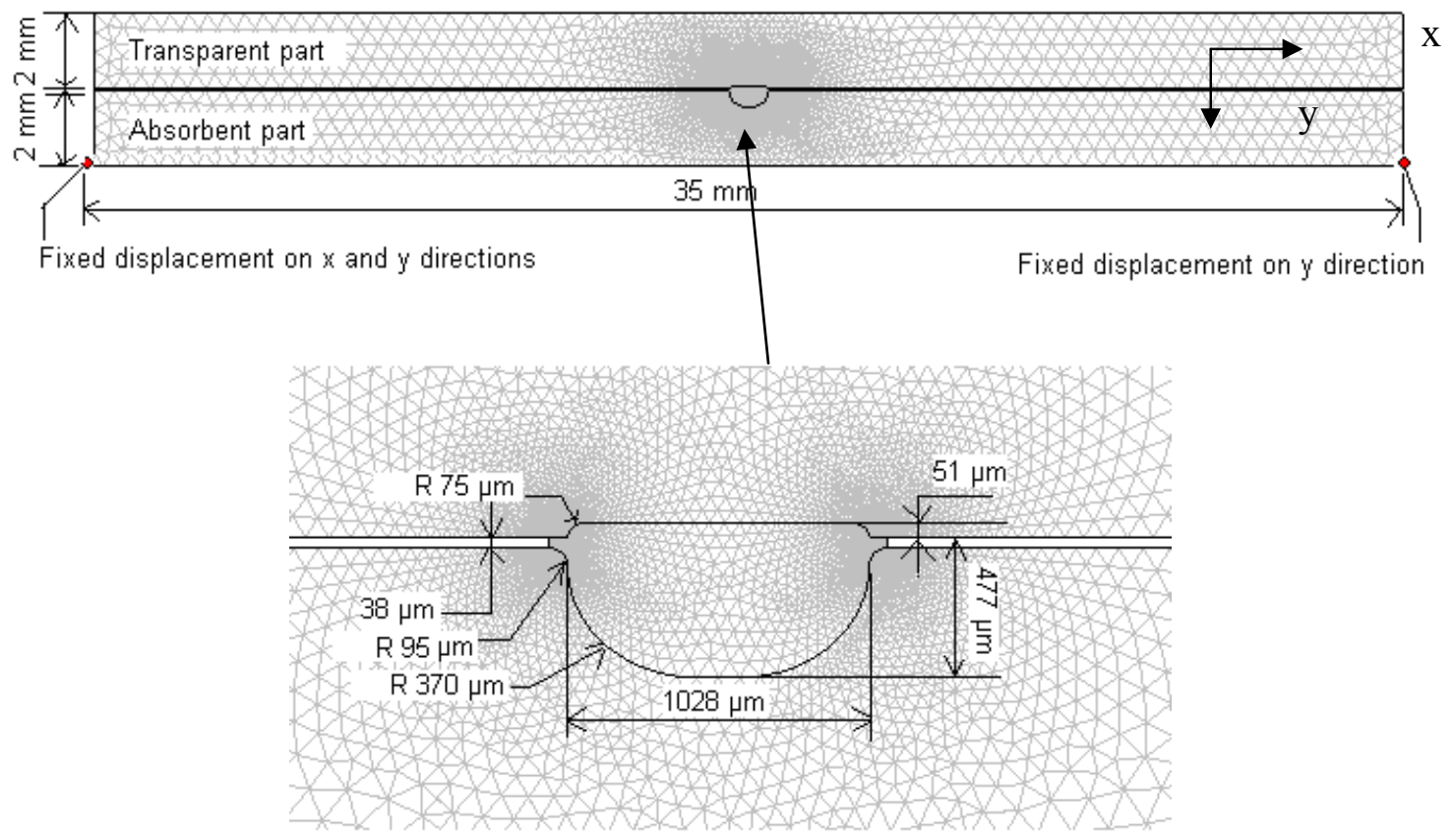

Figure 5-2 Model mesh of the 2-D thermal-mechanical coupled FE model with gap.

There are 13447 elements with 82206 degrees of freedom for the model with a maximum mesh size of $0.5 \mathrm{~mm}$ and a mesh growth rate of 1.1 . The computing time for this model was $270 \mathrm{~s}$.

\subsection{Modeling results and discussion}

\subsubsection{Mesh size and time step sensitivity}

The purpose of the mesh size sensitivity analysis is to make sure that one can get the same results regardless of the mesh size. Figure 5-3 shows the maximum temperature and deformation at the center of the bottom line (the point $(17.5,18)$ ) for the no-gap model at a time of $60 \mathrm{~s}$ as a function of mesh size. It shows that a stable temperature and 
deformation output can be obtained when the maximum mesh size is not more than 0.5 $\mathrm{mm}$. It also shows that greater mesh size would work too. However, as the model could be solved sufficiently quickly with the given mesh size, further increase in mesh size was not needed.

The sensitivity analysis on the time step also needed to be performed. Figure 5-4 shows the simulated temperature as a function of the time for two different time steps of 0.5 and $0.05 \mathrm{~s}$ for the no-gap model at a position of $(17.5,20)$. It is observed that, at a time of approximately $100 \mathrm{~s}$, the temperature is within $\pm 1^{\circ} \mathrm{C}$ of ambient throughout the entire assembly for either time step. So time step of $0.5 \mathrm{~s}$ was selected. For the gap model, at a time of approximately $90 \mathrm{~s}$, the temperature is within $\pm 1^{\circ} \mathrm{C}$ of ambient throughout the entire assembly. At these times, the positions of the free surface with respect to its initial position as well as data on local stress were extracted from the software output. 


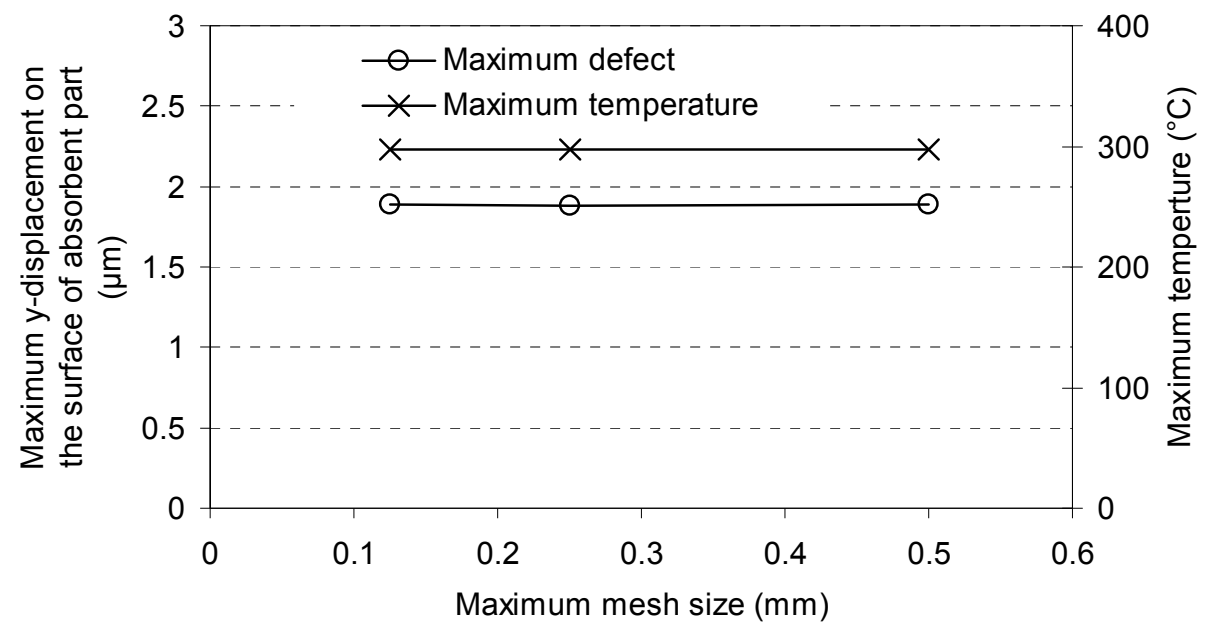

Figure 5-3 Sensitivity analysis for the mesh sizes influence on the simulated temperature and surface deformation of absorbent part

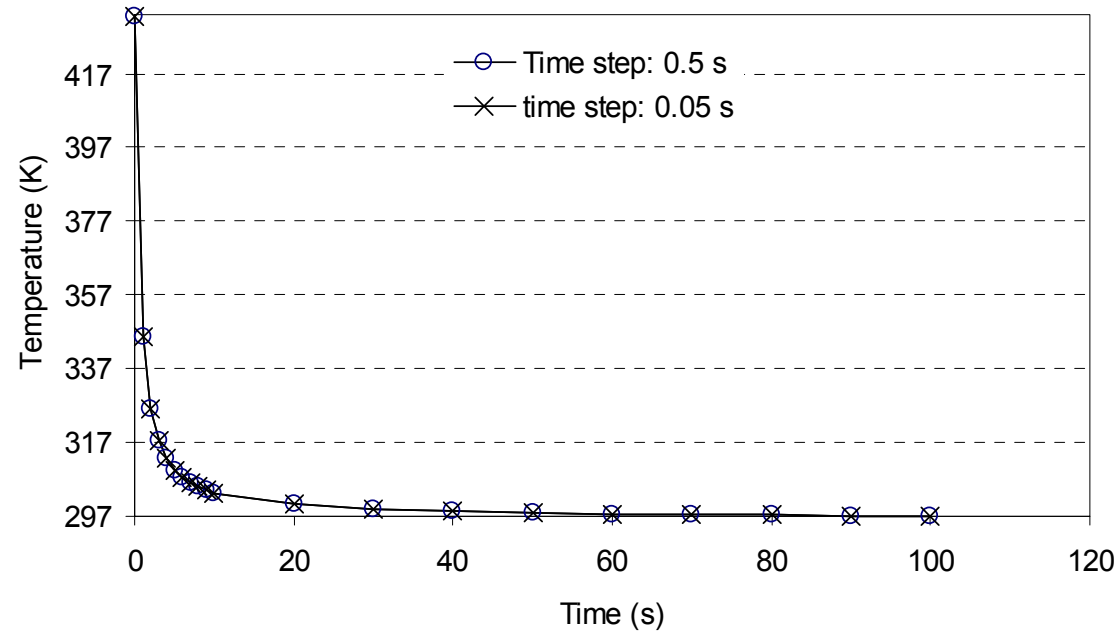

Figure 5-4 Sensitivity analysis of the time step influence on the simulated temperature. 


\subsubsection{Simulated temperature}

Before discussing the effects of internal stresses on the deformation of the absorbent surface, it is necessary to examine the continuity of the heat transfer modeling. The mathematical model for heat transfer by conduction is the heat equation [97]:

$$
\rho C p \frac{\partial T}{\partial t}-\nabla \cdot(k \nabla T)=Q \quad \text { Equation } 5-1
$$

where $T$ is the temperature, $\rho$ is the density, $C p$ is the heat capacity at constant pressure, $k$ is thermal conductivity, and $Q$ is a heat source or a heat sink. In our model, there is no heat source available and so $Q=0$.

The equation of boundary condition for heat flux [97]:

$$
n \cdot(k \cdot \nabla T)=q_{0}+h \cdot\left(T_{\mathrm{inf}}-T\right)
$$

where $h$ is the heat transfer coefficient, $q_{0}$ is the inward heat flux, and $T_{\text {inf }}$ is the ambient bulk temperature.

The default setting for the interior boundaries is "Continuity." This means that the heat flux in the normal direction is continuous across the boundary.

Based on the equations above, COMSOL calculates the temperature for a given time. Figure 5-5 shows the temperature result for the 2-D coupled model without gap taken at a time of $100 \mathrm{~s}$. Figure 5-6 shows the temperature distribution for the 2-D coupled model with gap at the same time. It is observed from these two figures that the temperature 
distribution shows very good continuity. That suggests that both subdomain settings and boundary setting of heat transfer module are reasonable.

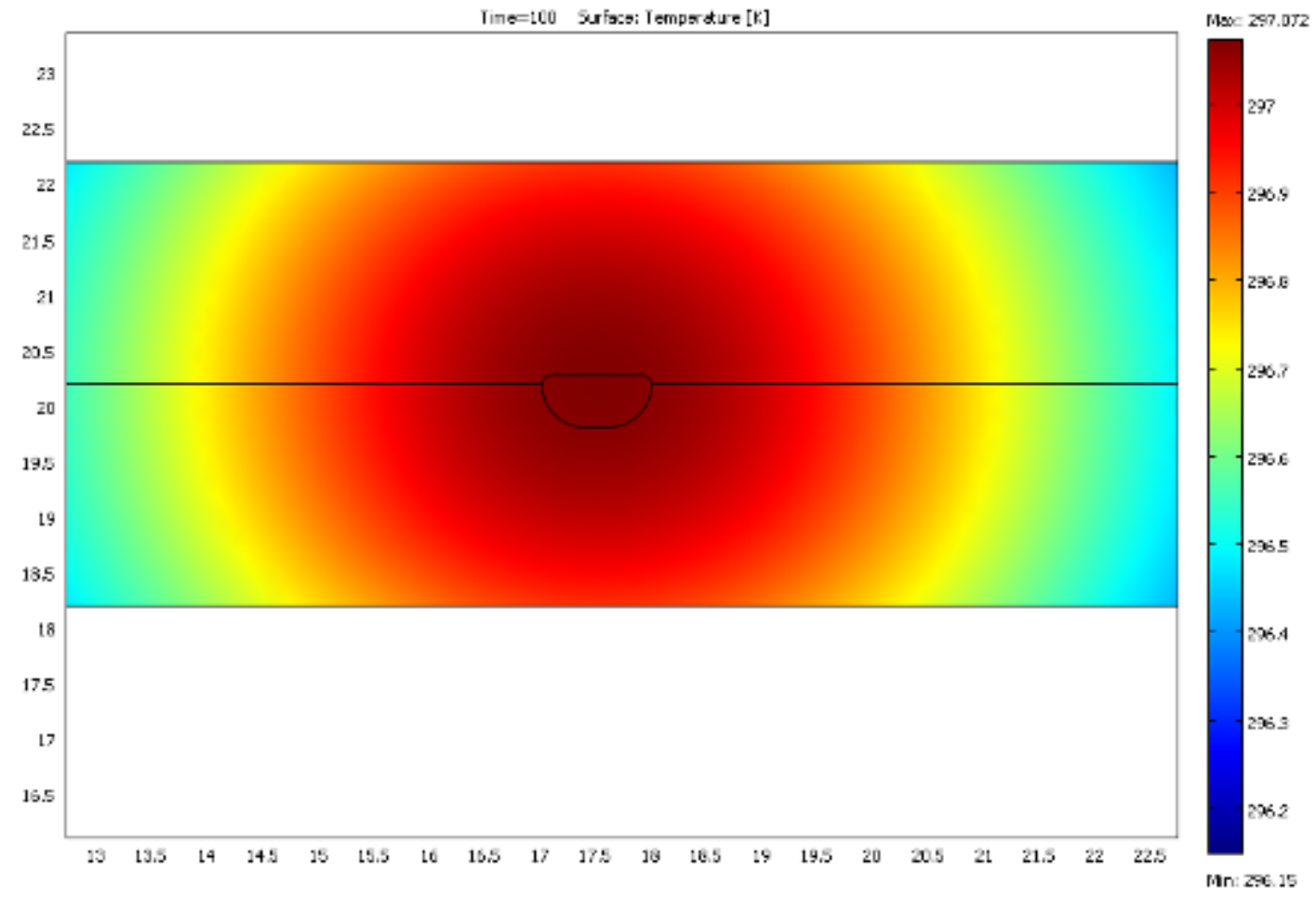

Figure 5-5 Example of heat transfer model output (no-gap model) 


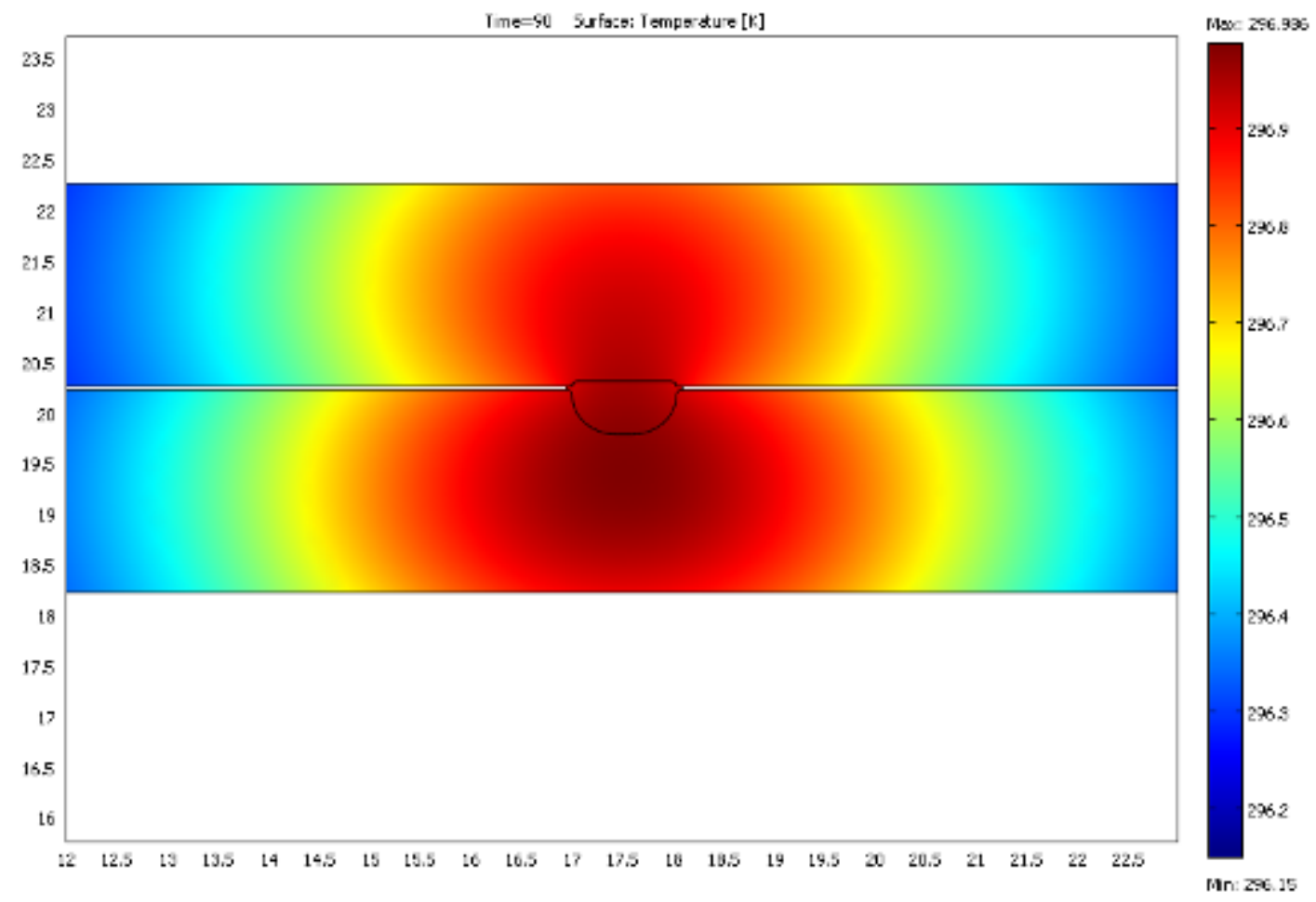

Figure 5-6 Example of heat transfer model output (gap model)

\subsubsection{Simulated deformation of the surface}

Assuming no viscous-like behaviour occurs, thermal deformation of the parts can be simulated based on the stress-strain relation [68]:

$$
\begin{gathered}
\varepsilon^{e l}=\frac{1+v}{E} \sigma-\frac{v}{E} \sigma \delta \\
\varepsilon^{t h}=\alpha\left(T-T_{i}\right) \delta
\end{gathered}
$$


where $\varepsilon^{e l}, \varepsilon^{\text {th }}$ are the elastic and thermal strain components of polymer; $E$ is the elastic modulus; $v$ is the Poisson's ratio; $\sigma$ are the stress components; $\alpha$ is the linear thermal expansion coefficient; $T$ and $T i$ are the current and initial temperatures respectively.

Using Equations 5-3 and 5-4, we can combine the heat transfer model and stressstrain analysis model to get displacement due to the temperature change in the heat affected zone.

Figure 5-7 shows the deformation on the surface of absorbent part when there is no gap between transparent part and absorbent part. The result in Figure 5-7 corresponds to the bottom boundary in Figure 5-1. From the direction of the defect, one can see it is a sink of maximum dimension $0.040 \mathrm{~mm}$. This is consistent with the experimental observations that showed that shrinkage of the material when the two plates were in contact lead to sink marks on the surface of the black component. The magnitude of the sink-mark is of the same order of magnitude to that observed experimentally. However, one must recall that the magnitude is somewhat arbitrary and depends on the value of the thermal expansion coefficient which was in this case $0.001498 \mathrm{~K}^{-1}$. As stated above, the purpose of the analysis was to determine whether or not this geometry, when subjected to volume loss in the HAZ, would exhibit sink mark-like defects. Further and more accurate simulation work is required in order to predict the material flow during LTW which would lead to a better estimate of volume loss and part deformation.

Figure 5-8 shows the deformation on the surface of absorbent part when there is a gap between transparent part and absorbent part. The result in Figure 5-8 corresponds to 
the bottom boundary in Figure 5-2. From the direction of the defect, one can see it is a rib of maximum height of $48 \mu \mathrm{m}$. Similar to the results in Figure 5-7, the data in Figure 5-8 agree qualitatively with the experimental results discussed in Chapter 4. Recall that, when gaps were present at the interface, rib-like defects were observed. Again, care must be taken when examining the size of the defect. Although its magnitude is again comparable to that observed experimentally, it is dependent on the value of the coefficient of thermal expansion used in the simulation. As stated above, more work is required to better estimate this material loss.

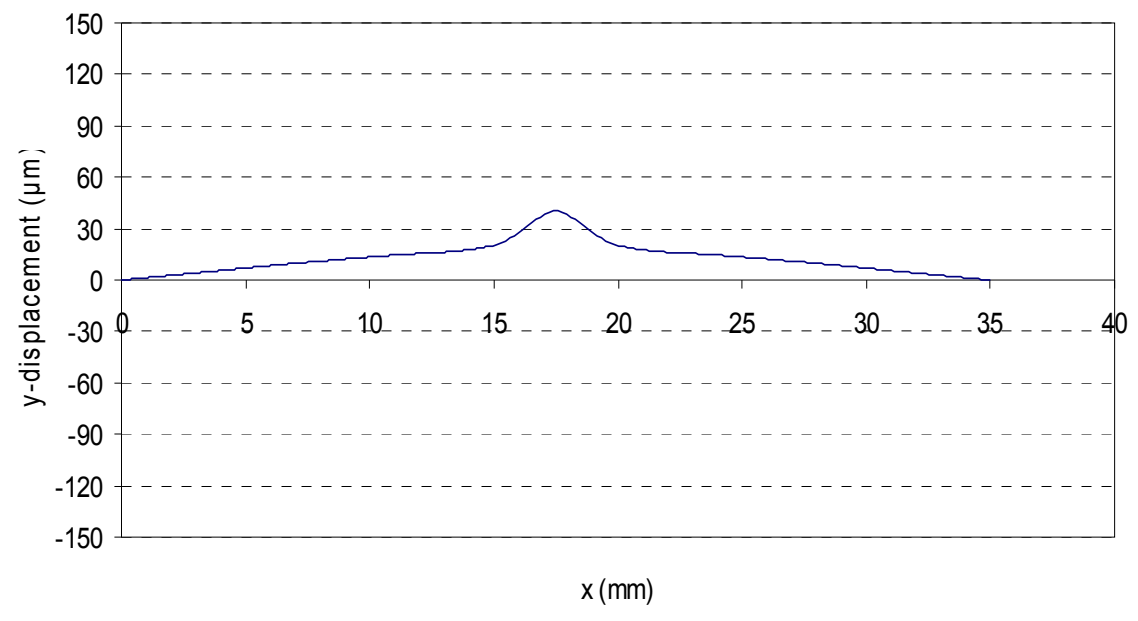

Figure 5-7 Deformation on surface of absorbent part (no gap model) 


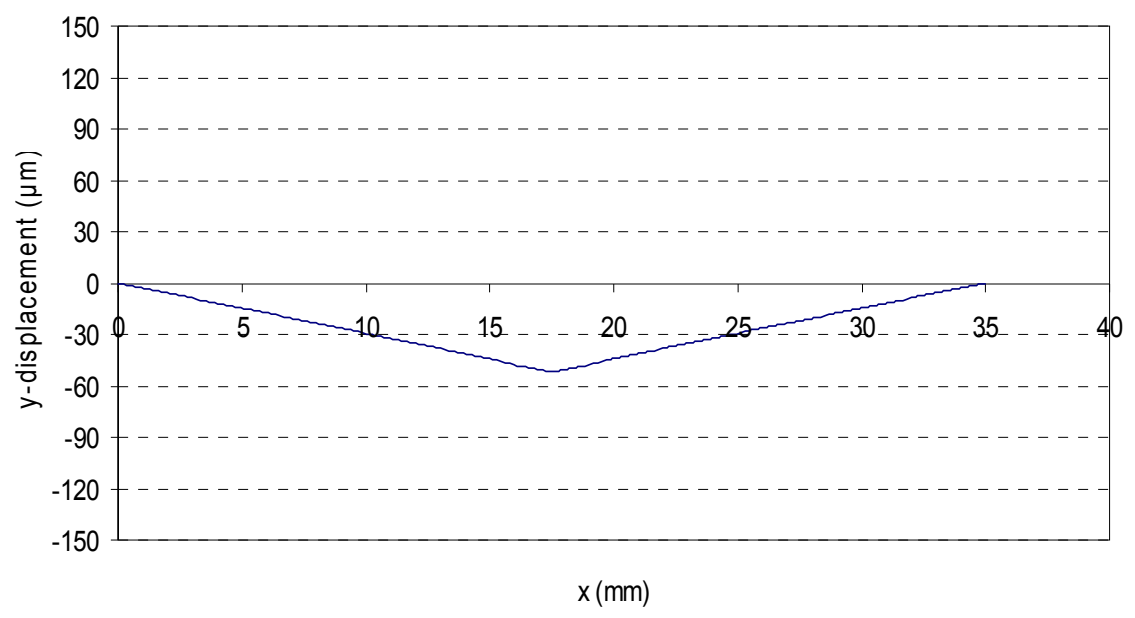

Figure 5-8 Deformation on surface of absorbent part (gap model)

\subsubsection{Simulated residual stresses}

It is also insightful to examine the internal stresses generated in modeling. Figure 5-9 shows the distribution of the residual normal stresses in the vertical y-direction generated in the 2-D coupled modeling when there is no gap between transparent part and absorbent part. It is observed that the stresses in the HAZ are tensile. This is expected due to the volume loss imposed on the geometry. These tensile stresses, as well as those located above and below the HAZ, will pull in the top and bottom free surfaces to create the sink mark deformations observed in the model and experimentally.

Figure 5-10 shows the distribution of the residual normal stresses in the horizontal $\mathrm{x}$ direction generated in the 2-D coupled modeling when there is no gap between 
transparent part and absorbent part. It is observed that the stresses in the heat affected zone are again tensile - as expected. These tensile stresses, as well as those located to the left and right of the HAZ, will pull in material laterally towards the HAZ. As material is pulled toward the centre, this type of stress field is expected to create a bulge or rib above and below the HAZ. The resulting competition between vertical and horizontal residual tensile stresses ultimately resulted in the sink marks for this type of geometry. This agrees with the mechanism analysis in Section 4.3.3.

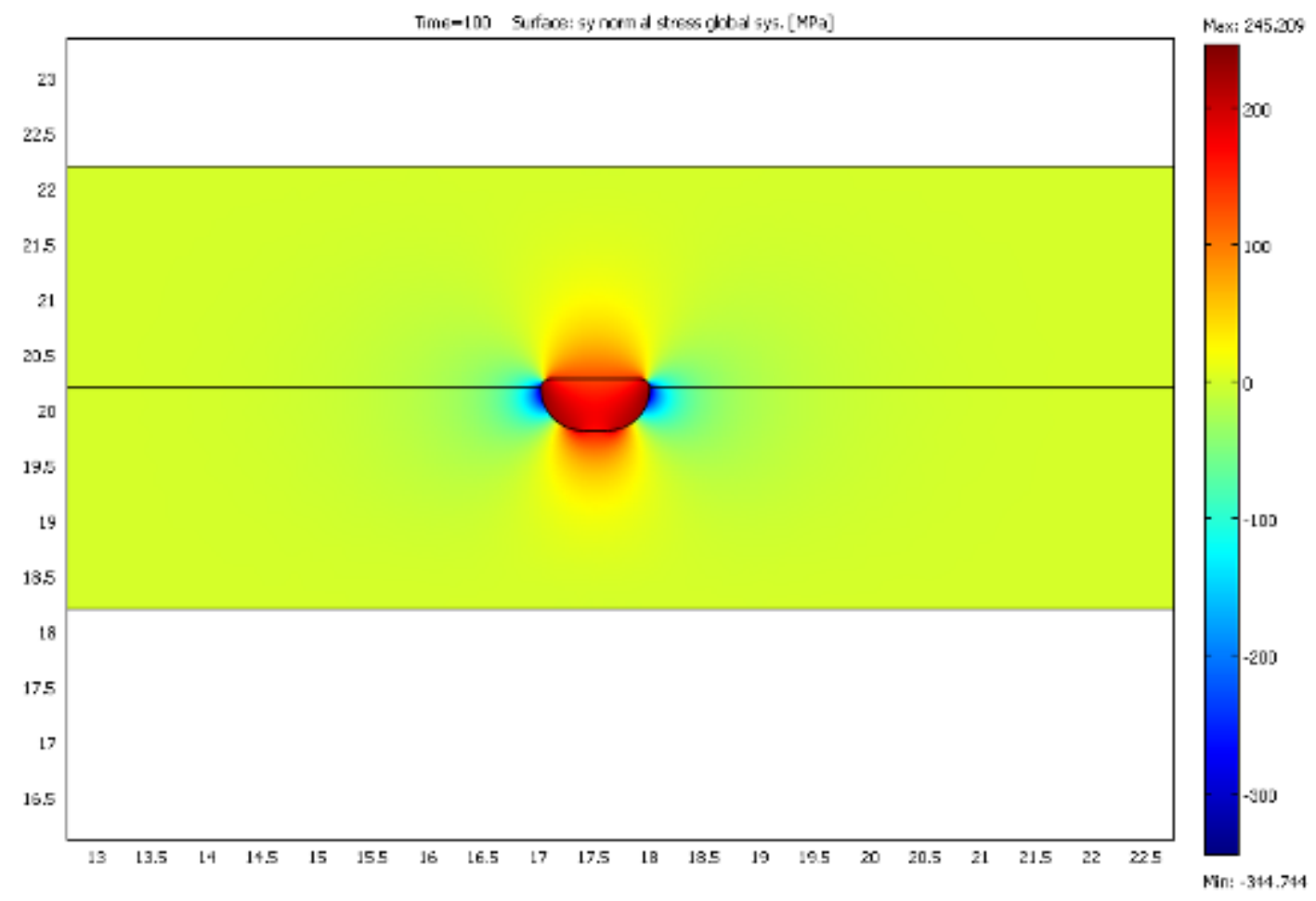

Figure 5-9 Distribution of the residual normal stresses in the vertical y-direction generated in the 2-D coupled modeling (no gap model) 


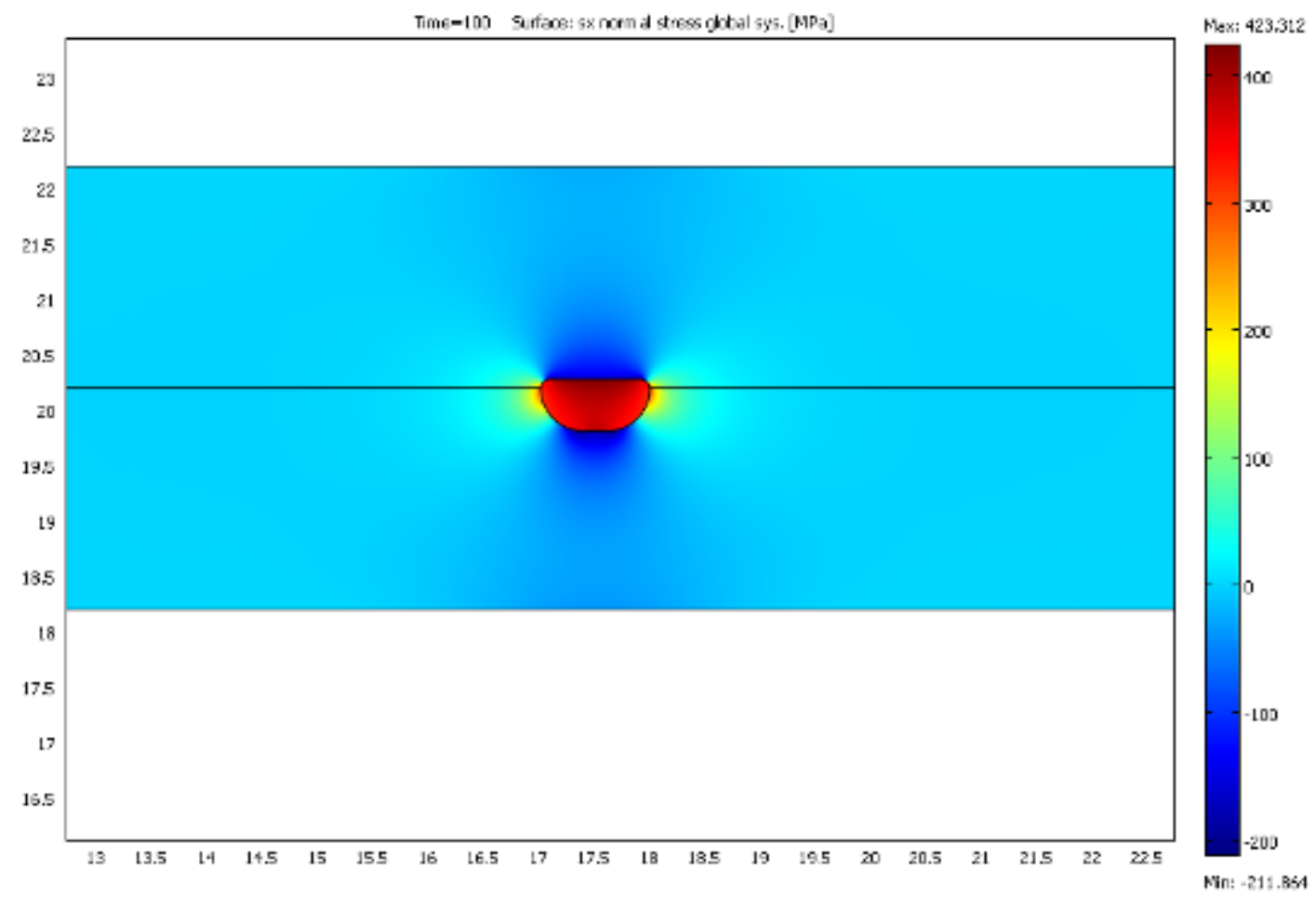

Figure 5-10 Distribution of the residual normal stresses in the horizontal x-direction generated in the 2-D coupled modeling (no gap model)

Figure 5-11 shows the distribution of the residual normal stresses generated in the vertical $\mathrm{y}$-direction in the 2-D coupled modeling when there is a gap between transparent part and absorbent part. Unlike in the no-gap case, there is essentially no y-direction stress in this case. The tensile stresses that would have been generated by material loss were eliminated as the upper part was able to move down. The movement of the upper part was not possible in the no-gap situation because of interference with the absorbent part. 
Figure 5-12 shows the distribution of the residual normal stresses in the horizontal $\mathrm{x}-$ direction generated in the 2-D coupled modeling when there is a gap between transparent part and absorbent part. Similar to the results in Figure 5-10, it is observed that the stresses in the heat affected zone are again tensile - as expected. These tensile stresses, as well as those located to the left and right of the HAZ, will pull in material laterally towards the HAZ. As material is pulled toward the centre, this type of stress field is expected to create a bulge or rib above and below the HAZ. Unlike what was observed in the no-gap condition, the resulting competition between vertical and horizontal residual tensile stresses clearly resulted in the ribs for this type of geometry. Again, this agrees with the mechanism analysis in Section 4.3.3. 


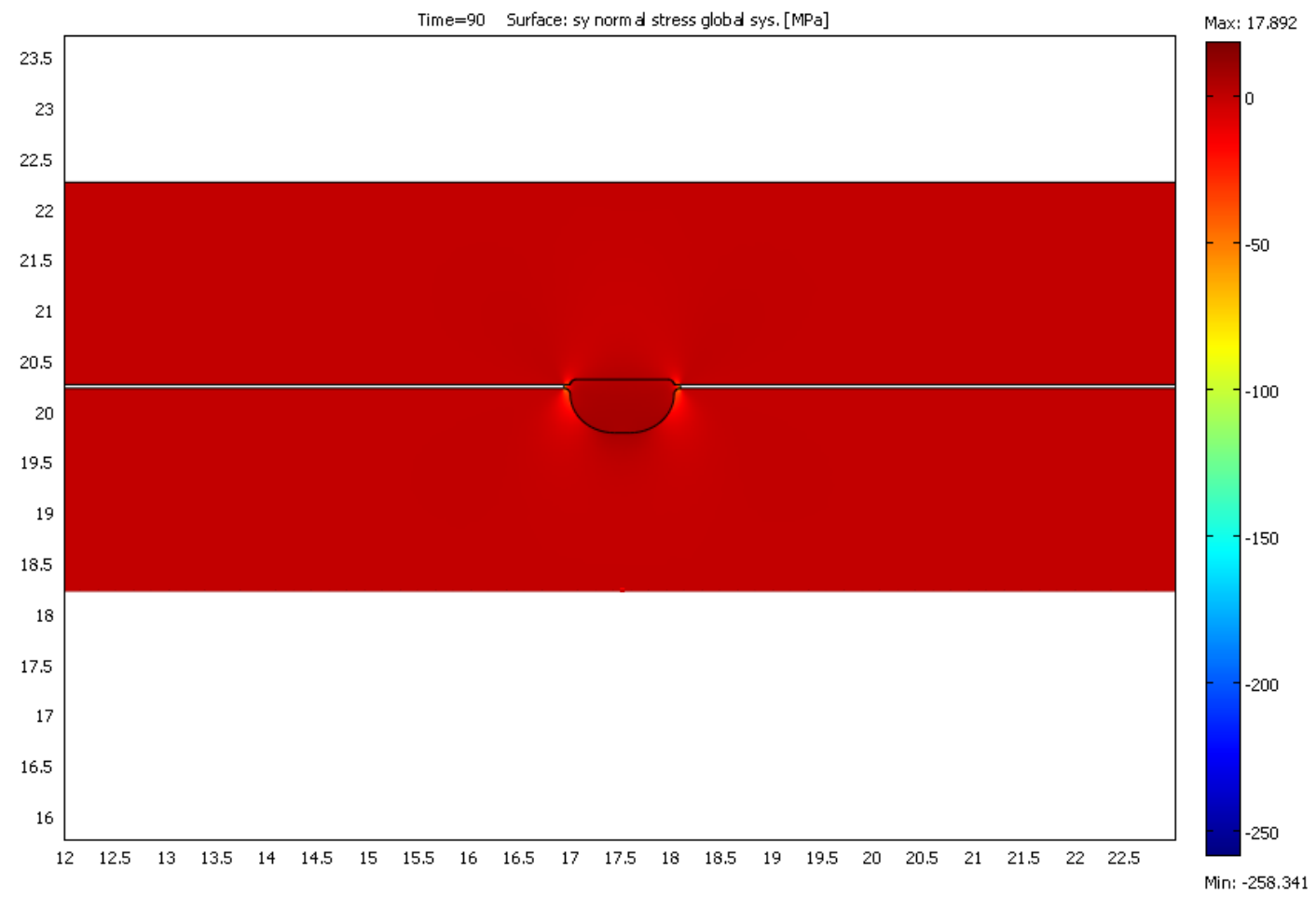

Figure 5-11 Distribution of the residual normal stresses in the vertical y-direction generated in the 2-D coupled modeling (gap model) 


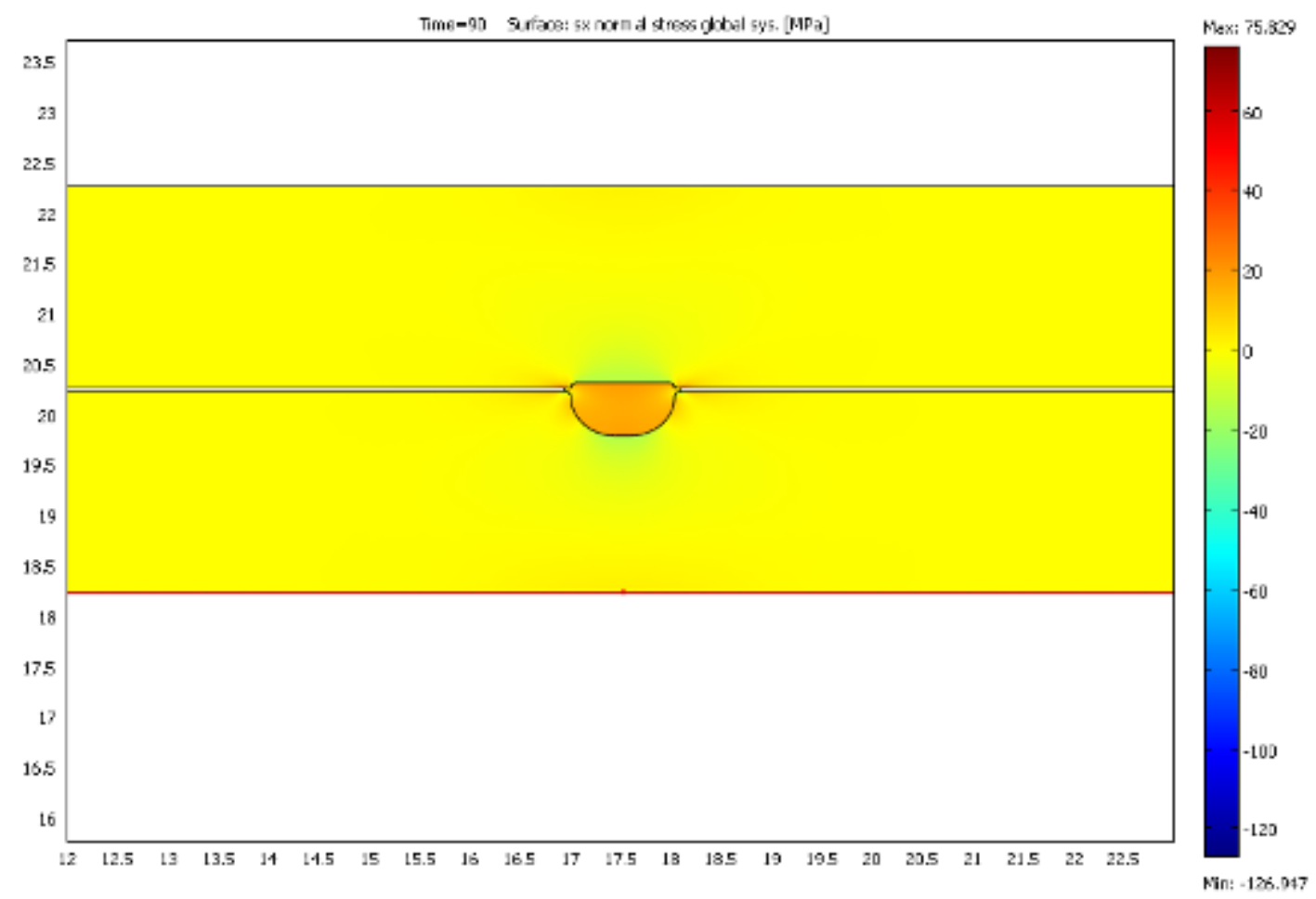

Figure 5-12 Distribution of the residual normal stresses in the horizontal y-direction generated in the 2-D coupled modeling (gap model) 


\section{Chapter 6 \\ Mechanical testing}

The influence of part (thickness) and process (laser power) parameters on the weld strength was investigated. This chapter will describe the mechanical testing including the weld method (Section 6.1.1), the test method (Section 6.1.2), and the fracture surface analysis (Section 6.1.3). The mechanical testing results will be discussed in Section 6.2.

\subsection{Method}

\subsubsection{Welding}

The weld strength was evaluated using the tensile shear strength test. The dimensions of the specimen are shown in Figure 6-1. From this figure, one can see that the weldline is located at the centre of the specimen and is parallel to the pull direction. The overlap length is $20 \mathrm{~mm}$ and the assembly length of the weldline is $15 \mathrm{~mm}$. These test conditions were selected based on the previous work by Dr. M. Chen $[27,98]$. The weld conditions are the same as those used for the surface tests (see Table 4-1). Only specimens containing 0.2 wt.\% CB were tested as the smallest surface defects were generally observed at the highest CB level. 


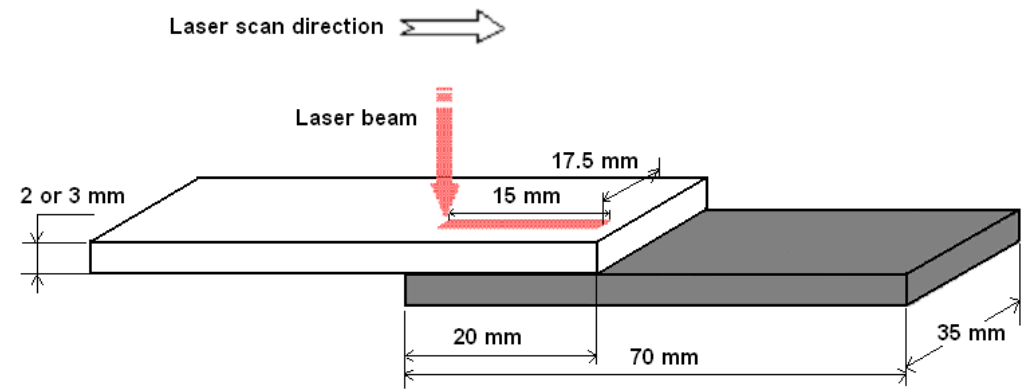

Figure 6-1 Dimensions of the lap shear strength test specimens

\subsubsection{The tensile shear strength test}

The force at break of the lap welds was assessed on the INSTRON Model 4206 Universal testing machine at a cross-head speed of $5 \mathrm{~mm} / \mathrm{min}$. A schematic of overlap joint shear strength test is shown in Figure 6-2. The direction of the pull strength was parallel to the weldline. The force at break was divided by the weld area (weld width times weld length) and used to calculate an "apparent" shear strength (the force at break).

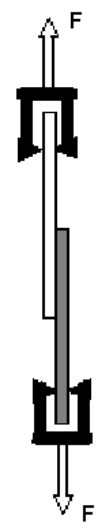

Figure 6-2 Schematic representation of lap joint shear strength test 
The weld widths and lengths were measured on the fractured specimens (Figure 6-3). A scanner was used to obtain an image of the weld fracture surface on the laser-absorbent part. As shown in the figure, five width measurements were made and then averaged.

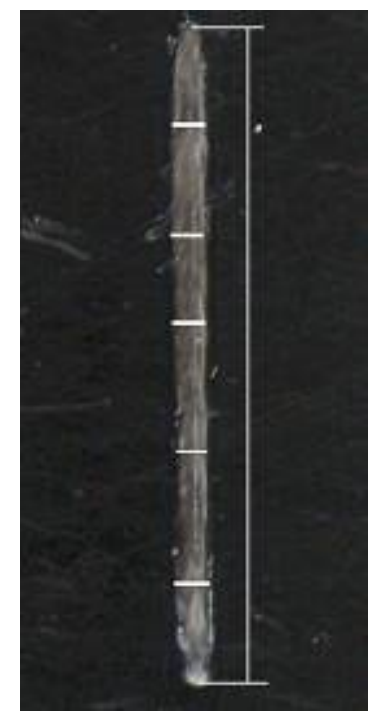

Figure 6-3 Weld width and length measurement on the fracture surface after the shear strength test

\subsubsection{Fracture surface}

In addition to shear strength, the fracture surface was also visualized using a Philips XL 30 CP Scanning Electron Microscope (SEM) located at RMC to qualitatively assess the weld quality including the weld area, heat affected zone, and voids in the weld. 


\subsection{Results and Discussion}

Figure 6-4 shows a plot of the force at break as a function of laser power for $2 \mathrm{~mm}$ and $3 \mathrm{~mm}$ specimens. It is observed that the force at break increases abruptly from zero at a critical power level of approximately $5 \mathrm{~W}$. The load at break then slowly increases with power. At the critical power setting, enough power was absorbed by the black material to allow melting and molecular diffusion to occur at the weld interface. Higher powers result in higher temperatures at the weld interface that produce wider weld widths and increased diffusion. Both of these lead to higher weld strength.

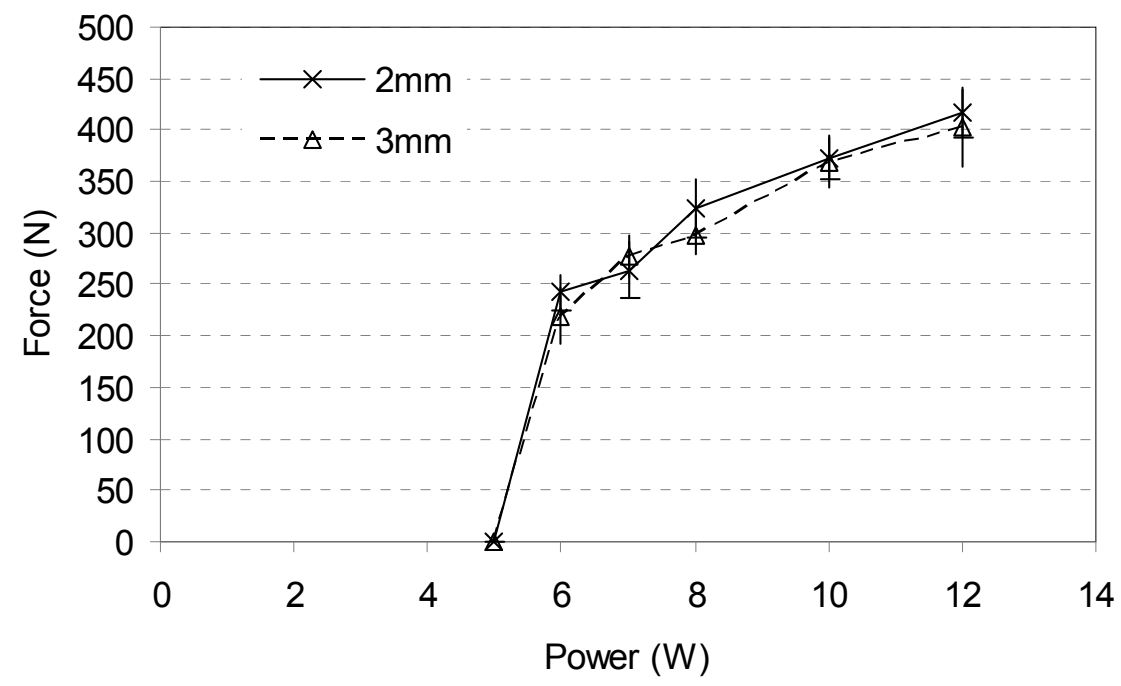

Figure 6-4 Maximum force at break as a function of laser power (the error bars represent one standard deviation). 
The weld width as a function of power for the two thicknesses is shown in Figure 6-5. It is observed that for both thicknesses, the weld width increased with the power. This suggests that more energy was delivered to weld interface which caused more material to melt when increasing the power. It is also observed that the weld width increased with the thickness of the transparent part. This suggests that, under the same weld power, more scattering of the laser beam has taken place in $3 \mathrm{~mm}$ thick transparent parts compared to $2 \mathrm{~mm}$ parts. These results are consistent with the phenomenon observed from the microstructure, i.e. the depths of $\mathrm{HAZ}$ are smaller for the same $\mathrm{CB}$ level yet the widths are greater.

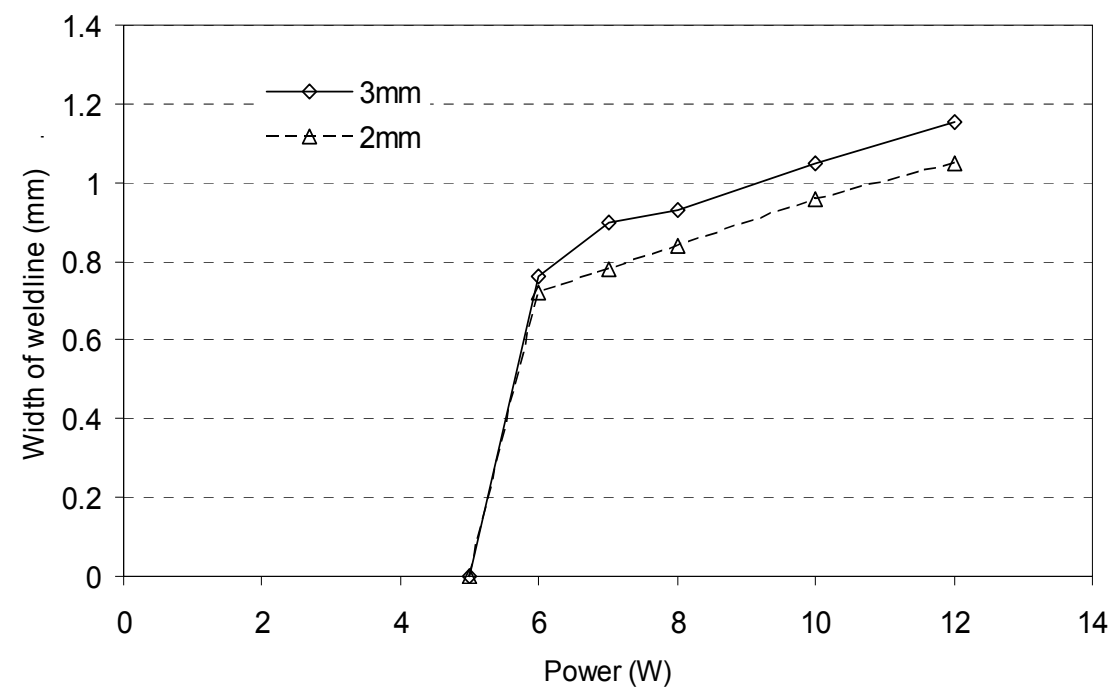

Figure 6-5 Weld width as a function of laser power 
The force and weld width data can be used to calculate an apparent shear strength. Figure 6-6 shows a plot of the weld shear stress as a function of laser power for $2 \mathrm{~mm}$ and $3 \mathrm{~mm}$ specimens. It is observed that the trends between $2 \mathrm{~mm}$ and $3 \mathrm{~mm}$ specimens are very similar. Above $6 \mathrm{~W}$, the strength appears to have reached a maximum of approximately 22-23 MPa. Weld strength of similar laser welded PP specimens have been reported to be $25 \mathrm{MPa}$ which is comparable to the result presented here [99]. When power increased, the force at break and weld area also increased. This resulted in the near constant weld strength seen in this figure.

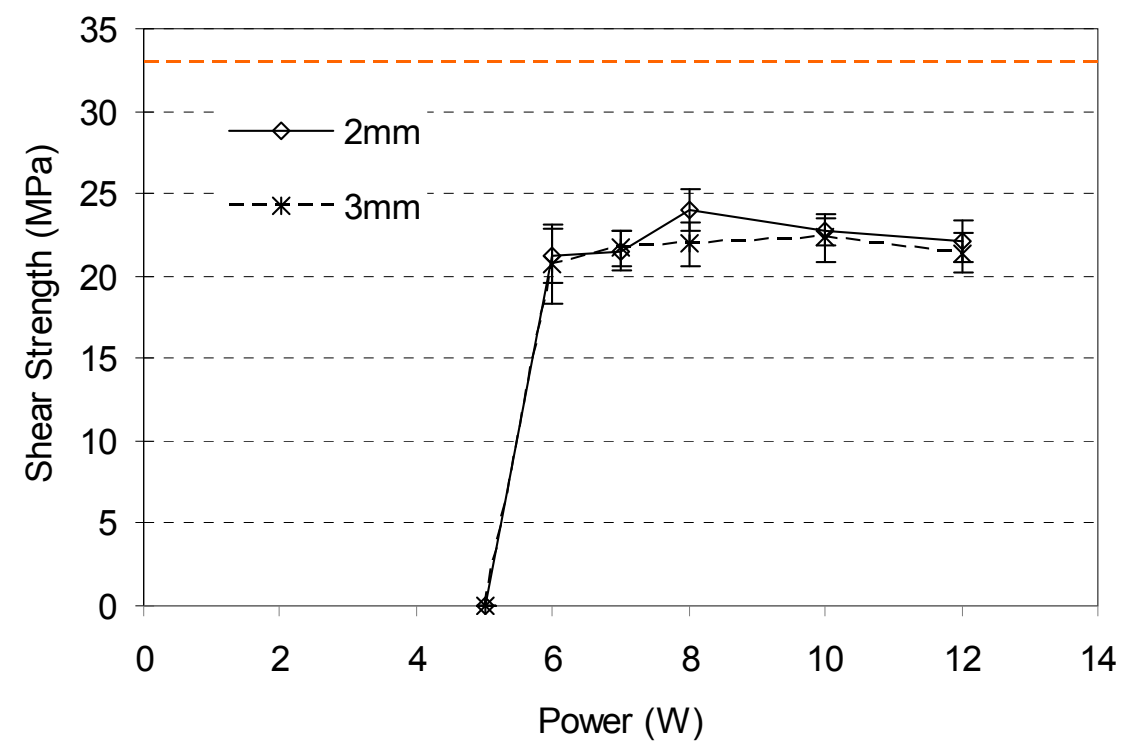

Figure 6-6 Weld shear strength as a function of laser power (the error bars represent standard deviation). 
In order to qualitatively assess the welds, the microstructure images of the fracture surface were taken using the SEM. Figure 6-7 shows the microstructures of the fracture surface for $3 \mathrm{~mm}$ specimens at $6 \mathrm{~W}, 7 \mathrm{~W}, 10 \mathrm{~W}$, and $12 \mathrm{~W}$ laser power. It is observed from the images that the width of the heat affected zone increases with the power. This agrees with the trend shown in Figure 6-5. From Figure 6-7(d), one can see that there is a big void, which was formed because of degradation. This can explain why the shear stress became a little bit lower at $12 \mathrm{~W}$ laser power (as in Figure 6-6). The shear strength is expected to decrease more significantly if the laser power were further increased.

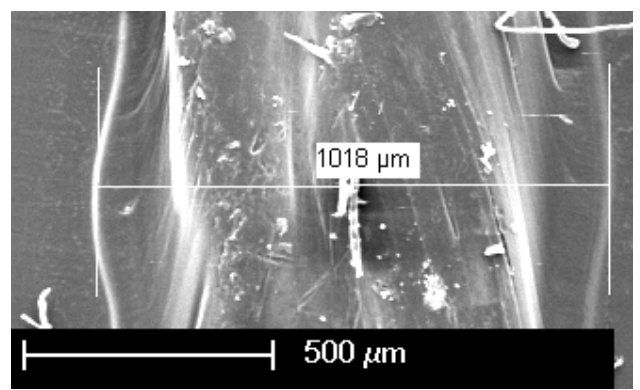

(a)

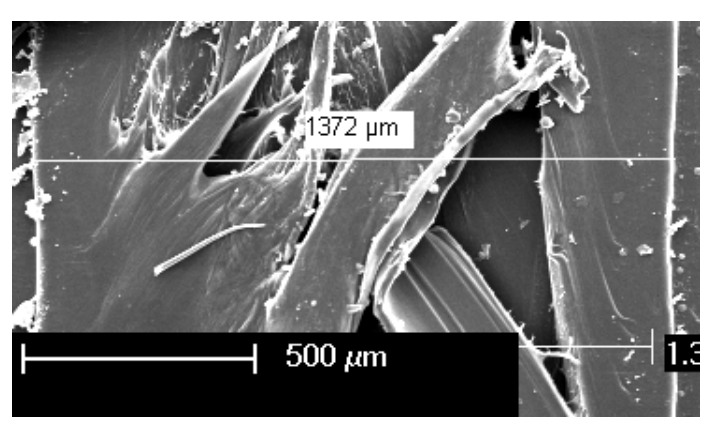

(c)

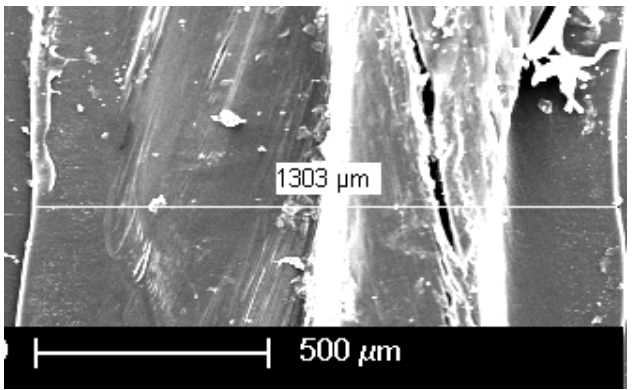

(b)

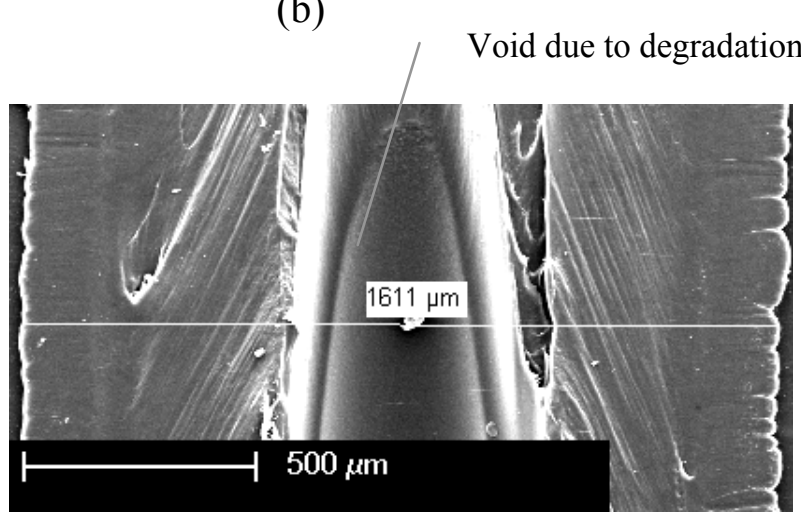

(d)

Figure 6-7 Microstructures of the fracture surface taken by the SEM. Part thickness is $3 \mathrm{~mm}$, laser power is: (a) $6 \mathrm{~W}$, (b) $7 \mathrm{~W}$, (c) $10 \mathrm{~W}$, (d) $12 \mathrm{~W}$ 


\section{Chapter 7 \\ Conclusions and Recommendations}

\subsection{Conclusions}

This thesis has examined the effect of polypropylene homopolymer (PP) material (PP carbon black level), part (thickness of both transparent and absorbent parts) and laser (power, speed) on the ability to read the weld through the absorbent part. This is the first time such an investigation has been carried out for LTW. The key findings are summarized below:

1. Two types of defects were observed:

a. Rib-like surface defects resembling small protrusions were observed on all welded specimens. The ribs occurred when weld flash was visible. It was the only type of surface defect observed for the thicker $3 \mathrm{~mm}$ thick specimens.

b. Sink-mark-like deformations resembling small valleys were observed in $2 \mathrm{~mm}$ thick specimens along the latter half of the weldline. The sink-mark like defects occurred when no flash was visible

2. Generally, the size of both rib and sink defects increased with laser power. When the laser power is increased at a constant scan speed and CB level, the energy delivered to the absorbent part increased too. This resulted in either higher temperatures and/or larger volumes of molten material. The melting, thermal expansion and subsequent solidification of larger volumes of molten polymer created internal stresses that caused 
the polymer to deform at the external surface of the laser-absorbent part. The tensile test data suggest that the lowest power resulting in weld would result in near maximum weld strength while also minimizing defect size.

3. Higher CB levels combined with lower powers generally result in the smaller defects. The combination results in a small low-temperature melt pool that likely involve less thermal expansion and therefore less residual stress.

4. The residual stresses appear to be linked to the thermal expansion and flow of the polymer when it is heated. Material that has flowed away from its initial location may not return upon solidification. The loss of material creates residual stress. The resulting combination of horizontal stresses and vertical stresses created will form ribs if horizontal stresses predominate or will form sink marks if the vertical stresses predominate.

5. The stress that predominates appears to be linked to the boundary conditions between the two parts during solidification. If flash expands into the gap between the two parts, the horizontal stresses appear to dominate creating rib defects. Flow into the gap can occur if the pressure generated by thermal expansion pushed the two plates apart or if the two plates do not mate well. If no gap is present between the parts, material may be able to flow by thermally induced pressures back along the weld channel. Under these conditions, vertical stresses predominate and sink mark defects result. This mechanism was observed experimentally and illustrated through finite element modeling. 


\subsection{Recommendations}

Due to the surface waviness created in the injection moulding, $3 \mathrm{~mm}$ thick parts showed us totally different surface behavior from the $2 \mathrm{~mm}$ thick parts after the welding. Thus, for future work, it is recommended to investigate possibility of producing 3-mm parts with improved surface so as to confirm whether the surface waviness or the part thickness is responsible for the observed behavior.

Because we have predicted that higher laser power can result in poor surface quality, the laser powers which can cause significant degradation were not investigated. However, the plot of shear stress vs. laser power didn't show us the complete trend, i.e. we do not know when the strongest weld strength will be obtained. So, it is recommended to perform more welds using higher power.

In addition, in this research, we have successfully qualitatively simulated the surface deformation caused by the different boundary conditions. A quantitative model of the surface deformation in LTW could be considered for the future work. 


\section{References}

1. "Quasi-simultaneous welding", Leister USA, http://www.leisterusa.com/en/quasisimultanschweissen.html

2. A. Weber, "Welding with light", Assembly, v 45, n1, January 2002, pp34-43

3. B. Bryden, "High power diode laser transmission welding of plastics" Assembly Automation, V20, n2, 2000, pp136-139

4. D.A. Grewell, "Applications with infrared welding of thermoplastics," ANTEC1999, Society of Plastics Engineers, pp. 1411-1415

5. R. Prabhakaran, "Laser transmission welding of Nylon 6", MSc thesis, Queen's University, 2003.

6. K. Wood, "Taking subjectivity out of class A surface evaluation", Composites Technology, August 2008, pp. 67-70

7. "Class A surfacing", CATIA Tutor, http://catiatutor.com/Basic/CATIAHandbook/class-a-surfacing.html

8. K. Hoyden, P. Engelmann, "Smoke and mirrors: Hiding sink in plain sight", ANTEC2008, Society of Plastics Engineers, pp. 703-707

9. M. Pallante, "Mold texturing adds product value at low cost", Plastics Engineering, v 40, n 2, Feb 1984, pp. 45-47

10. C. Lee, "Finite element study of bond-line-read-out", Journal of Reinforced Plastic and Composites, v 14, n 11, Nov. 1995, pp1226-1249

11. Private communication with Kedzie Davis Fernholz from Ford Company on October $17^{\text {th }}, 2007$

12. K. Wood, "Taking subjectivity out of class A surface evaluation", Composites Technology, August 2008, pp 67-70 
13. V.A. Kagan, "Innovations in laser welding technology: state of the art in joining of thermoplastics and advances with colored nylon for automotive applications", SAE World Congress Proceedings, paper \#2002-01-0716, 2002

14. B. Baylis, P. Daly, H. Herfurth, "Laser transmission welding of polyamide tubes to plates", ANTEC2007, Society of Plastics Engineers, pp. 2793-2797

15. H. Potente, G. Fiegler, F. Becker and J. Korte, "comparative investigations on quasisimultaneous welding on the basis of the materials PEEK and PC", ANTEC2002, Society of Plastics Engineers

16. H. Potente, J. Korte, R. Stutz, "Laser-transmission welding of PE-HD", Kunststoffe Plast Europe, V87, 3, 1997, pp. 27-29

17. M. Rhew, A. Mokhtarzadeh, and A. Benatar, "Through tranmission laser welding of polycarbonate and high-density polyethylene," ANTEC2003, Society of Plastics Engineers, pp. 1116-1120

18. P. J. Bates, M.E. Druart, M. Chen, G. Zak and J. Billiet, "Influence of part thickness, glass fibre content and line energy on laser transmission welding of polyamide mXD", ANTEC2007, Society of Plastics Engineers, pp. 2783-2787

19. D. Grewell, and A. Benatar, "Experiments in micro-welding of polycarbonate with laser diodes", ANTEC2003, Society of Plastics Engineers, pp. 1039-1044.

20. J. Vetter, F. Duriau-Montagne, G.W. Ehrenstein, D. Hänsch, "Morphology and thermal loading in laser welding of thermoplastics", ANTEC2000

21. J. Schulz, E. Haberstroh, "Welding of polymers using a diode laser", ANTEC2000, Society of Plastics Engineers, pp. 1196-1201

22. R. Prabhakaran, M. Kontopoulou, G. Zak, P. Bates and B. Baylis, "Contour laser lasertransmission welding of glass reinforced nylon 6", Journal of Thermoplastic Composite Materials, Vol. 19, 2006 pp427-439

23. B. Baylis, R. Prabhakaran, P. Bates, Y. Huang, S. Xu and D. Watt, "Pyrometer measurements during laserwelding of thermoplastic elastomers to polypropylene and of nylon to itself", ANTEC2003, Society of Plastics Engineers

24. D. Grewell, T. Jerew, and A. Benatar, "Diode laser microwelding of polycarbonate and polystyrene", ANTEC2002, Society of Plastics Engineers 
25. D. Grewell, and A. Benatar, "Modeling heat flow for a moving heat source to describe scan micro-laser welding", ANTEC2003, Society of Plastics Engineers, pp. $1045-1050$

26. C. Wu, M. Cherdron and D. Douglass, "Laser welding of polypropylene to thermoplastic polyolefins", ANTEC2003, Society of Plastics Engineers, pp. 1147-1151

27. M. Chen, "Gap bridging in laser transmission welding of thermoplastics", Queen's University, Thesis, 2009

28. "II.8. Reflection, transmission, and absorption", Gigahertz-Optik, Inc., USA, http://www.light-measurement.com/reflection-absorption/

29. M. Chen, G. Zak, P.J. Bates, "Energy transmission during laser transmission welding of light-scattering polymers", submitted to Journal of Materials Processing Technology

30. F. Rathrnann, U. Russek, "Laser welding of polymers using high power diode lasers", Proceedings of the SPIE - The International Society for Optical Engineering, v 5121, 2003, pp385-398

31. M. Rhew, A. Mokhtarzadeh, and A. Benatar, "Diode laser chracterization and measurement of optical properties of polycarbonate and high-density polyethylene", ANTEC2003, Annual Technical Conference, pp. 1056-1060

32. V. A. Kagan, R. G. Bray, W. P. Kuhn, "Laser transmission welding of semicrystalline thermoplastics-part I: Optical characterization of Nylon-based plastics", ANTEC2000

33. C.Y. Wang, P.J. Bates, and G. Zak, "Optical properties characterization of thermoplastics used in laser transmission welding: transmittance and reflectance", ANTEC2009, Society of Plastics Engineers, pp. 1278-1282

34. C. Lee, R. Ballou, "Laser energy transmission (LET) measurements of 30\% glass reinforced nylon 6", ANTEC2007, Society of Plastics Engineers, pp. 1900-1904

35. J. Van de Ven, A. Erdman, "Simultaneous measurement of laser reflection and transmission of poly (vinyl chloride)", Optical Engineering, Vol. 45(9), 094301, September 2006, pp1-6

36. D. Grewell, P. Rooney, V. A. Kagan, "Relationship between optical properties and optimized processing parameters for through - transmission laser welding of thermoplastics", ANTEC2002 
37. V. A. Kagan, R. Bray and A. Chambers, "Forward to better understanding of optical characterization and development of colored polyamides for the infra-red/laser welding: part i - efficiency of polyamides for infra-red welding", ANTEC2001

38. V. A. Kagan, G. P. Pinho, "Laser transmission welding of semi-crystalline thermoplasticspart II: Analysis of mechanical performance of welded Nylon", ANTEC2000

39. E. Haberstroh, J. Schulz, R. Luetzeler, "Thermographic characterisation of polymers for the laser transmission welding" ANTEC2002, pp. 1137-1141

40. V. A. Kagan, N. M. Woosman, "Efficiency of clear-welding technology for polyamides", Journal of Reinforced Plastics and Composites, v 23, n 4, 2004, pp. 351359

41. J. Schulz, E. Haberstroh, "Welding of polymers using a diode laser", ANTEC2000, pp. 1196-1201

42. S. Glaser, "Colorants and special additives for laser welding", Joining Plastics, 25-26 April 2006, London, Uk

43. V. A. Kagan, A. Chambers and R. Bray, "Forward to better understanding of optical characterization and development of colored polyamides for the infra-red/laser welding: part II - family of colored polyamides", ANTEC2001

44. I.A. Jones and N.S. Taylor, R. Sallavanti, J. Griffiths, "Use of infrared dyes for transmission laser welding of plastics", ANTEC2000

45. D. Grewell, W. Nijenhuis, "TTIR welding of aliphatic polyketone" ANTEC2000, pp. $1148-1152$

46. P. Roony, "Plastic laser welding", ANTEC2002, pp. 1110-1114

47. R. A. Grimm, B. Christel, and J. Robinson, "Methods for making nearly invisible welded joints in clear polymers", ANTEC2000, pp. 1153-1158

48. T. Richter, "Study on improvement in gap-bridging during welding PP with a diode laser", Master's thesis at Fraunhofer Institute for Laser Technology, March 2000

49. H. Potente, J. Korte, F. Becker, "Laser transmission welding of thermoplastics: analysis of the heating phase", ANTEC1998, pp. 1022-1025 
50. M. Chen, G. Zak, P.J. Bates, "Laser absorption coefficient measurement of amorphous polymers for laser transmission welding”, ANTEC2006, pp. 2291-2295

51. E. Haberstroh, R. Lützeler, "Influence of carbon black pigmentation on the laser beam welding of plastics micro parts", Journal of Polymer Engineering, Vol.21, No. 2-3, 2001, pp.119-129

52. H. Klein, E. Haberstroh, "Laser beam welding of plastic micro parts", ANTEC1999, pp. 1406-1410

53. J. Murphy, “Additives for plastics handbook”, 2001, pp. 85-90

54. C. Y. Wang, P.J. Bates, M. Aghamirian, G. Zak, R. Nicholls, M. Chen, "Quantitative carbon black morphological analysis of polymers used in laser transmission welding", Welding in the World, Vol. 51, No. 3/4, Mar/Apr 2007, pp. 85-90

55. I. Jones, "Laser welding for plastic components", Assembly Automation, v 22, n 2, p $129-135,2002$

56. X. Wang, K. Yang, H. Zhang, H. Liu, "Experiment research on laser transmission welding of two different thermoplastics ", Hanjie Xuebao/Transactions of the China Welding Institution, v 30, n 5, May 2009, pp97-100

57. "bielomatik turns to fiber lasers for faster welding of plastics", Bielomatik Inc., New Hudson, Michigan, USA, Sep 5, 2006

$<$ http://www.optoiq.com/index/display/article-display/270904/articles/optoiq2/lasersfor_manufacturing/laser-markets_/2009/12/web-exclusives/bielomatik-turns-to-fiberlasers-for-faster-welding-of-plastics.html>

58. “Clearweld concept”, GENTEX, http://www.clearweld.com/concept.aspx

59. Y. Kurosaki, T. Matayoshi, K. Sato, "Overlap welding of thermoplastic parts without causing surface thermal damage by using a CO2 laser”, ANTEC2003, pp. 1121-1125

60. Y. Kurosaki, T. Matayoshi, "Study of controllability of melt depth in infrared laser penetration welding of thermoplastics", ANTEC2004, pp. 1222-1226

61. J. Van de Ven, A. Erdman, "Laser transmission welding of thermoplastics - part 1: temperature and pressure modeling", Journal of Manufacturing Science and Engineering, Vol. 129, 2007, pp849-858 
62. F. Becker, H. Potente, "A step towards understanding the heating phase of laser transmission welding in polymers", Polymer engineering and science, February 2002, v.42, No.2, pp365-374

63. L.S. Mayboudi, A.M. Birk, G. Zak, P.J. Bates, "A 2-D thermal model for laser transmission welding of thermoplastics", ICALEO 2005 Congress Proceedings - Laser Materials Processing Conference, 2005, pp402-409

64. A. Kritskiy, "Laser welding of nylon tubes to plates using conical mirrors", MSc thesis, Queen's University, 2009

65. L.S. Mayboudi, A.M. Birk, G. Zak, P.J. Bates, "A 3-D thermal model of laser transmission contour welding for a lap joint”, ANTEC2007, pp. 2813-2817

66. L.S. Mayboudi, A.M. Birk, G. Zak, P.J. Bates, "A three-dimensional thermal finite element model of laser transmission welding for lap-joint", International Journal of Modeling and Simulation, Vol. 29, No. 2, 2009, pp149-155

67. M. Fargas, L. Wilke, O. Meier, H. Potente, "Analysis of weld seam quality for laser transmission welding of thermoplastics based on fluid dynamical processes", ANTEC2007, pp. 2808-2812

68. H. Potente, G. Fiegler, "Laser transmission welding of thermoplastics-modeling of flows and temperature profiles", ANTEC2004, pp. 1193-1199

69. H. Potente, G. Fiegler, H. Haferkamp, M. Fargas, A. von Busse, J. Bunte, “An approach to model the melt displacement and temperature profiles during the laser through-transmission welding of thermoplastics", Polymer Engineering and Science, 2006, DOI 10.1002/pen, pp1565-1575

70. L. Wilke, H. Potente, J. Schnieders, "Simulation of quasi-simultaneous and simultaneous laser welding”, IIW 2006

71. F. Johannaber, Injection Molding Machines: A User's Guide, Hanser Gardner Publications, 1994

72. S. Chen, C. Tseng, and C. Su, "Study on the rib-designed part surface quality molded by external gas-assisted injection", ANTEC2008, Plastics: Annual Technical Conference Proceedings, pp. 2133-2137 
73. K. B. Horton. "Quantifying a key injection moulding attribute defect". Unpublished master's thesis, Western Michigan University, Kalamazoo, MI. 1999

74. M. Akay, S. Ozden, "Measurement of residual stresses in injection moulded thermoplastics", Polymer Testing 13 (1994), pp. 323-354

75. D. Mathivanan, and N.S. Parthasarathy, "Sink mark prediction and optimization - a review", ANTEC2008, Plastics: Annual Technical Conference Proceedings, pp. 21262132

76. B. Dong, C. Shen and Q. Li, "Optimization of parts with RIB using gas assisted injection moulding technique", ANTEC2005, Annual Technical Conference Proceedings, pp. 49-53

77. D. Mathivanan, N.S. Parthasarathy, "Sink-mark minimization in injection moulding through response surface regression modeling and genetic algorithm", International Journal of Advanced Manufacturing Technology, v 45, n 9-10, December 2009, pp. 867874

78. F. Ampthor, "Sink reduction in SMC moulding", Automotive Plastics, v 36, n 5, May 1978, pp. $48-51$

79. B. Stillhard, "Sheet moulding compound basic considerations", Advances in Polymer Technology, v 10, n 1, Spring 1990, pp13-21

80. S. Fays, "Adhesive bonding technology in the automotive industry", Adhesion and Interface, v 4, n 2, 2003, pp37-48

81. S. Basu, H. Kia, "Strategies to reduce bond-line read-out in adhesive joined SMC automotive body panels", Journal of Composite Materials, v 42, n 17, September 2008, pp1801-1815

82. X. Wang, Q. Li, C. Shen, and S. Lu, "Effect of process parameters and two-way interactions on sink mark depth of injection molded parts by using the design of experiment method", Polymer-Plastic Technology and Engineering, 47, 2008, pp30-35

83. J. Jeong, Y. Im, "Estimation of sink mark depth in compression molded SMC parts with substructures", Journal of Composite Materials, 31, 1997, pp2161-2187 
84. R. Hsakou, "Curvature: the relevant criterion for Class "A" surface quality", JEC Composites Magazine, n 23, March 2006, pp105-108

85. "Database of Pro-fax ${ }^{\circledR}$ 6323", Basell Polyolefins Company - Polypropylene Homopolymer, http://www.muehlstein.com/pdfs/DataSheets/Pro-fax6323.pdf

86. Operating manual for the ROFIN DL $\times 16$ Industrial Diode Laser, 2003

87. L.S. Mayboudi, M.Chen, G. Zak, A.M. Birk and P.J. Bates, "Characterization of beam profile for high-power diode lasers with application to laser welding of polymers", ANTEC2006, pp. 2274-2278

88. M. Chen, G. Zak, P.J. Bates, "Non-contact method for estimating contour laser transmission welding start-up conditions", IIW 2007, pp. 2-5

89. M.Chen, G. Zak, P.J. Bates, M. McLeod and D.Rouison, "Surface damage threshold in laser transmission welding of polycarbonate", ANTEC2007, pp. 2798-2802

90. M. Chen, G. Zak, P.J. Bates, "Laser absorption coefficient measurement of amorphous polymers for laser transmission welding”, ANTEC2006, pp. 2291-2295

91. Private communication with M. Chen from Queen's University on November $25^{\text {th }}$, 2009

92. R. Siegel, J.R. Howell, Thermal radiation heat transfer, Third edition, Hemisphere Publishing Corporation, 1992, pp 520-540

93. "Polypropylene specifications", Boedeker, 904 West $6^{\text {th }}$ Street, Shiner, Texas 77984 USA, http://www.boedeker.com/polyp_p.htm

94. "Polypropylene, homopolymer", Emco Industrial Plastics, http://www.emcoplastics.com/index.cfm?fuseaction=product.display\&product_ID $=40 \& P$ arentCat $=36$

95. "Thermoplastic properties database. Web Edition Ver 1.1", Gammadot Rheology, http://www.gammadot.com/index.htm?Techzone/nexus/PP/PPdatasheet.htm $\sim$ mainFrame

96. Private email from COMSOL support

97. COMSOL multiphysics ${ }^{\circledR}$ modeling guide, version 3.5 a. 
98. M. Chen, G. Zak, P. Bates, B. Baylis, M. McLeod, "Method of evaluating shear strengths in contour laser transmission welding", SAE 2007, 2007-01-0571

99. M. Chen, G. Zak, P.J. Bates, "Estimating contour Laser Transmission Welding startup conditions using a novel non-contact method," Welding in the World, IIW-1912-08, Vol. 52, No. 11/12, Nov/Dec 2008. 


\section{Appendix A}

The non-contact welding method [88]

In the non-contact method as shown in Figure A-1, two $0.305 \mathrm{~mm}$ metal shims are placed between the transparent part and absorbent part in order to prevent the welding occurring between two parts during scanning. A series of laser scans are made at increasing power levels at a fixed scan speed of $1500 \mathrm{~mm} / \mathrm{min}$.

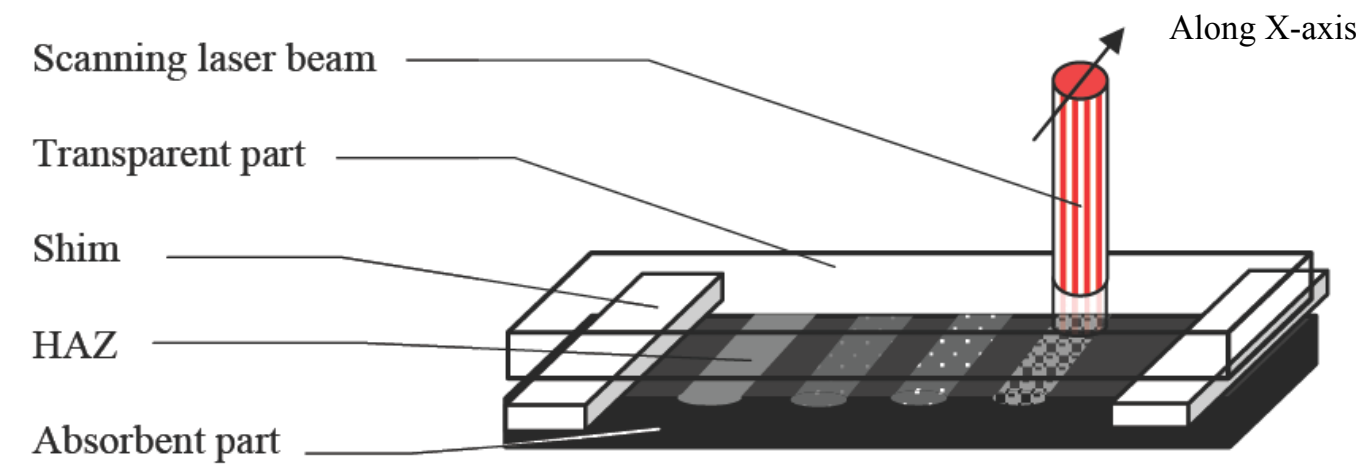

Figure A-1 Schematic representation of the non-contact scanning experimental set-up [88]

Figure A-2 shows the surface appearance of both laser transparent part and laser absorbent part after a series of laser scans in non-contact method for $2 \mathrm{~mm}$ thick PP with 0.2 wt. $\%$ CB level. In this case, the scan powers are from 2 to $14 \mathrm{~W}$. The black lines in this figure correspond to the heat-affected zone caused by material that has been melted and subsequently re-solidified. The width of lines increased with increasing power is related to scattering of the beam as it passes through the transparent part.

It is observed that the surface melting of the laser-absorbent part occurred at $2 \mathrm{~W}$. However, the depth of the weld line became clearer at $6 \mathrm{~W}$. That is to say, weld with good strength would occur around 6W. It is also observed in this figure that there is 
vapour condensation on the laser transparent part at $13 \mathrm{~W}$ and $14 \mathrm{~W}$. That means the surface degradation began to occur around scan power of $13 \mathrm{~W}$. So for $2 \mathrm{~mm}$ PP with 0.2 wt.\% CB level, the power range of $6 \mathrm{~W}$ to $12 \mathrm{~W}$ was selected.

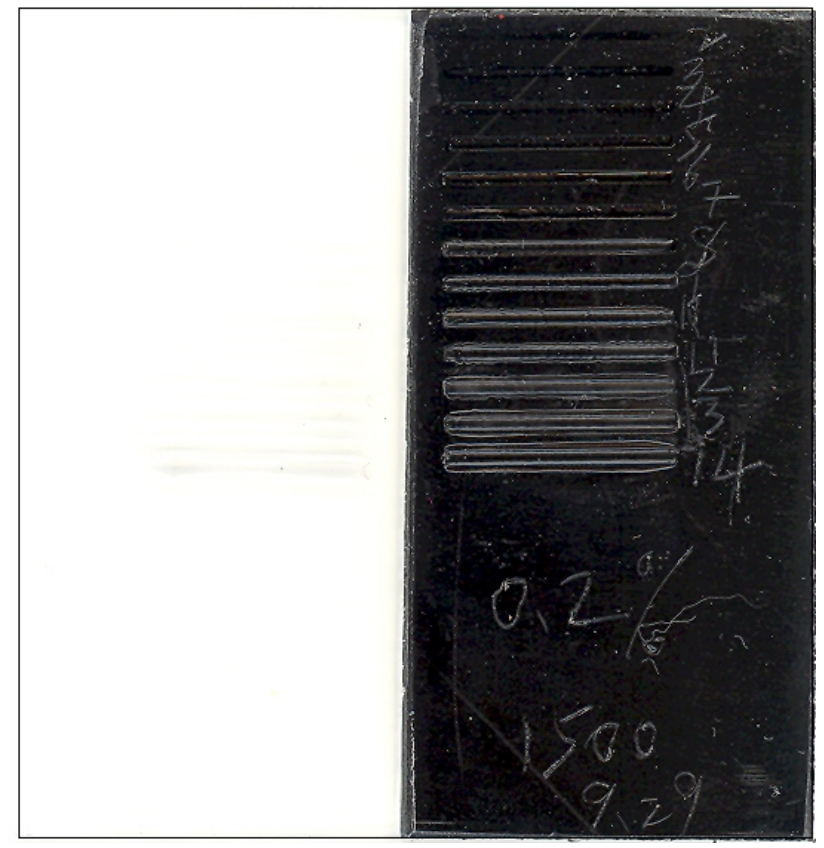

Figure A-2 Surface appearance of the laser-absorbent part after a series of laser scans in noncontact method for PP (Thickness $2 \mathrm{~mm}, 0.2 \mathrm{wt} . \% \mathrm{CB}$, Speed $1500 \mathrm{~mm} / \mathrm{min}$ ) 


\section{Appendix B}

The depth or height dimensional data for each CB level, power setting, and thickness

\begin{tabular}{|c|c|c|c|c|}
\hline \multirow{2}{*}{$\begin{array}{l}\text { Thickness } \\
\text { (mm) }\end{array}$} & \multirow{2}{*}{$\begin{array}{c}\text { CB level } \\
\text { (wt. \%) }\end{array}$} & \multirow{2}{*}{$\begin{array}{c}\text { Power setting } \\
\text { (W) }\end{array}$} & \multicolumn{2}{|c|}{$\begin{array}{c}\text { Maximum depth or height } \\
(\mu \mathrm{m})\end{array}$} \\
\hline & & & Sink & Rib \\
\hline \multirow{15}{*}{2} & \multirow{5}{*}{0.05} & 12 & 24.3 & 18.9 \\
\hline & & 14 & 44.5 & 18.7 \\
\hline & & 16 & 52.1 & 22.1 \\
\hline & & 18 & 71.2 & 12.7 \\
\hline & & 20 & 101.7 & 11.3 \\
\hline & \multirow{5}{*}{0.1} & 7 & 8.2 & 21.8 \\
\hline & & 8 & 10.6 & 23.4 \\
\hline & & 10 & 11.5 & 26.9 \\
\hline & & 12 & 34.6 & 33.9 \\
\hline & & 14 & 41.9 & 42.4 \\
\hline & \multirow{5}{*}{0.2} & 6 & 0 & 9.8 \\
\hline & & 7 & 18.5 & 21.8 \\
\hline & & 8 & 21.0 & 22.4 \\
\hline & & 10 & 40.4 & 31.5 \\
\hline & & 12 & 55.0 & 36.8 \\
\hline \multirow{15}{*}{3} & \multirow{5}{*}{0.05} & 15 & N/A & 42.4 \\
\hline & & 17 & N/A & 46.9 \\
\hline & & 19 & N/A & 50.3 \\
\hline & & 21 & N/A & 58.3 \\
\hline & & 23 & N/A & 71.8 \\
\hline & \multirow{5}{*}{0.1} & 9 & N/A & 14.0 \\
\hline & & 10 & N/A & 17.9 \\
\hline & & 11 & N/A & 33.1 \\
\hline & & 13 & N/A & 39.9 \\
\hline & & 15 & N/A & 44.8 \\
\hline & \multirow{5}{*}{0.2} & 6 & N/A & 8.2 \\
\hline & & 7 & N/A & 8.8 \\
\hline & & 8 & N/A & 14.5 \\
\hline & & 10 & N/A & 16.7 \\
\hline & & 12 & N/A & 22.6 \\
\hline
\end{tabular}

